\title{
BIM EXECUTION PROCESS OF CONSTRUCTION COMPANIES FOR BUILDING PROJECTS
}

\author{
A Thesis Submitted to \\ the Graduate School of Engineering and Sciences of \\ İzmir Institute of Technology \\ in Partial Fulfillment of the Requirements for the Degree of \\ MASTER OF SCIENCE \\ in Architecture \\ by \\ Bilge GERÇEK
}

June 2016

İZMíR 
We approve the thesis of Bilge GERÇEK

Examining Committee Members:

Prof. Dr. Serdar KALE

Department of Architecture, İzmir Institute of Technology

$\overline{\text { Prof. Dr. Yeşim Kamile AKTUĞLU }}$

Department of Architecture, Dokuz Eylül University

Prof. Dr. I. Sevil SARIYILDIZ

Department of Architecture, Yaşar University

Prof. Dr. H. Murat GÜNAYDIN

Department of Architecture, İstanbul Technical University

Assoc. Prof. Dr. M. Emre İLAL

Department of Architecture, İzmir Institute of Technology

20/June/2016

Assoc. Prof. Dr. M. Emre İLAL

Supervisor, Department of Architecture, İzmir Institute of Technology
Prof. Dr. H. Murat GÜNAYDIN

Co-Supervisor, Department of Architecture, İstanbul Technical University

Dr. Onur B. TOKDEMIR

Co-Supervisor, Rönesans Holding
Assoc. Prof. Dr. ŞENIZZ ÇIKIŞ

Head of the Department of Architecture
Prof. Dr. Bilge KARAÇALI

Dean of Graduate School of

Engineering and Sciences 


\section{ABSTRACT \\ BIM EXECUTION PROCESS OF CONSTRUCTION COMPANIES FOR BUILDING PROJECTS}

Building Information Modeling (BIM) is an emerging concept in architecture, engineering and construction (AEC) industry promising to replace traditional 2D based construction documentation and management procedures and to reduce rework and cost in project execution. The level of information that could be assigned to building objects in BIM technologies could provide vast amounts of benefits to construction projects throughout projects' life-cycle. Implementation of BIM, however, requires strategic planning to enable achieving these potential benefits.

Industry-wide and organizational implementation guidelines and standards have been published around the world either to encourage organizations to adopt BIM or to present the minimum requirements to be followed where BIM implementation is a statutory obligation. In contrast, BIM implementation and/or deliverables has not been mandated by government or organizations yet in Turkey, therefore organizations which plan to adopt BIM processes have to develop their own implementation plans.

The purpose of this study is to provide guidance in BIM implementation for construction companies particularly during the construction phase of the building projects. BIM standards and guidelines, and studies related to BIM implementation have been reviewed and important aspects of implementation have been identified. A case study of BIM implementation at a large construction company in Turkey to conduct quantity takeoff and cost estimation are presented and unique challenges of BIM implementation in Turkish AEC industry are discussed. 


\section{ÖZET}

\section{INNŞAAT FIRMALARININ BINA PROJELERİ İÇIN YAPI BILLGI MODELLEME SISTEMLERİ UYGULAMA SÜRECI}

Yapı Bilgi Modelleme (YBM) yapı sektöründe geleneksel olarak kullanılan iki boyutlu proje sunum yöntemlerinin ve buna bağlı yönetim süreçlerinin yerini almakta olan ve yapı projelerinde verim artışı sağlayabilen bir teknolojidir. Yapı bileşenlerine atanabilen kapsamlı yapı bilgisi projelerin yaşam döngüsü süresince pek çok farklı kullanım alanında fayda sağlamaktadır. İçerdikleri yüksek detayda veri nedeniyle YBM uygulamalarından bu faydaların sağlanabilmesi için stratejik planlama gerekir.

Dünyada endüstri çapında ve firma bazında YBM uygulamalarına yönelik pek çok kılavuz ve standart metin, YBM kullanımının arttırılması ya da YBM kullanımının yasal zorunluluk olduğu durumlarda asgari uygulama gereksinimlerinin tanımlanması için yayınlanmıştır. Türkiye'de ise YBM kullanımı henüz herhangi bir kurum veya kuruluş tarafından zorunlu kılınmamıştır, ilgili kılavuz ve standart metinler yayınlanmamıştır. Bu nedenle YBM teknolojisinden faydalanmak isteyen firmalar kendi standartlarını geliştirmek zorundadır.

$\mathrm{Bu}$ çalışmanın amacı bina projelerinin inşaat aşamasında YBM uygulaması yapmayı planlayan inşaat firmalarına yardımcı olmaktır. Bunu sağlamak için yayınlanmış YBM kılavuz ve standart metinleri ile YBM konusunda yapılmış akademik çalışmalar incelenmiştir. Türkiye' de faaliyet gösteren büyük bir inşaat firmasında metraj ve maliyet tahmini alanında kullanılan YBM uygulamaları vaka çalışması olarak sunulmuş ve Türk yapı sektöründe YBM uygulamalarına ilişkin zorluklar tartışılmıştır. 


\section{ACKNOWLEDGEMENTS}

I would like to thank to my advisor, Assoc. Prof. Dr. M. Emre ILAL for his guidance, patience, and motivation. His guidance helped me to complete this study. I would also like to express my sincere gratitude to my co-advisors, Prof. Dr. H. Murat GUNAYDIN and Dr. Onur B. TOKDEMIR for their insightful guidance, sharing their networks with me and supporting me in pursuing my goals.

I would also like to express my very profound gratitude to my amazing family, my beloved husband and my best friend Gurcan GERCEK, my parents Edibe and Namik Kemal YURDERI, and my brother Emre Kemal YURDERI, for their unconditional love, support and faith in me. This and my all previous accomplishments would not have been possible without them. 


\section{TABLE OF CONTENTS}

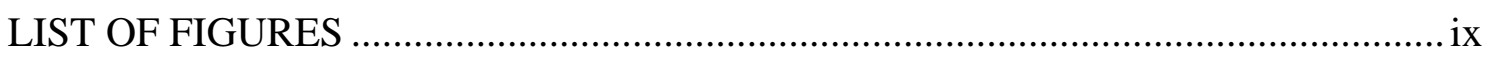

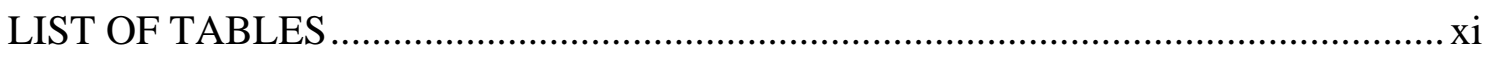

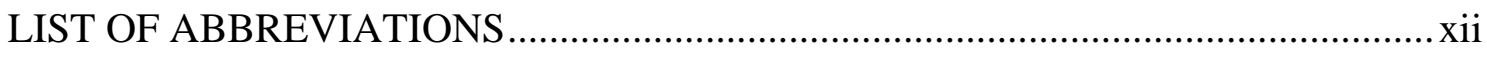

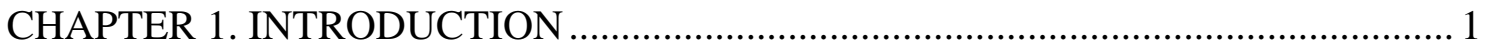

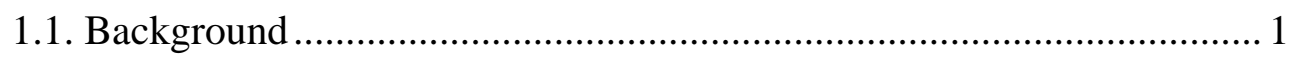

1.1.1. Current State of the Construction Industry ................................... 1

1.1.2. The New Paradigm: Building Information Modeling...................... 3

1.1.3. Transition to BIM.......................................................................... 5

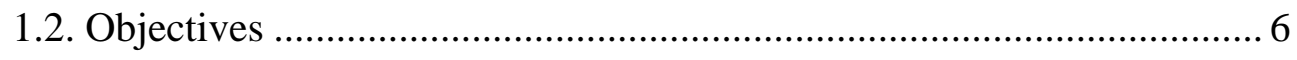

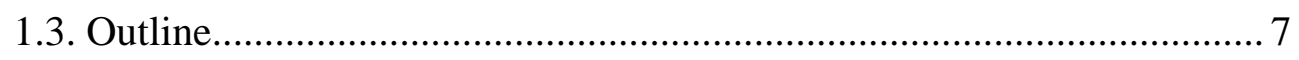

CHAPTER 2. BUILDING INFORMATION MODELING......................................... 8

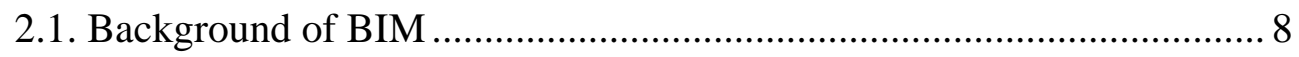

2.2. Characteristics and Basic Concepts of BIM ...................................... 12

2.2.1. Characteristics of BIM ................................................................ 12

2.2.2. Interoperability and Information Exchange ................................. 13

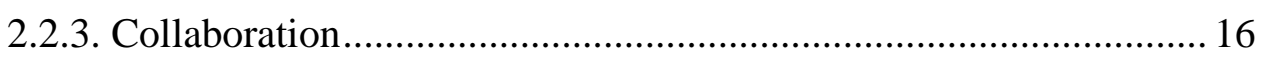

2.3. BIM Tools and Applications............................................................ 18

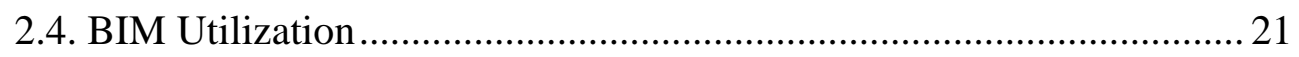

2.5. Challenges for BIM Implementation and/or Adoption ......................... 24

2.5.1. Organizational Issues ................................................................... 24

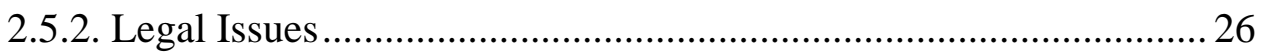

2.6. Adoption Rates of BIM.................................................................... 27

2.6.1. Legislation Actions ................................................................ 31

CHAPTER 3. BIM IMPLEMENTATION PLANS AND STANDARDS..................... 35 


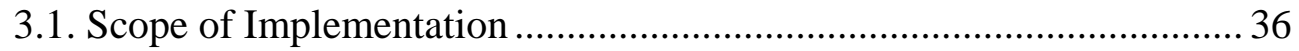

3.1.1. Organizational BIM Mission and Vision ...................................... 36

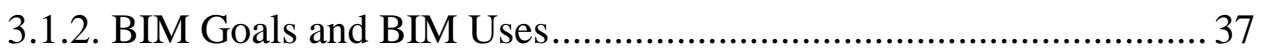

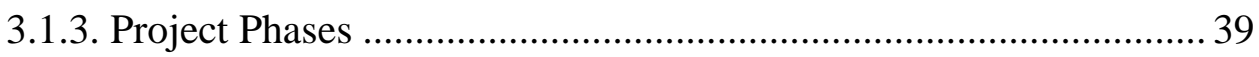

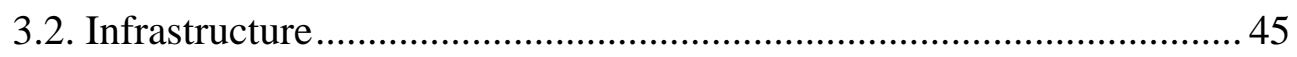

3.2.1. Organizational Roles and Responsibilities ................................... 45

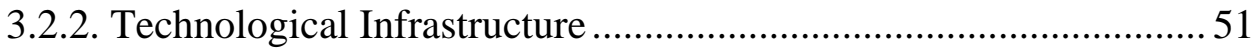

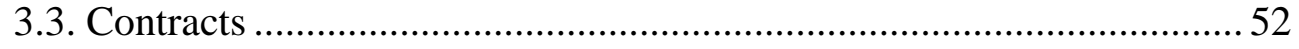

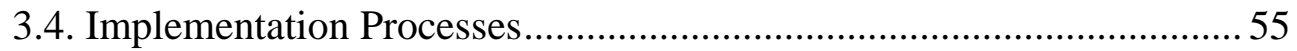

3.4.1. Project Information ....................................................................... 55

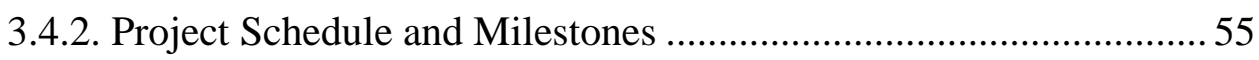

3.4.3. BIM Project Execution Process .................................................... 56

3.4.4. Information Exchange and Collaboration Procedure...................... 60

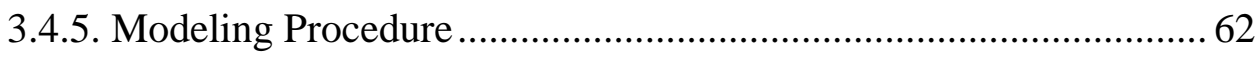

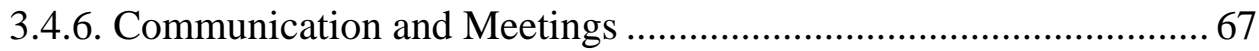

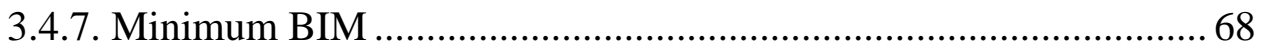

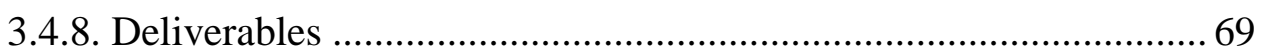

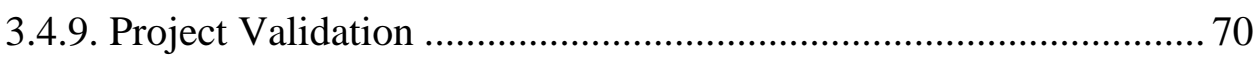

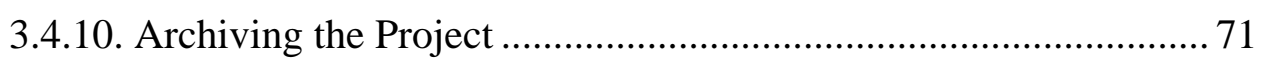

CHAPTER 4. CASE STUDY: BIM IMPLEMENTATION FOR QUANTITY TAKEOFF AND COST ESTIMATION PURPOSES ......................... 73

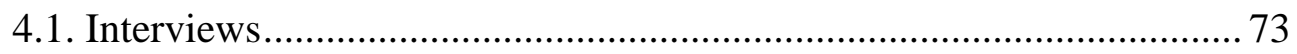

4.2. BIM Implementation Strategy at LC .................................................. 74

4.2.1. Pre-implementation Phase: .......................................................... 75

4.2.2. Implementation Phase: .................................................................... 78

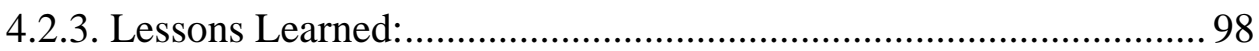

CHAPTER 5. CONCLUSION AND RECOMMENDATIONS .................................. 102

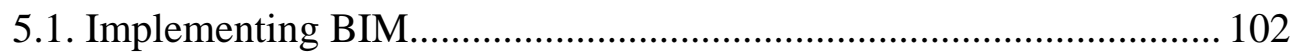

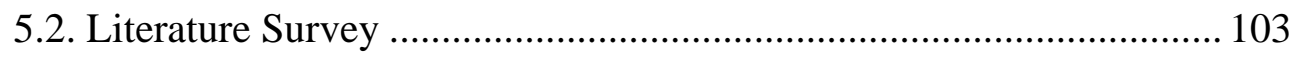

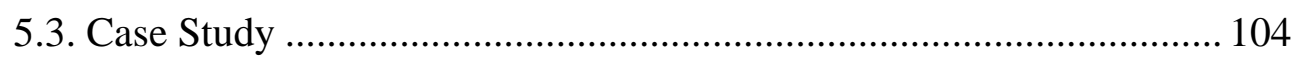

5.4. Barriers for BIM Adoption in Turkey................................................ 105 
5.5. Limitations 107

5.6. Future Work 107

REFERENCES 109

APPENDICES

APPENDIX A COMPARISON MATRIX OF BIM IMPLEMENTATION PLANS AND STANDARDS.

APPENDIX B INTERVIEW GUIDE FOR QUALITATIVE STUDY 125 


\section{LIST OF FIGURES}

Figure

Page

Figure 1.1. Indexes of Labor Productivity for Construction and Nonfarm Industries $1964-2009$........................................................ 1

Figure 1.2. Value Added, Cost of Changes, and Current Compensation Distribution for Design Services ....................................................................................... 4

Figure 1.3. Flow Chart of the Study ………............................................................... 7

Figure 2.1. Staff Effort Breakdown ............................................................................ 17

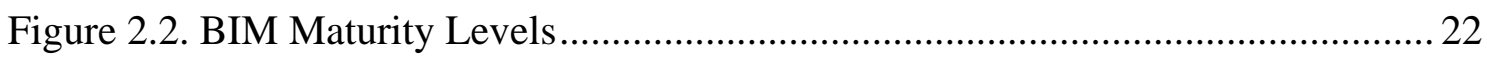

Figure 2.3. Building Information Continuity Illustrated.............................................. 23

Figure 2.4. CAD versus BIM Adoption Chart........................................................... 27

Figure 2.5. BIM Adoption Rates According to International BIM Report...................... 28

Figure 2.6. Length of Time Contractors Have Been Using BIM by Country ................ 29

Figure 2.7. Contractors' Approach to Requiring BIM Expertise in Team Formation .... 30

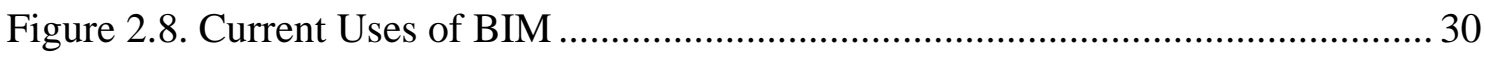

Figure 2.9. Impact of BIM Engagement Level on ROI ............................................ 31

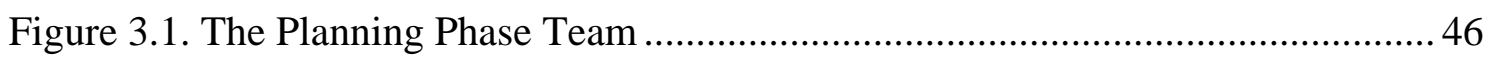

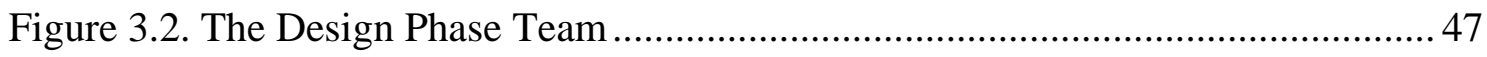

Figure 3.3. The Construction Phase Team.................................................................... 47

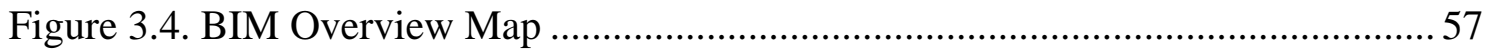

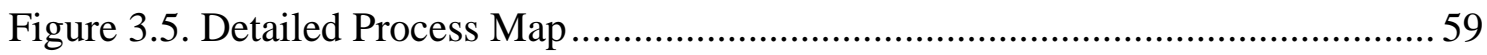

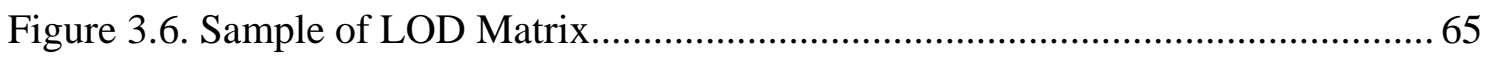

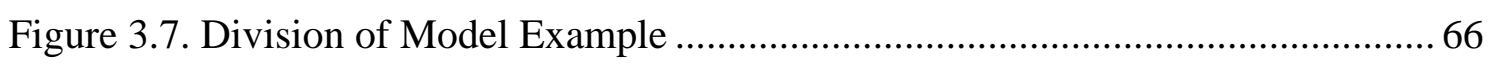

Figure 3.8. Minimum BIM Diagram for Tabular BIM Capability Maturity Model

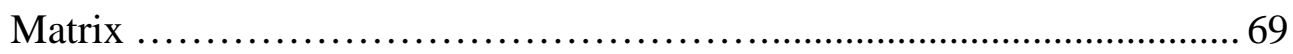

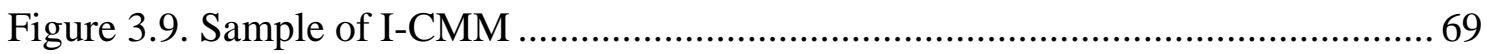

Figure 4.1. Fileset Structure that Groups Reference Files and BIM Files..................... 81

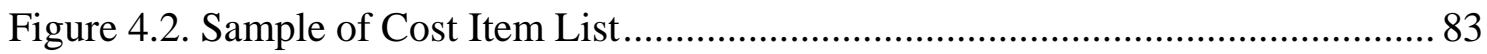

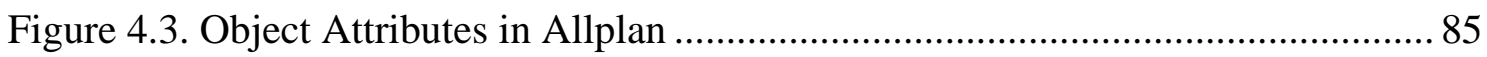

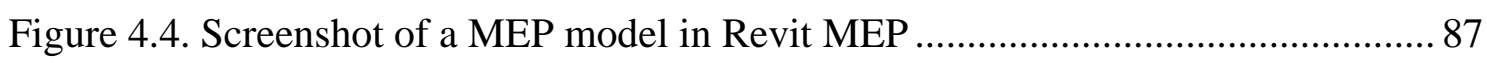

Figure 4.5. Sample of Report Template for Formwork QTO Created in VWD............. 88

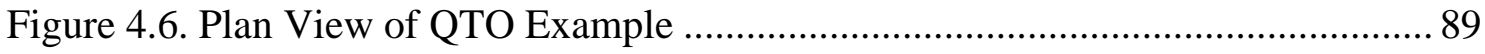




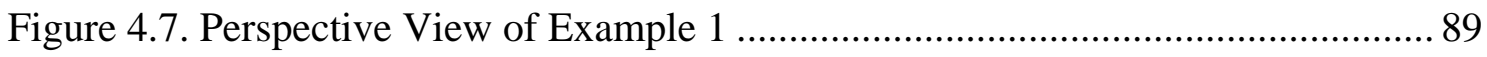

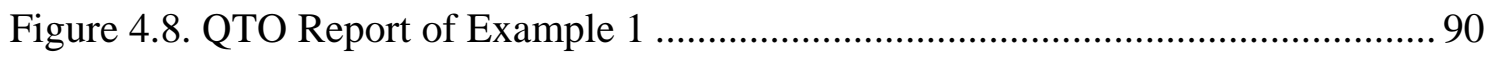

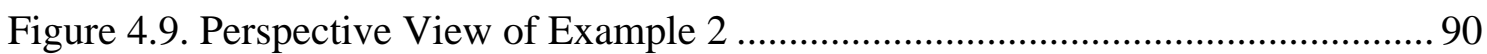

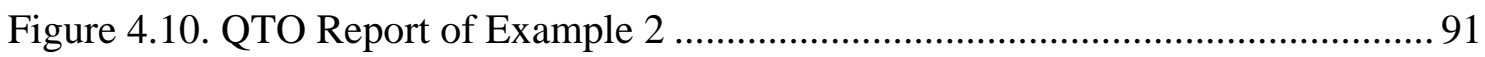

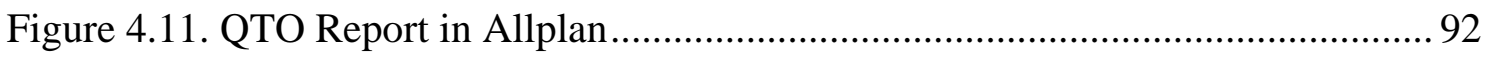

Figure 4.12. A Snapshot of Assigning Selection Sets to Tasks ..................................... 94

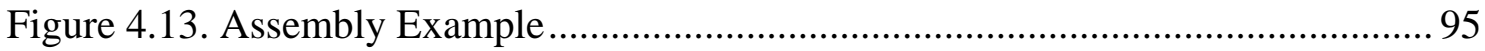

Figure 4.14. 2D Cost Code Structure Example ............................................................... 96

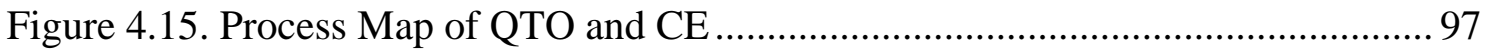




\section{LIST OF TABLES}

Table

Page

Table 2.1. Comparison of Common Tasks of Construction Processes in 2D CAD and

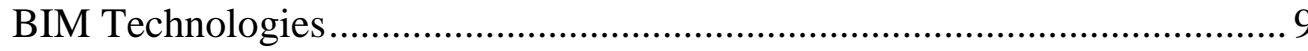

Table 2.2. Sample of BIM Applications that Support IFC Format................................ 14

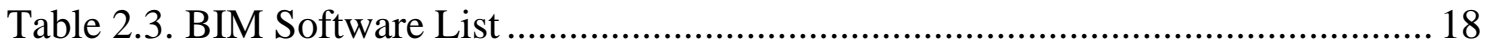

Table 3.1. Model Content and Uses of Project Phases …............................................... 40

Table 3.2. Digital Data Protocol Table ............................................................................. 53

Table 3.3. Sample of Project Information Table ........................................................... 55

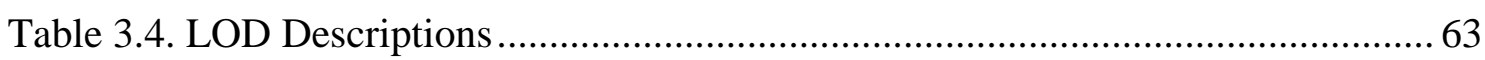

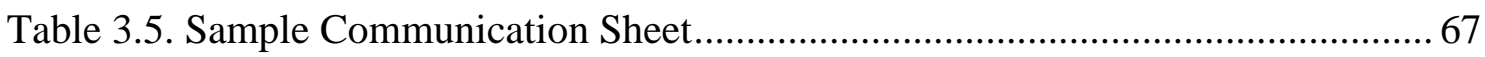

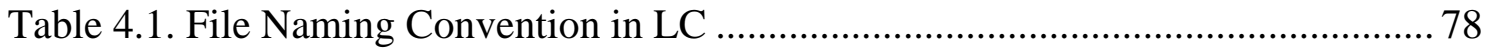

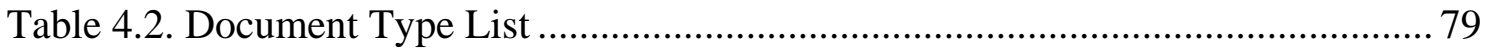

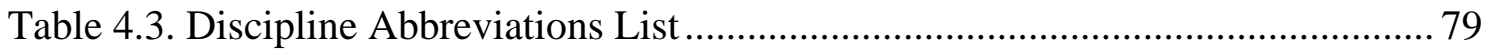

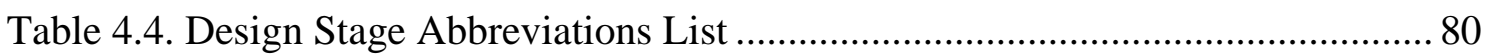




\section{LIST OF ABBREVIATIONS}

AEC Architecture, Engineering and Construction

AIA The American Institute of Architects

BIM Building Information Modeling

BYND Cost Database of the Ministry of Environment and Urbanization

CAD Computer Aided Drafting

CCD Cost Database Developed by LC

CDE Common Data Environment

CE Cost Estimation

COBie Construction Operations Building Information Exchange

CPI Cost Performance Index

CSI Construction Specification Institute

DBB Design-Bid-Build

ECM Enterprise Content Management

ERP Enterprise Resource Planning

EVM Earned Value Management

FM Facility Management

GSA US General Services Administration

IDM Information Delivery Manuals

IFC Industry Foundation Classes

IPD Integrated Project Delivery

LC Name of the Company Referred to in the Case Study

LOD Level of Development

MEA Model Element Author

MEP Mechanical, Electrical and Plumbing

MVD Model View Definition

NBIMS National Building Information Modeling Standards of United States

NBIS National Institute of Building Sciences of United States

NBS National Building Specification

QTO Quantity Takeoff 
RIBA The Royal Institute of British Architects

ROI Return on Investment

SPI Schedule Performance Index

VWD Visual Web Developer 


\section{CHAPTER 1}

\section{INTRODUCTION}

\subsection{Background}

\subsubsection{Current State of the Construction Industry}

BIM is becoming increasingly vital for the fragmented construction industry with its service providers, suppliers, customers and the number of each counts in millions all around the world. Most activities associated with the industry consist of craft processes implemented on-site. Although there has been great improvements in materials and building techniques in construction industry that are results of technological advances and innovations, labor productivity levels is one major subject that the industry is criticized for. Eastman et al. (2011) conducted a research on productivity in construction industry which includes only design and construction phase labor, excluding the offsite activities. The research showed that labor productivity has not been improved much relative to nonfarm industries for decades.

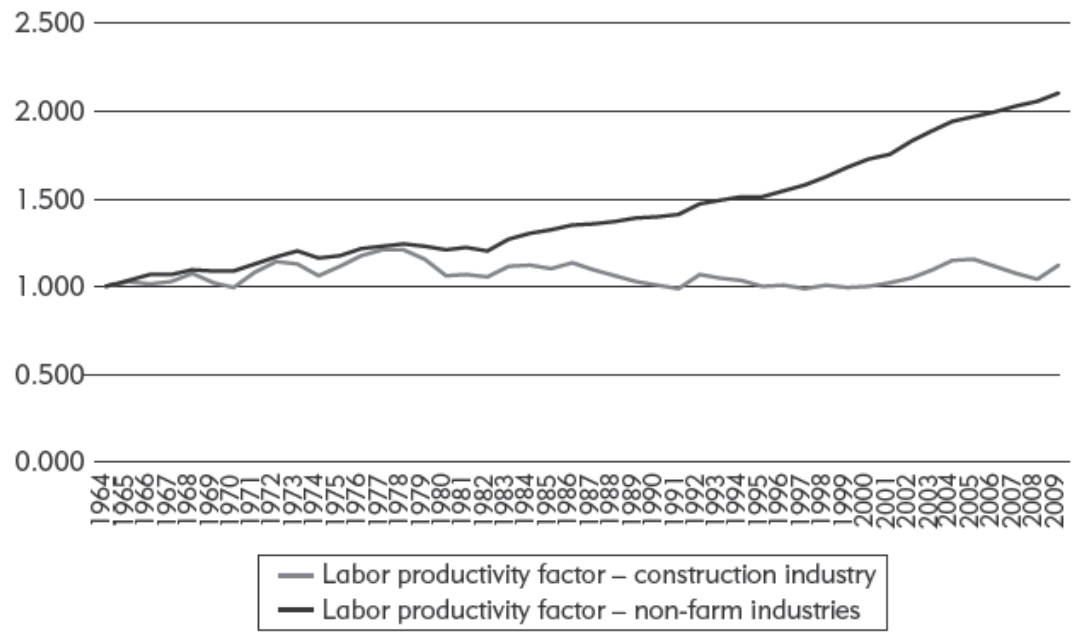

Figure 1.1. Indexes of Labor Productivity for Construction and Nonfarm Industries 19642009 (Source: Teicholz, 2007) 
Comparing construction industry with other industries such as automobile and aircraft industries can generate misleading results because of the differences in (1) the number of customers and suppliers, and (2) production methods (Smith \& Tardif, 2009). Aircraft and automobile industries are based on manufacturing in factories. Nature of these industries differs mostly in control, supply and skills of labor. Optimization in construction industry is performed by business owners, in small scale, only applicable to their own businesses because of the fragmented nature of the industry.

Eastman et al. (2011) suggests that the reasons for low labor productivity rates in construction industry includes:

- Fragmented industry which small scale firms with less than 5 employees constitutes $65 \%$ of all.

- Negligence of the change in field labor productivity due to the improvements in equipment used on site and the cheap man-power that can be obtained by immigrant workers

- Labor intensive phases that can be performed in building projects such as alterations, reconstruction, maintenance, etc.

- Reluctance to adopt new business practices in construction industry

- Short term business relations among project stakeholders because of the nature of construction practice.

Smith and Tardif (2009) add that construction productivity is not increasing exponentially because of the "lack of reliable statistical productivity data about construction activities”, and suggest that conservative business environment in construction industry is due to this situation which fuels resistance to change.

Environmental concerns related to raw materials and energy consumption are other subjects that construction industry is criticized for. Consumption of raw materials and energy in construction has been increasing exponentially for decades (Smith \& Tardif, 2009). High population rates and inefficient methods of production that are currently in use are some of the reasons for the rise in consumption levels. Construction industry has been consuming $40 \%$ of raw materials and energy that are produced all over the world (Roodman \& Lenssen, 1995). 72\% of electricity produced is consumed by nonindustrial buildings in the U.S., and it is estimated that "total U.S. energy consumption will increase 31\% by 2030” (Office of Integrated Analysis and Forecasting, 2007). 
Additionally, it is claimed that construction industry lacks in coordination and collaboration among its stakeholders, and in focus on customer requirements/requests (Elmualim \& Gilder, 2014). Communication is still based on paper-based documentation in current business practice (Eastman et al., 2011). This mode of communication makes it difficult to detect possible errors and omissions in documentation that could result in financial losses and delays. Although efforts have been addressed to eliminate the deficiencies of paper-based modes of communication by electronic file sharing systems, these only help in improving the delivery time of the information, not reducing the number and severity of the errors in project delivery.

Cultural and technological change to overcome the shortcomings of the industry may provide higher quality services and products with less energy and raw material during the construction, occupation and demolition phases, and to increase efficiency in working environment by facilitating coordination and collaboration.

Technological advances and innovations have helped several industries to increase efficiency, and standards of deliverables. Construction industry, however, has been failing in keeping pace with advances in information technology. This failure to low productivity levels in construction in comparison with other industries (Eastman et al., 2011; Smith \& Tardif, 2009).

To help decrease the level of energy consumption, construction industry can adopt new approaches. A considerable amount of savings can be achieved by planning the project's life-cycle from preliminary design phase "through proper design i.e., building shape and orientation, natural heating and cooling, daylighting and ventilation strategies, proper shading, and straightforward, off - the - shelf building energy efficiency measures" (Mazria \& Kershner, 2008) till demolition phase to enable reuse of building elements.

\subsubsection{The New Paradigm: Building Information Modeling}

Within this framework BIM has been an emerging approach to replace inefficient ways of project generation and delivery in construction industry for more than a decade. As it is defined by the National Building Information Modeling Standard (NBIMS) Committee of the National Institute of Building Sciences (NIBS), BIM is "an improved planning, design, construction, operation, and maintenance process using a standardized machine-readable information model for each facility, new or old, which contains all 
appropriate information created or gathered about that facility in a format useable by all throughout its lifecycle.” (NIBS, 2008).

BIM utilization can significantly increase the level of collaboration on project execution and through collaboration, it can decrease "the amount of time required for producing construction documentation” (Eastman et al., 2011). In traditional project implementation, design changes may occur during construction documentation phase because of the lack of collaboration among project stakeholders in the early phases of projects. However BIM implementation offers an effective early collaboration where it is easier to identify problems in design before construction documentation and make necessary changes. The MacLeamy Curve that is given in Figure 1.2 illustrates the distribution of design effort and its effect on project depending on the project phases.

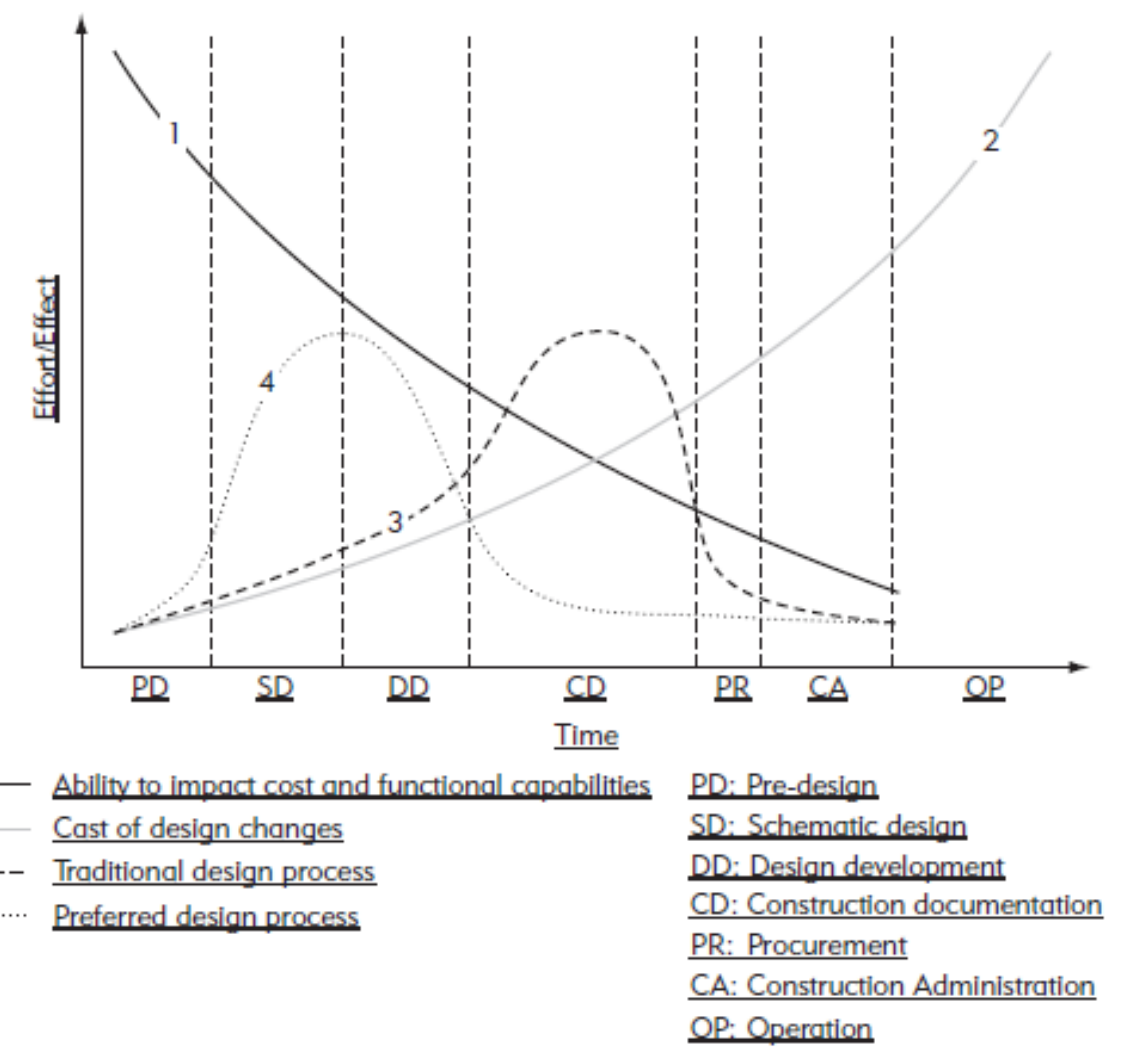

Figure 1.2. Value Added, Cost of Changes, and Current Compensation Distribution for Services (Source: Eastman et. al. 2011)

Benefits of BIM utilization in AEC industry are not limited to benefits associated with collaboration. Structured information generation and analysis capabilities that BIM 
tools provide could expand these benefits from project's inception to demolition (Eastman et al., 2011). Research showed that BIM has a positive influence on quality and time completion in building projects (Elmualim \& Gilder, 2014), and structured information it provides can facilitate to decrease energy consumption levels related to construction industry especially when implemented begins in design and construction phases of the project (Smith \& Tardif, 2009). However AEC industry has been skeptical about adopting new workflows related to BIM. (Olatunji, 2011). Although the current construction industry is still dependent on 2D drawing sets at the construction site, it is expected that the practice will evolve into a paperless, model-based environment where BIM technology is adopted for document generation (Eastman et al., 2011).

\subsubsection{Transition to BIM}

To foster this transition to BIM processes, there are several documents published around the world as standards and guidelines. These documents refer to different aspects of BIM implementation. For instance, in national BIM standards specifics of BIM execution process that is required to be adopted such as standardization of information are identified (National Institute of Building Sciences, 2015), whereas guidelines that are published by institutions explain the BIM deliverables to be submitted at the end of the project (MIT Department of Facilities, 2012). Although the content of these documents vary, they provide insights into the essentials of BIM execution process where companies may refer to while developing their customized execution processes to perform specific purposes by utilizing BIM tools.

Adopting BIM processes when BIM is not mandated by any organization and there is an absence of BIM standards and guidelines would require a comprehensive research on fundamental concepts on execution process of BIM. Since BIM adoption has not been mandated in Turkey yet, BIM standards have not been identified. Companies that intended to implement BIM have to develop their customized execution processes. 


\subsection{Objectives}

The purpose of this study is to facilitate BIM adoption for construction companies by providing structured information on BIM execution process, and to decrease initial costs of BIM execution related to research and resource allocation. A catalog is created by reviewing, compiling and categorizing the contents of documents related to BIM execution process to help companies develop their customized implementation plans. This is useful especially when BIM implementation is not mandated by any organization and there is an absence of BIM implementation guidelines to adopt. The catalog complied as part of this thesis presents the contents of 23 BIM implementation standards and guidelines. At the beginning of this study 55 documents have been ascertained. Since the BIM execution process is the focus of the study, 23 of these 55 documents have been reviewed and the contents of these have been organized to determine a structure of execution process plan. The intent is to offer companies an opportunity to determine which subjects are relevant to their targeted uses of BIM. Flowchart representing the aim and methodology to achieve this purpose is given in Figure 1.3. 
Aim

To facilitate BIM adaptation by providing a structured information on BIM execution process

\begin{tabular}{|l|}
\hline \multicolumn{2}{|c|}{ Literature Review } \\
\hline Resources on BIM \\
\hline Created a catalog by reviewing, compiling and categorizing contents of BIM guidelines and standards \\
\hline \\
\hline Customized BIM execution process developed by reviewing the catalog \\
\hline Execution process of BIM-based quantity takeoff \\
and cost estimation purposes \\
\hline
\end{tabular}

Figure 1.3. Flow Chart of the Study

\subsection{Outline}

Background information on BIM and application areas of BIM technologies are identified in Chapter 2. In chapter 3, the contents of BIM implementation guidelines and standards are explained in detail and the topics identified in the analysis are categorized into groups that may be used as a framework for planning the execution process. Chapter 4 presents a case study on BIM implementation in Turkey based on a customized BIM execution process to perform quantity takeoff (QTO) and cost estimation (CE). The potentials and challenges of BIM implementation in the context of the Turkish construction industry are also discussed in Chapter 4. Discussion on the findings of the study and recommendations on BIM implementation process in Turkey are given in Chapter 5. 


\section{CHAPTER 2}

\section{BUILDING INFORMATION MODELING}

In this chapter a literature review of BIM is presented. Foundations and characteristics of BIM, basic concepts of BIM (e.g. interoperability, information exchange, collaboration), overview of BIM tools, benefits and challenges of BIM utilization, BIM adoption rates around the world and legislative actions are explained.

\subsection{Background of BIM}

The foundations of BIM lay in solid modeling efforts to generate 3D geometries representing a significant potential not only for AEC industry, but also entertainment industry. In 1970s, three independent groups, Ian Braid at Cambridge University, Bruce Baumgart at Stanford, and Ari Requicha and Herb Voelcker at the University of Rochester, had managed to develop the ability to generate and edit 3D shapes (Eastman et al., 2011).

Adaptation of this new technology to building modeling dated back to late 1970s and early 1980s (Eastman et al., 2011). Research on computer aided drafting (CAD) systems had been conducted by multiple stakeholders from universities, AEC professionals, aerospace teams, etc. to develop basic capabilities. Due to the deficiencies in hardware and the initial cost of implementation of this technology, AEC industry adopted 2D CAD systems which inherited paper-based traditional project implementation practices, whereas aerospace and manufacturing industries adopted and invested in 3D CAD systems.

Recognition of parametric modeling, as a next level of 3D CAD systems, enabled defining connections among objects. Multiple objects could become interdependent by sharing parameters. Change in one object affects the interdependent ones and their parameters are adjusted automatically. Defining assemblies from interdependent objects, that are able to evaluate changes and automatically respond to them led to the current BIM technology (Eastman et al., 2011). 
There has been a transition from traditional 2D CAD to BIM technologies in construction industry. Some limitations of 2D CAD systems are (Crotty, 2012):

- The need for interpretation of drawings to evaluate the design and make decisions which may lead to erroneous results in construction,

- The difficulty of ensuring design is represented correctly in corresponding drawings,

- Lack of information on the drawings to specify details of building elements due to the vector-based representation mode,

- The difficulty of representing complex shapes and forms.

This transition is also called a "paradigm shift" due to the fundamental changes it brings along to the project implementation practice (Denzer \& Hedges, 2008; Reddy, 2011). It requires more than adopting new software applications to implement construction projects, since "BIM is a set of interacting policies, processes and technologies producing a methodology to manage the essential building design and project data in digital format” (Race, 2012). The differences in common tasks of construction processes can be seen in Table 2.1 (The Associated General Contractors of America, 2005).

Table 2.1. Comparison of Common Tasks of Construction Processes in 2D CAD and BIM Technologies (Source: AGC, 2005)

\begin{tabular}{|c|c|c|}
\hline 2D Based Process & & BIM Based Process \\
\hline Linear, Phased & Design & Concurrent, Iterative \\
\hline Paper 2D & Drawings & $\begin{array}{c}\text { Digital 3D Object based tied to } \\
\text { intelligent data }\end{array}$ \\
\hline $\begin{array}{l}\text { Evaluated over days in } \\
\text { 2D }\end{array}$ & $\begin{array}{c}\text { Value Engineering } \\
\text { Alternatives }\end{array}$ & Evaluated in 3D instantly \\
\hline Unclear Elevations & Site Planning & Relief Contours \\
\hline Slow and Detailed & Code Review & Expedited and Automated \\
\hline Light Tables & Design Validation & Clash Detection with Audit Trails \\
\hline 2D Drawings & Field Drawings & 2D Drawings and Perspectives \\
\hline $\begin{array}{l}\text { Assembled near } \\
\text { completion }\end{array}$ & Closeout Documents & $\begin{array}{c}\text { Intelligent models for } \\
\text { operations and } \\
\text { maintenance instructions; Constantly } \\
\text { updated during construction }\end{array}$ \\
\hline
\end{tabular}

(cont. on next page) 
Table 2.1. (cont.)

\begin{tabular}{|c|c|c|}
\hline 2D Based Process & BIM Based Process \\
\hline Stand AloneActivities & Scheduling & Activities linked to Models \\
\hline $\begin{array}{c}\text { Limited Scenarios } \\
\text { evaluated }\end{array}$ & Sequence Planning & $\begin{array}{c}\text { Extensive Scenarios Evaluated } \\
\text { earlier in the process }\end{array}$ \\
\hline Paper Shop Drawings & Field Coordination & $\begin{array}{c}\text { Overlaying Digital Models using } \\
\text { collision detection software }\end{array}$ \\
\hline Use manuals & Operation Training & Visual \\
\hline
\end{tabular}

Strategic implementation plans are required to enable businesses to benefit from the potential for "improving communication among business partners, improving the quality of information available for decision making, improving the quality of services delivered, reducing cycle time, and reducing cost at every stage in the life cycle of a building.” (Smith \& Tardif, 2009).

Limiting the transition plan to BIM to utilization of a new software application is a legacy of CAD era which had an unstructured approach to technology deployment. The narrow focus on drafting that the CAD era possessed, limits the benefits of BIM technology (Smith \& Tardif, 2009).

For BIM to achieve its potentials, in each phase of a project, all stakeholders should understand and acknowledge that their contribution to the project would not affect only a small part of the life-cycle of the project such as design phase, but the whole (Smith \& Tardif, 2009). The model should have structured information that enables utilization from inception to demolition of the project. Eastman et al. (2011) categorize the benefits, which are enabled when the realization of the potentials of BIM is dawn by all stakeholders, into four groups: (1) preconstruction benefits, (2) design benefits, (3) construction and fabrication benefits, (4) post construction benefits. During the preconstruction phase, design alternatives could be analyzed through BIM models to evaluate the feasibility of the project and the performance of the design. Better design decisions through earlier collaboration among stakeholders, verification of convenience of building design to owners' requirements, fast generation of design documents could be obtained by implementing BIM during design stages. When construction phase begins, models could facilitate detecting design problems, planning and monitoring construction, updating the design according to the changes done at the construction site, fabrication of building components, and removal of waste from the processes. BIM technologies and 
methods can be beneficial after the construction is completed as well. The models could be utilized in operations and management phase of the project to support decision making and asset management processes, and even during the demolition phase of the project by planning the reuse of the building components.

A research shows that BIM provides better "information management for the building lifecycle; increased efficiency leading to improved design; reduced error, rework and waste in design and construction; improved risk management; lean construction and design; gaining supply-chain support in producing documentation construction management appreciation of the use of technology" (Khosrowshahi \& Arayici, 2012). BIM eliminates the need for interpretation of the information due to the structured building information utilized and/or processed from BIMs; and this reduces the risks related to human judgement and intuition (Crotty, 2012). Another research reveals that enhancing organizational image is one of the major benefits that $32 \%$ of the participants agreed on (McGraw Hill Construction, 2014). Additionally, it enables the non-technical stakeholders such as clients, users, etc. "to visualize the end product” (The Associated General Contractors of America, 2005).

The project stakeholders and especially the owner of the project have to have realistic expectations for the outcomes to implement BIM successfully without subsequent litigations (Kymmel, 2008). The implementation would require time to develop the best practice regarding the uses of BIM that the company plans to accomplish. Expecting immediate cost savings on project implementation instead of expecting to achieve higher quality on project deliverables may lead to conflict among stakeholders that could jeopardize the success of BIM implementation.

Some major BIM application areas are scope clarification, design validation, design options analysis, virtual mock-ups, scenario exploration, program compliance, building performance, conflict identification and resolution, operation simulation, code compliance, quantity takeoff, cost estimation, scheduling, generating shop and fabrication drawings, material supplier integration, prefabrication, production data delivery into asbuilt BIM in design and construction phases, configuration, commissioning, facility management, financial asset management, performance monitoring in post-construction and operations phases (Ashcraft, 2008; Eastman et al., 2011; Khosrowshahi \& Arayici, 2012; Senate Properties, 2012; The Associated General Contractors of America, 2005). 


\subsection{Characteristics and Basic Concepts of BIM}

\subsubsection{Characteristics of BIM}

Current BIM technology is based on "object-based parametric modeling capabilities". Parametric objects consist of "geometric definitions and associated data and rules”; the rules for the objects “automatically modify associated geometries” and identify “object feasibility regarding size, manufacturing, etc.” (Eastman et al., 2011).

BIM tools include "predefined set of object classes". The level of aggregation of the object classes define correlations between objects (Eastman et al., 2011). For instance, a wall is associated to its bounding surfaces, or a door/window requires a wall to be placed into.

Parametric objects can carry property information regarding all phases of project's life-cycle such as name, material, cost, etc. (Eastman et al., 2011). Users have to be sure they embedded all necessary property information to parametric objects to be able to process them to perform analysis for different purposes. A key to an enduring implementation of BIM is to generate information that has a continuous potential throughout the life-cycle of a project. The usage of the models should not be limited to the team that creates them or to a single purpose, but it should be enabled utilizing the information for various purposes in later phases of the project (Smith \& Tardif, 2009).

All drawing sets of construction projects are generated from a single building model in which each building object is created for once with necessary properties assigned. This process eliminates the possible human errors that may happen while creating independent views of the project manually like in $2 \mathrm{D}$ vector-based practice. To generate full drawing sets, it is not required to create each building component that would be constructed on site, because this would take a considerable amount of time. Instead, partial drawings could be associated with the model that is automatically updated when the model changes (Eastman et al., 2011).

Reports, schedules also can be retrieved from building models by compiling the property information that components carry. Although authoring software applications provide some default reporting tools, customization according to the company's business practice may require to create new templates with rules identifying which information would be included in the output. 


\subsubsection{Interoperability and Information Exchange}

To effectively use building information models (BIMs) within groups from different disciplines, the data should be able to be shared among stakeholders which means among different software applications. There have been efforts to develop a common format for information exchange procedures. Some of the most common formats of interoperability that was adopted during exchange of CAD files were DXF (Drawing eXchange Format) by Autodesk, IGES (Initial Graphic Exchange Specification) a vendor-neutral file format, ISO-STEP (Standard for the Exchange of Product Model Data).

The most common data formats in current construction industry are IFC (Industry Foundation Classes) by buildingSMART and CIS/2 (CIMsteel Integration Standard Version 2) (Eastman et al., 2011). As this study does not focus on steel construction, only IFC format will be discussed.

IFC is an open and "neutral data format to describe, exchange and share information typically used within the building and facility management industry sector” and includes an "object-oriented data model based on class definitions representing the things (elements, processes, etc.) that are used by software applications" ("Basic Informations - IFC," 2011).

IFC carries not only geometric data but also semantic information such as color, material, properties, thermal conductivity, cost data, etc. and relations between objects. It is one of the richest formats which includes 327 data types, 653 entity definitions, and 317 property sets in version 2x3; and when a particular element is not defined in these classes, there is an extension mechanism named IfcProxy objects to include new elements (Steel, Drogemuller, \& Toth, 2012).

Major software applications provide support for import and export functions for IFC utilization. buildingSMART has developed "IFC-Compatible Implementations Database” where users can interactively search for software applications that support IFC utilization . A sample from the database that shows architecture and construction management tools is given in Table 2.2. 
Table 2.2. Sample of BIM Applications that Support IFC Format (Source: buildingSMART)

\begin{tabular}{|c|c|c|c|}
\hline Туре & Name & $\begin{array}{l}\text { Import/ } \\
\text { Export }\end{array}$ & URL \\
\hline \multirow{6}{*}{ 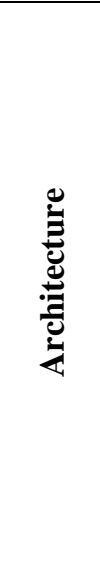 } & 4M IDEA Architecture & $\begin{array}{l}\text { Import } \\
\text { Export }\end{array}$ & $\underline{\text { http://www.bim-architecture.com/bim/ }}$ \\
\hline & AutoCAD Architecture & $\begin{array}{l}\text { Import } \\
\text { Export }\end{array}$ & http://usa.autodesk.com/autocad-architecture/ \\
\hline & ArchiCAD & $\begin{array}{l}\text { Import } \\
\text { Export }\end{array}$ & http://www.graphisoft.com/products/archicad/ \\
\hline & Allplan Architecture & $\begin{array}{l}\text { Import } \\
\text { Export }\end{array}$ & $\begin{array}{l}\text { http://www.nemetschek.eu/solutions/architecture.ht } \\
\text { ml }\end{array}$ \\
\hline & Bentley Speedikon V8i & Export & $\begin{array}{l}\text { http://www.bentley.com/en- } \\
\text { US/Products/Bentley+speedikon+Architectural/ }\end{array}$ \\
\hline & Revit Architecture & $\begin{array}{l}\text { Import } \\
\text { Export }\end{array}$ & $\begin{array}{l}\text { http://usa.autodesk.com/revit/architectural-design- } \\
\text { software/ }\end{array}$ \\
\hline \multirow{6}{*}{ 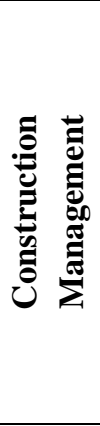 } & DProfiler & Export & http://www.beck-technology.com/product_dp.asp \\
\hline & IFC Takeoff for MS Excel & $\begin{array}{l}\text { Import } \\
\text { Export }\end{array}$ & $\begin{array}{l}\text { http://www.digitalalchemypro.com/html/products/ } \\
\text { DAProducts_IfcTakeoff.html }\end{array}$ \\
\hline & Navisworks & Import & http://usa.autodesk.com/navisworks/ \\
\hline & Tekla BIMsight & Import & http://www.teklabimsight.com/ \\
\hline & Vico Office Suite & Import & $\begin{array}{l}\text { http://www.vicosoftware.com/products/Vico- } \\
\text { Office/tabid/85286/Default.aspx }\end{array}$ \\
\hline & Synchro Professional & Import & $\begin{array}{l}\text { http://www.synchroltd.com/shop/synchro- } \\
\text { professional_synchropro.htm }\end{array}$ \\
\hline
\end{tabular}

There is another method for information exchange that a company may adopt. The concept called "intra-operability" may be adopted to avoid converting of BIM data, between various formats. Intra-operability means "the ability to transfer project data between software modules or programs within a software company's internal suite of software packages” (Kensek, 2014). It may seem like an effective way of sharing information during the project implementation, if there is only one company/team to work on the project due to the high level of control over technical infrastructure it requires. Yet, even if the company implements its projects without any other stakeholders, in depth estimates and research in the potential uses of BIM that may be performed in the future are needed to make sure that the chosen software package would provide sufficient tools.

Standardization of information is another important concept in interoperability. Common methods of standardization such as naming conventions for building objects or enumeration for cataloging the objects should be adopted by all project stakeholders. MasterFormat and UniFormat by the Construction Specification Institute (CSI) “organize construction information based on the type of work performed and the type of element 
being installed in a project” (Weygant, 2011).These formats provide a logical hierarchy and a database which makes extraction of necessary information to organize project manuals and detailed cost information easier.

There is another classification system for the construction industry named OmniClass which incorporates MasterFormat for work results and UniFormat for elements. It expands the contents of other classification systems to provide a comprehensive strategy for organizing information that BIM implementation requires. It consists of 15 tables that "break down the construction environment into discrete types of information” (Brodt, 2011). OmniClass has been gaining importance for facility management phase of the project due to the ability it provides to identify systems within a facility by the information on "Elements" table. It is also included in COBie (Construction Operations Building Information Exchange) data standard which is a specification for facility asset information delivery (East, 2014b).

COBie structures the information that would be submitted to the owner at the end of the project to facilitate operations and management phases (Eastman et al., 2011). It is worth noting that COBie is not a technology, but rather a standard for structured information exchange (Smith \& Tardif, 2009). Data is collected according its types such as building, storey, spatial container, furnishing, etc. from project stakeholders throughout the project implementation via BIMs according to the COBie specifications for each project phase. The data can be utilized either in IFC format or in spreadsheet format. (East, 2014a).

Structured data created during BIM implementation has to be exchanged between project stakeholders. To define a methodology to specify processes and information flows, buildingSMART has developed Information Delivery Manuals (IDM) (Karlshoj, 2011). This document was later accepted and published as a standard named "ISO 294811:2010 Building Information Modelling - Information Delivery Manual”. IDM targets both users and software providers: it provides a framework for describing the content of information to be exchanged according to the associated processes for users, and helps identify the information structure to be supported for software providers (IFCwiki, 2008).

Since there is a heavy amount of information included in the collected data, a method to define subsets of the IFC schema that satisfy the exchange requirements has been developed. This concept is called Model View Definition (MVD). MVDs help BIM teams to decide what to implement, and also helps the owners to know what to expect in the submission documents, by identifying what information should be included for an 
effective exchange (Eastman et al., 2011). They are suggested to be the "best method for exchange of system layout information” (NIBS, 2015). MVDs can facilitate defining the content of the BIMs and the workflow to create them according to future use. Different types of MVDs such as Coordination View, Structural Analysis View, Basic Facilities Management (FM) View, etc. are available for use of specific information exchange purposes. Official MVDs are developed and published by buildingSMART, however, several other organizations and/or development teams have been working on developing MVDs and after an approval process their contributions can also be published as official MVD via buildingSMART website.

\subsubsection{Collaboration}

Collaboration is one of the major aspects of construction projects. Technological developments in the industry make collaboration a key factor which has a significant influence on success of projects (Rahman, Endut, Faisol, \& Paydar, 2014).

Project delivery methods used in construction industry may enhance the project's outcomes related to BIM depending on the level of collaboration that is performed. Continuous collaboration throughout the project's life-cycle would increase the benefit of using BIM. For instance, Design-Bid-Build (DBB) approach which is the most frequently used approach in the world and distributes the responsibilities for design, contract documents and construction phases to various stakeholders could limit the advantages of BIM implementation because of its fragmented characteristics (Eastman et al., 2011). Despite these limitations, studies shows that projects still can benefit from BIM technologies even when using the DBB approach (The Associated General Contractors of America, 2005).

On the other hand, Design-Build approach may present great opportunities, because owner contracts with a single team/company that would be responsible for design and construction phases (Eastman et al., 2011). This may help project team to develop a comprehensive project execution plan by enabling to define end-uses for the BIMs in earlier phases of the project and developing the building information without any interruptions.

The American Institute of Architects (AIA, 2007) defines Integrated Project Delivery (IPD) as “a project delivery approach that integrates people, systems, business 
structures and practices into a process that collaboratively harnesses the talents and insights of all participants to optimize project results, increase value to the owner, reduce waste, and maximize efficiency through all phases of design, fabrication, and construction”. The definition of IPD resembles the definition of BIM. The collaboration that is proposed in IPD starts in early design and continues until FM. The owner and the project stakeholders work together throughout the project to meet the project requirements by reducing time and cost (Eastman et al., 2011).

Regardless of the project delivery method, owners have major impact on BIM implementation as one of the main stakeholders of the project. Even if the company is ready to implement BIM in construction projects, the owner may not be aware of the advantages that BIM can provide in the later phases of project's life-cycle and could insist on following traditional paths. In that case, owners may be trained to inform about what BIM is and what to expect from it (Kensek, 2014).

The staff effort workload would be shifted while implementing BIM. Initially, this change may cause stress-related resistance among stakeholders, and hinders collaboration. In traditional project delivery process, the high level of workload is completed during the construction documents phase, whereas it is completed during design phases in BIM implementation (Epstein, 2012). Acknowledging the change could facilitate increasing the level of collaboration.

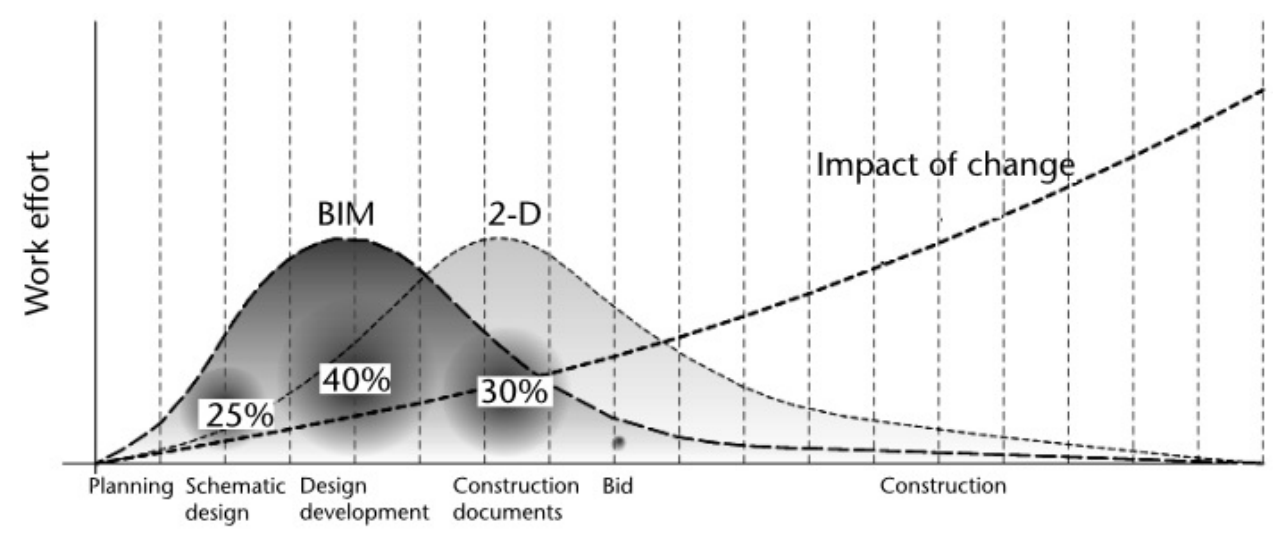

Figure 2.1. Staff Effort Breakdown (Source: Epstein, 2012)

Early collaboration has a strong influence on successful transition to BIM in implementation process. Each stakeholder should be on the same page with the goals and 
deliverables. To do that, meetings including as many stakeholders as possible preferably starting from the early phases of the project should be held. Even then, there may be major revisions throughout the implementation. (Kensek, 2014).

Methods of collaboration while implementing BIM may vary according to the requirements of each project. The alternatives of strategies on information exchange and communication that can be adopted are explained in Chapter 3 under associated headings.

\subsection{BIM Tools and Applications}

Technological infrastructure may influence the BIM implementation to a great extent. Not only software and hardware selections, but also platforms to share information among stakeholders during the process should be considered to enable implementation and collaboration.

There are several software applications available in the market for specific BIM purposes such as authoring, construction, etc. Some of the most common BIM tools are given in Table 2.3. Each company should research and evaluate the options and services that are provided with various tools, and select the best one with regard to the expected applications, performance and economic impact. Exploring the types of software that the company's existing business partners use could help overcome interoperability issues which might arise during implementation.

Table 2.3. BIM Software List

\begin{tabular}{|l|l|l|}
\hline \multicolumn{2}{|c|}{ SOFTWARE } & \multicolumn{1}{c|}{ VENDOR'S DESCRIPTION } \\
\hline \multirow{2}{*}{ REVIT } & $\begin{array}{l}\text { Revit is specifically built for Building Information Modeling (BIM), } \\
\text { including features for architectural design, MEP and structural } \\
\text { engineering, and construction. } \\
\text { Url: http://www.autodesk.com/products/revit-family/overview }\end{array}$ \\
\cline { 3 - 4 } & \multirow{2}{*}{ MICROSTATION } & $\begin{array}{l}\text { The MicroStation family of products provide the power and versatility to } \\
\text { precisely view, model, document, and visualize information-rich 2D and } \\
\text { 3D designs of all types and scales for professionals in every discipline on } \\
\text { infrastructure projects of every type. } \\
\text { Url: https://www.bentley.com/en/products/brands/microstation }\end{array}$ \\
\hline
\end{tabular}

(cont. on next page) 
Table 2.3. (Cont.)

\begin{tabular}{|c|c|c|}
\hline & SOFTWARE & VENDOR'S DESCRIPTION \\
\hline \multirow{4}{*}{ 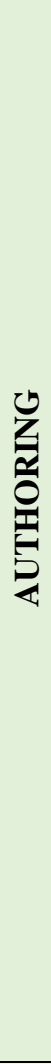 } & ALLPLAN & $\begin{array}{l}\text { Allplan develops powerful IT solutions for architects, civil } \\
\text { engineers, construction companies, and facility managers. } \\
\text { The core product Allplan offers flexible and efficient tools } \\
\text { for seamless planning and realization of visionary } \\
\text { architecture and innovative engineering products. } \\
\text { Url: https://www.allplan.com/en.html }\end{array}$ \\
\hline & ARCHICAD & $\begin{array}{l}\text { ARCHICAD enables to combine creative freedom with the } \\
\text { well-known efficiency of its robust Building Information } \\
\text { Model. A comprehensive set of tools supports the creative } \\
\text { process within the context of the project. } \\
\text { Url: http://www.graphisoft.com/archicad/archicad/overview/ }\end{array}$ \\
\hline & $\begin{array}{l}\text { VECTORWORKS } \\
\text { ARCHITECT }\end{array}$ & $\begin{array}{l}\text { Vectorworks Architect software delivers a design suite of } \\
\text { capabilities that provide freedom of artistic expression with } \\
\text { the robust capabilities of BIM, great documentation, and the } \\
\text { intelligent tools to advance and communicate ideas in 2D or } \\
\text { 3D. } \\
\text { Url: http://www.vectorworks.net/architect/ }\end{array}$ \\
\hline & TEKLA STRUCTURES & $\begin{array}{l}\text { Using Tekla Structures, engineers can create a single building } \\
\text { model in order to collaborate efficiently with architects, } \\
\text { mechanical \& electrical engineers, contractors and } \\
\text { fabricators.They can produce all structural documentation, } \\
\text { including construction drawings, steel and reinforcement } \\
\text { detailed drawings, reports and material schedules. } \\
\text { Url: http://www.tekla.com/us/products/tekla-structures }\end{array}$ \\
\hline \multirow{4}{*}{ 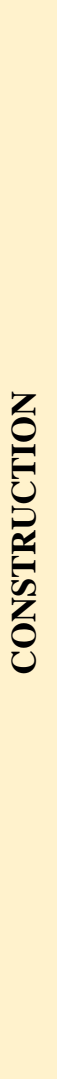 } & NAVISWORKS & $\begin{array}{l}\text { Navisworks }{ }^{\circledR} \text { project review software products enables } \\
\text { architecture, engineering, and construction professionals to } \\
\text { holistically review integrated models and data with } \\
\text { stakeholders to gain better control over project outcomes. } \\
\text { Url: http://www.autodesk.com/products/navisworks/overview }\end{array}$ \\
\hline & $\begin{array}{l}\text { SOLIBRI MODEL } \\
\text { CHECKER }\end{array}$ & $\begin{array}{l}\text { Solibri Model Checker (SMC) helps to find and visualize } \\
\text { issues and problems before and during construction. It will } \\
\text { also provide a wealth of information that can be taken off } \\
\text { throughout the building's life-cycle and utilized for needs } \\
\text { that include area calculation, accessibility and building code } \\
\text { compliance. } \\
\text { Url: www.solibri.com/products/solibri-model-checker/ }\end{array}$ \\
\hline & VICO OFFICE SUITE & $\begin{array}{l}\text { Vico Office }{ }^{\mathrm{TM}} \text { is purpose-built for construction, and is } \\
\text { designed as a tightly-integrated, BIM-neutral platform to } \\
\text { which multiple types of BIM models can be published, } \\
\text { synthesized, and augmented with cost and schedule } \\
\text { information. } \\
\text { Url: http://www.vicosoftware.com/products/Vico-Office/ }\end{array}$ \\
\hline & CONSTRUCTION SIM & $\begin{array}{l}\text { ConstructSim provides features for virtual construction } \\
\text { simulation, work packaging, status tracking, information } \\
\text { mobility and look-ahead planning features. } \\
\text { Url: https://www.bentley.com/en/products/product- } \\
\text { line/construction-software/constructsim }\end{array}$ \\
\hline
\end{tabular}

(cont. on next page) 
Table 2.3. (Cont.)

\begin{tabular}{|c|c|c|}
\hline & SOFTWARE & VENDOR'S DESCRIPTION \\
\hline \multirow{5}{*}{ 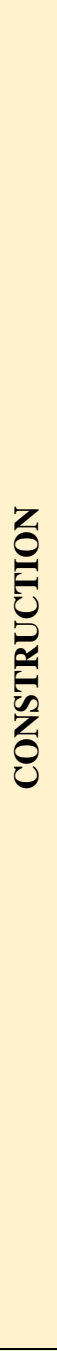 } & CONSTRUCTION SIM & $\begin{array}{l}\text { ConstructSim provides features for virtual construction } \\
\text { simulation, work packaging, status tracking, information } \\
\text { mobility and look-ahead planning features. } \\
\text { Url: https://www.bentley.com/en/products/product- } \\
\text { line/construction-software/constructsim }\end{array}$ \\
\hline & TEKLA BIMSIGHT & $\begin{array}{l}\text { Tekla BimSight combines models, checks for clashes and } \\
\text { shares information using the same easy-to-use BIM } \\
\text { environment. } \\
\text { Url: https://www.teklabimsight.com/ }\end{array}$ \\
\hline & SYNCHRO PROFESSIONAL & $\begin{array}{l}\text { Synchro PRO enables to visually review construction project } \\
\text { schedule in real time- edit it- add logistics, temporary works } \\
\text { and resources- discover conflicts in space and time (not only } \\
\text { design) as well as unsafe work conditions, optimize and } \\
\text { validate your approach before construction ever begins. } \\
\text { Url: https://synchroltd.com/synchro-pro/ }\end{array}$ \\
\hline & INNOVAYA & $\begin{array}{l}\text { Innovaya Visual Simulation associates BIM objects with } \\
\text { scheduling activities, performing 4D construction planning } \\
\text { and constructability analysis. It effectively improves project } \\
\text { communication, coordination, and construction logistics } \\
\text { planning.It helps to build optimized task sequences resulting } \\
\text { in project time savings and play what-if scenarios with } \\
\text { traditional GANTT chart schedules. } \\
\text { Url: http://www.innovaya.com/ }\end{array}$ \\
\hline & ONUMA & $\begin{array}{l}\text { Onuma allows a team to input the programming criteria, and } \\
\text { automatically produce adjacency and stacking diagrams, lows } \\
\text { the seamless transition from building design and construction } \\
\text { into operation and maintenance, while combining it with } \\
\text { Geographic Information Systems (GIS). } \\
\text { Url: http://onuma-bim.com/ }\end{array}$ \\
\hline \multirow[t]{2}{*}{ 禹 } & GREEN BUILDING STUDIO & $\begin{array}{l}\text { Green Building Studio® energy-analysis software enables } \\
\text { architects and designers to perform whole-building analysis, } \\
\text { optimize energy consumption, and work toward carbon- } \\
\text { neutral building designs earlier in the process. Cloud-based } \\
\text { energy-efficiency software helps teams achieve sustainable } \\
\text { building designs faster and more accurately with powerful } \\
\text { energy- and carbon-analysis tools. } \\
\text { Url: http://www.autodesk.com/products/green-building- } \\
\text { studio/overview }\end{array}$ \\
\hline & IESVE FOR ENGINEERS & $\begin{array}{l}\text { VE for Engineers can virtually test the feasibility of different } \\
\text { energy saving strategies and new technologies. It offers a } \\
\text { wide range of approved guided tools and analysis capabilities } \\
\text { which make achieving green building rating systems easy } \\
\text { and cost effective. } \\
\text { Url: https://www.iesve.com/software/ve-for-engineers }\end{array}$ \\
\hline
\end{tabular}

(cont. on next page) 
Table 2.3. (Cont.)

\begin{tabular}{|l|l|l|}
\hline \multirow{2}{*}{$\begin{array}{l}\text { HEVACOMP DYNAMIC } \\
\text { SIMULATION }\end{array}$} & $\begin{array}{l}\text { Hevacomp Dynamic Simulation performs whole } \\
\text { building energy simulations that go beyond HVAC } \\
\text { and lighting analysis, compares design alternatives } \\
\text { and facilitates well-informed decisions to improve } \\
\text { building design. }\end{array}$ \\
$\begin{array}{l}\text { Url: https://www.bentley.com/en/products/product- } \\
\text { line/building-design-software/hevacomp-dynamic- } \\
\text { simulation }\end{array}$ \\
\hline \multirow{2}{*}{ DESIGN BUILDER } & $\begin{array}{l}\text { Assess energy efficiency and carbon performance } \\
\text { during early stage design. Visualise solar shading } \\
\text { and explore designs to maximise comfort and the } \\
\text { benefits of daylighting and natural ventilation. } \\
\text { Enables to model HVAC, daylighting, airflow, cost, } \\
\text { energy and carbon. Optimise solutions to meet } \\
\text { design goals and maximise the benefits. } \\
\text { Url: http://www.designbuilder.co.uk/ }\end{array}$ \\
\hline
\end{tabular}

Building projects potentially generate large amounts of information and documents which can be unmanageable without a systematic approach to store them. Since there is an absence of file naming conventions in the AEC industry, companies have to deal with this issue on their own. Content management systems that are commercially available can be utilized and a file naming convention should be developed for use within the company. "File Properties" can be assigned to all electronic files which could help in sorting the files whenever a search is needed (Smith \& Tardif, 2009).

\subsection{BIM Utilization}

As it is previously mentioned, construction project documentation has been evolving from 2D to BIM processes. Jung and Joo (2011) categorize utilization of BIMs into two categories: passive use and active use. Passive use means utilizing the BIMs as input information to conduct independent outputs such as energy analysis, scheduling, construction planning, etc. It facilitates coordination among project stakeholders. It is also called as "Vanilla BIM” by Hugo Sheward and Charles Eastman (Kensek \& Noble, 2014 ). Active use which is also called as "Knowledge-Based BIM", on the other hand, refers to BIMs that include design knowledge information "in the form of design rules, parametric constraints, and/or parametric objects”. It allows automated design practices 
such as qualitative spatial reasoning studies where "design knowledge is embedded into graphic objects” to assist design process.

Implementing BIM does not mean that the all the BIMs carry the same level of information. The maturity level may vary. The differences in the maturity levels of BIMs during the implementation may disrupt collaboration. To facilitate an effective coordination and collaboration among project stakeholders, BIM maturity levels have been identified. There are four levels of information maturity, Level 0 to Level 3, according to the BIM maturity levels (BIM Industry Working Group, 2011). A diagram that represents these levels is given in Figure 2.2. The definitions of these levels are:

- Level 0: Representation of vector-based 2D data in either paper or electronic format without common standards.

- Level 1: Representation of 2D or 3D data with possibly some data structures. Level 1 lacks information exchange procedures among project teams.

- Level 2: Representation of 3D data which has attached building information on and is separated according to the disciplines. Discipline-specific 3D information is combined to process the information for further purposes such as scheduling, cost estimation, etc.

- Level 3: Collaborative and online model that integrates with the web services and can be "managed by a collaborative model server".

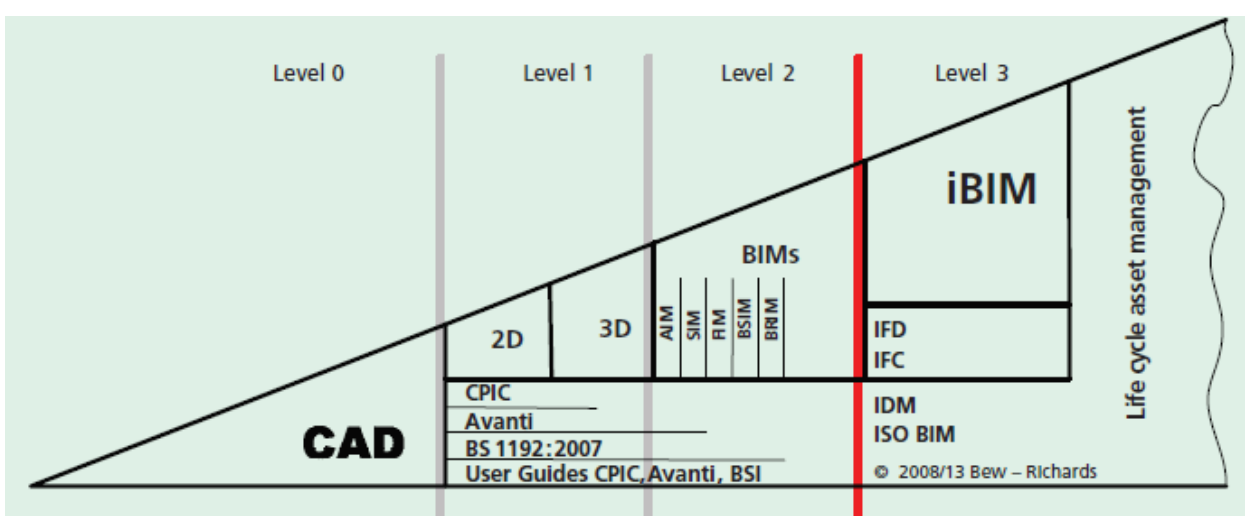

Figure 2.2. BIM Maturity Levels (Source: Bew \& Richards, 2008)

Succar (2009) also conducted a research that identifies BIM implementation stages. The stages resemble BIM Maturity Levels, but have different names: Pre-BIM 
Status, Stage 1 - object-based modeling, Stage 2 - model-based collaboration, and Stage 3 - network-based integration respectively.

BIM includes multiple dimensions of information. 3D refers to spatial dimensions that the model represents; $4^{\text {th }}$ dimension is the time for construction sequencing; $5^{\text {th }}$ dimension is cost for quantities and cost information; $6^{\text {th }}$ dimension is the associated information including specifications (Saxon, 2013).

In today's business practice almost all building information is created electronically. However it is generally degraded to non-electronical forms for information exchange purposes (Smith \& Tardif, 2009). This prevents benefitting from the potentials of BIM. Therefore the information exchange procedures have significant importance.

The construction documents issued for bidding contains the most elaborated version of information created in most of the construction projects. "The maturity level of construction documents continually declines" after the building permit is obtained. (Smith \& Tardif, 2009). Changes done during the construction phase are not generally delivered. Even if models are updated, the information has to be logically structured to enable utilization during facilities management. In the case that intensive collaboration is obtained to enhance the utilization of BIM throughout the project's life-cycle, the as-built or even better as-maintained models could be available to use (Figure 2.3). This could prevent building information from remaining idle after construction phase.

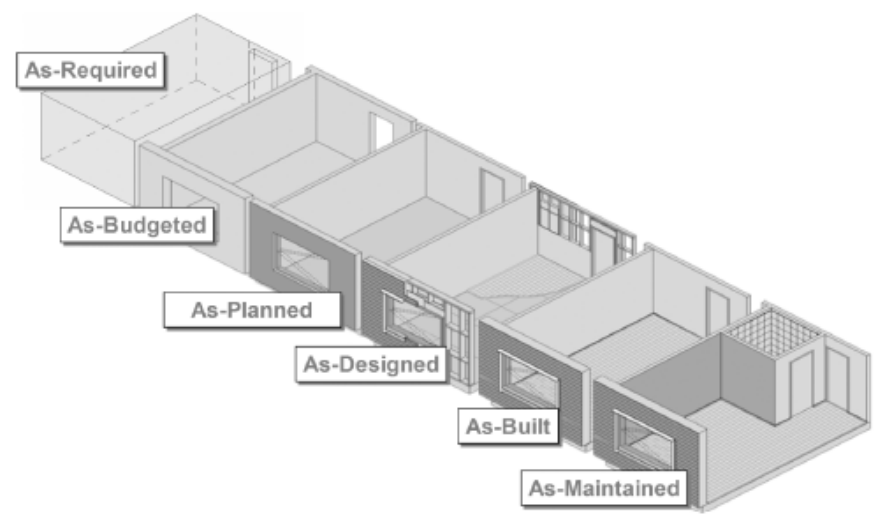

Figure 2.3. Building Information Continuity Illustrated (Source: Smith \& Tardif, 2012) 


\subsection{Challenges for BIM Implementation and/or Adoption}

Besides the benefits, there are also challenges for BIM implementation that requires consideration to succeed in the paradigm shift. Challenges may be related to management, stakeholders, technical, financial and/or legal issues.

\subsubsection{Organizational Issues}

Several research efforts reveal that non-technical issues which include managerial and organizational subjects are the most challenging part of BIM implementation (Gu \& London, 2010; Jung \& Joo, 2011; Khosrowshahi \& Arayici, 2012; Won, Lee, Dossick, \& Messner, 2013; N. W. Jr. Young \& Jones, 2008; N. W. Jr. Young, Jones, Bernstein, \& Gudgel, 2009).

Lack of industry standards on BIM implementation is an important challenge for BIM adoption (Won et al., 2013). It makes designing new implementation and training plans more difficult for companies. Moreover it usually limits the benefits in subprocesses and discourage moving away from existing processes of companies (Samuelson \& Bjork, 2014). Individual attempts to design BIM implementation plans without a common base point can lead to avoiding standardization of the outcomes of the implementations which can also affect collaboration among project stakeholders.

Implementation of BIM requires much more than providing technical infrastructure. Implementation plans that include the processes and workflows need to be developed (Elmualim \& Gilder, 2014). This may be a challenge for companies due to the lack of expertise on BIM (Won et al., 2013). The development process could be iterative and time-consuming which could make adoption even harder in the competitive AEC industry.

Training plan on BIM technologies and processes is another challenge to consider carefully (Elmualim \& Gilder, 2014). The content and the methods of the plan should be designed to provide smooth transition to BIM. It is important to acknowledge that there would be a learning curve (Won et al., 2013). It is suggested to give 3 to 6 months to the employees for adapting themselves to the new process and standards within the company and understand the benefits of BIM, and 12 to 24 months for implementing and sustaining 
the change to have a comprehensive implementation process (The Centre for Contsruction IT, 2013)

BIM is a relatively new concept in AEC industry with unproven means and methods. Resistance to change traditional practices in project implementation is one of the major challenges (Khosrowshahi \& Arayici, 2012; Won et al., 2013). Even if the technical resources are supplied to implement BIM, project success depends on the stakeholders whose participation is essential. Adapting a new way of undertaking that changes the practice of well-known tasks will take longer and can cause distress at first. Some experienced BIM Managers consider overcoming the resistance as one of the main goals to succeed in BIM implementation (Holzer, 2015).

Training plan may not be limited to BIM technologies and processes. Administrative infrastructure of the company could also be changed for BIM implementation (Khosrowshahi \& Arayici, 2012). For instance, new roles may be defined and recruited, new reporting procedures could be adopted. Training plan could also include training the owners of the projects. They should also understand the new changes and challenges to provide a consistent and cooperative environment to support the stakeholders on the transition process to succeed (Reddy, 2011).

Ensuring the accuracy of the new processes and workflows that have been developed to implement BIM is critically important for successful business practice. Software related problems may arise, unless the workflow and its results are confirmed to be accurate. In the case of software related problems which are not realized during the implementation, there may be losses, for instance, during the bidding phase of the project. There are verdicts of some law suits from the U.S. stating that companies that are implementing BIM are responsible for this kind of flaws in their workflows not the software providers (Ashcraft, 2008).

Management problems of BIM implementation is another challenge that may be experienced (Won et al., 2013). Management positions related to BIM require profound understanding of BIM technologies and processes. BIM implementation within the company and with other stakeholders should be managed effectively in the manner of enhancing collaboration.

The cost of BIM implementation including training, hardware, software, recruitment, services, and contingencies apart from regular business costs of the companies could be a major challenge (Olatunji, 2011). Technical infrastructure and adjusting the administrative structure of the firms would be initial costs of the 
implementation. Training could cost most in these initial investments (Hardin, 2009). After the initial costs, the actual labor cost of transition to BIM "tends to average between $0.1 \%$ and $0.5 \%$ of the total construction costs" (The Associated General Contractors of America, 2005).

\subsubsection{Legal Issues}

Contractual issues related to BIM have significant importance to avoid litigations. Andre (2011) and Ashcraft (2008) suggest that contracts have to address liability, intellectual property (IP), responsibility for data, loss of data subjects to define responsibilities and allocate risks and liability. Some documents that companies can refer to when they work on their own contracts are:

- AIA G201-2013 Project Digital Data Protocol Form

- AIA G202-2013 Project Building Information Modeling Protocol Form

- AIA E203-2013 Building Information Modeling and Digital Data Exhibit

- ConsensusDocs 301 Building Information Modeling Addendum

"Information Provenance” is a quality of information that assures its reliability (Smith \& Tardif, 2009). It defines the correct or erroneous usage of the information by the receiver parties. Therefore it is suggested to be clarified in contract documents which stakeholders are allowed to author or change the BIM information during the implementation. Model Element Author (MEA) definitions per project as it is suggested by AIA (2013c) address information provenance issues. MEA clarifies which model element would be created by whom, in which level of the detail, and in which project phase of the project.

Ownership of BIMs is one of the contractual challenges related to BIM implementation (Azhar, 2011). Unless it is determined in the contracts, conflicts may arise. Owners may entitle themselves as the owners of the BIMs, and design teams may claim BIMs include proprietary data which limits the re-use of the information. To avoid these conflicts, AIA (2013a) suggests to determine the circumstances of transmission and ownership of digital data.

Data security of model servers should be obtained in implementation. Although “network security may have technical limitations”, contracts can include terms to protect 
intellectual property (IP) and copyrights and/or to alleviate the consequences of violations (Gu \& London, 2010).

\subsection{Adoption Rates of BIM}

CAD technologies have been used by AEC professionals for more than 20 years. This dominant technology is being replaced by BIM technologies since the introduction of BIM tools in early 2000s (Won et al., 2013). It took 12 years to replace hand-based drawing with CAD technologies, whereas BIM technologies have already been expanding their user groups in North America and Europe up to over 50\% for less than a decade (Deutsch, 2011; Saxon, 2013). BIM adoption rates versus CAD is given in Figure 2.4.

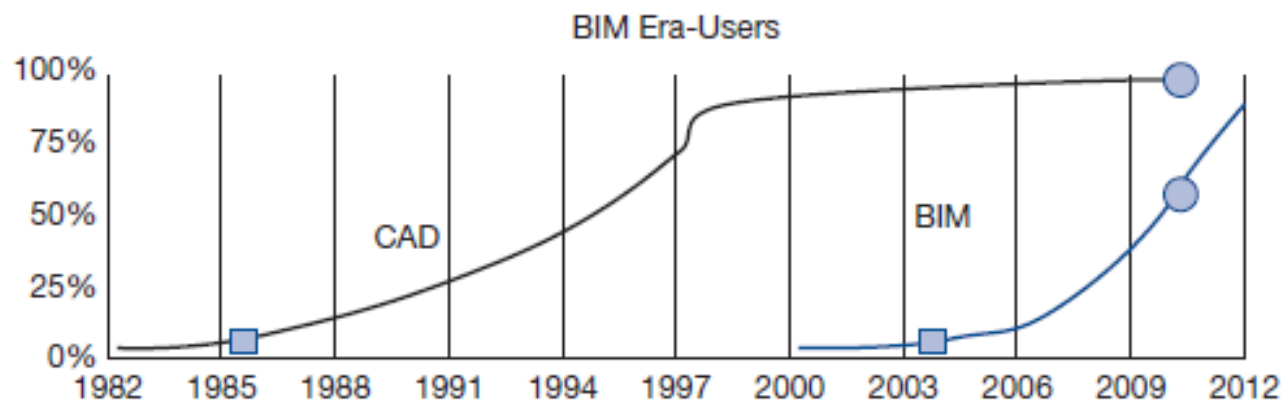

Figure 2.4. CAD versus BIM Adoption Chart (Source: Deutsch, 2011)

BIM adoption has not been a smooth process without failures. Until late 2000s, firms worked on technical and organizational challenges of the new technology to achieve best practices; this period is called the "early stage of BIM adoption” (Won et al., 2013). Due to the lack of industry standards and lack of technical and organizational expertise, some firms failed in adoption; but some were able to develop and improve their BIM implementation processes.

Critical success factors in BIM adoption are studied by Won et al. (Won et al., 2013). According to this study, the attitude of the stakeholders and the management of implementation process have major impact on success of the project. Top three critical success factors defined in this study are: (1) "willingness to share information among 
project participants” (2) “master BIM model team/manager”, (3) “effective collaboration among project participants”, respectively.

Won et al. (2013) categorize adoption levels (also called as level of engagement by McGraw Hill construction (2014)) into four different groups: (1) personal adoption which does not include any collaboration, (2) adoption within a team or company which refers to implementing BIM in single discipline, without information exchange with other disciplines, (3) adoption across different types of teams within a company to perform various uses of BIM from the same BIMs, (4) across companies which require complex collaboration procedures and solutions for interoperability issues. This categorization is similar to BIM maturity levels explained in BIM Utilization section of this study (Section 2.4). The difference between them is that adoption levels define the outcome of BIM maturity levels.

North America and Europe, followed by Asia Pacific have highest BIM adoption rates in the world (Saxon, 2013). A research shows that almost 70\% of contractors in North America has been using BIM (McGraw Hill Construction, 2014). Another recent research by the National Building Specification (NBS) which is owned by the Royal Institute of British Architects (RIBA) is conducted to compare BIM adoption in several countries (NBS, 2016). The study shows more than half of the participants in Canada, Denmark, and Japan have been using BIM (Figure 2.5). In UK, 13\% of the AEC professionals stated they use BIM in 2010, whereas $48 \%$ of the professionals stated that they use BIM and almost 60\% of them have reached Level 2 BIM (NBS, 2013, 2015).

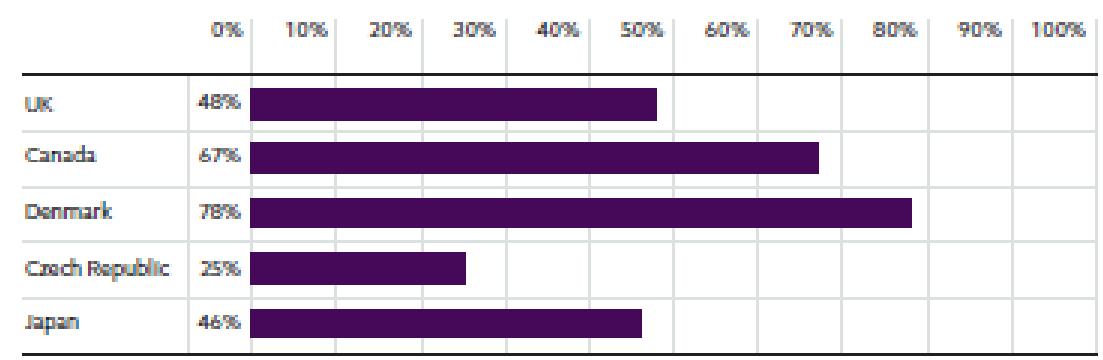

Figure 2.5. BIM Adoption Rates According to International BIM Report (Source: NBS, 2015)

Another research by McGraw Hill Construction (2014) reveals that there has been an ascending tendency in construction companies to adapt to BIM technologies over the 
last 5 years. Size of companies that adopt BIM vary. Majority of the companies that have more than 5 years of experience are large firms, and almost half of the companies that have 1-2 years of experience are small firms.

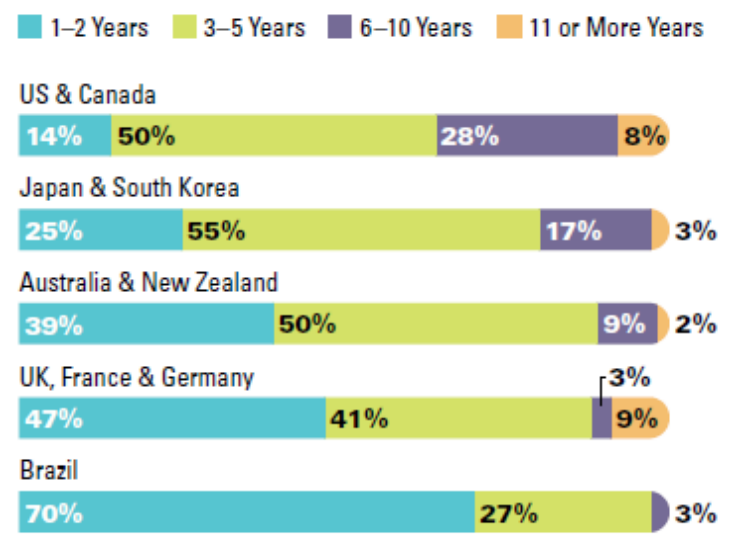

Figure 2.6. Length of Time Contractors Have Been Using BIM by Country (Source: McGraw Hill Construction, 2014)

Saxon (2013) states that the adoption levels of companies define the scope of BIM in AEC industry in the world. The more companies adopt BIM technologies and processes, the higher the level of adoption will be available to practice. In the current AEC industry, companies that have high adoption levels may have to limit the benefits of BIM to the early stages, because other stakeholders of the projects could demonstrate lack of experience and/or expertise on BIM.

Research shows that the companies that implement BIM in their projects prefer to participate in the projects with stakeholders who also have BIM experience (McGraw Hill Construction, 2014). The demand increases as the level of engagement and the size of the companies increases. Half of the participants state they only encourage other stakeholders to have BIM experience, whereas $30 \%$ of the contractors with high and very high BIM implementation levels in the research mandate implementing BIM in their projects. Most of the companies which do not require BIM experience from their stakeholders are small companies which have low level of engagement in BIM with less than 2 years of experience. The variations in results of requiring BIM expertise in team formation according to country is given in Figure 2.7 
We require companies be experienced in BIM

We encourage BIM expertise, but do not require it.

BIM expertise does not affect our decisions.

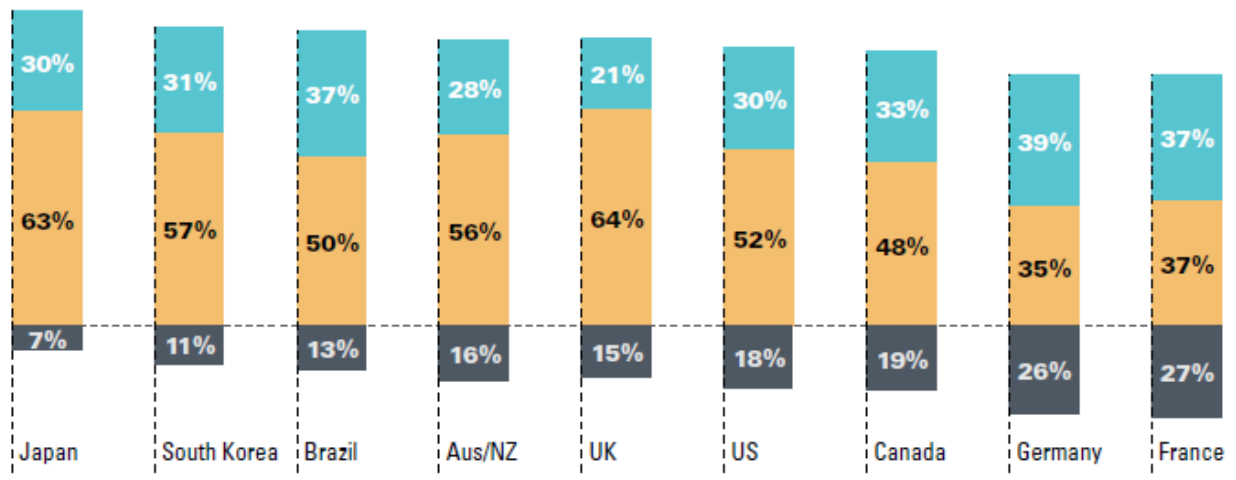

Figure 2.7. Contractors' Approach to Requiring BIM Expertise in Team Formation (Source: McGraw Hill Construction, 2014)

Over $90 \%$ of the companies that have a high level of adoption use BIM for 3D visualization purposes, almost $80 \%$ of them use BIM for clash detection, and more than half of them carry out performance analysis on BIMs (NBS, 2016). The decline in the implementation of uses of BIM may be due to the level of expertise they require, fragmented nature of AEC industry, lack of expertise of other project stakeholders they work with, and/or collaboration problems (Gu \& London, 2010).

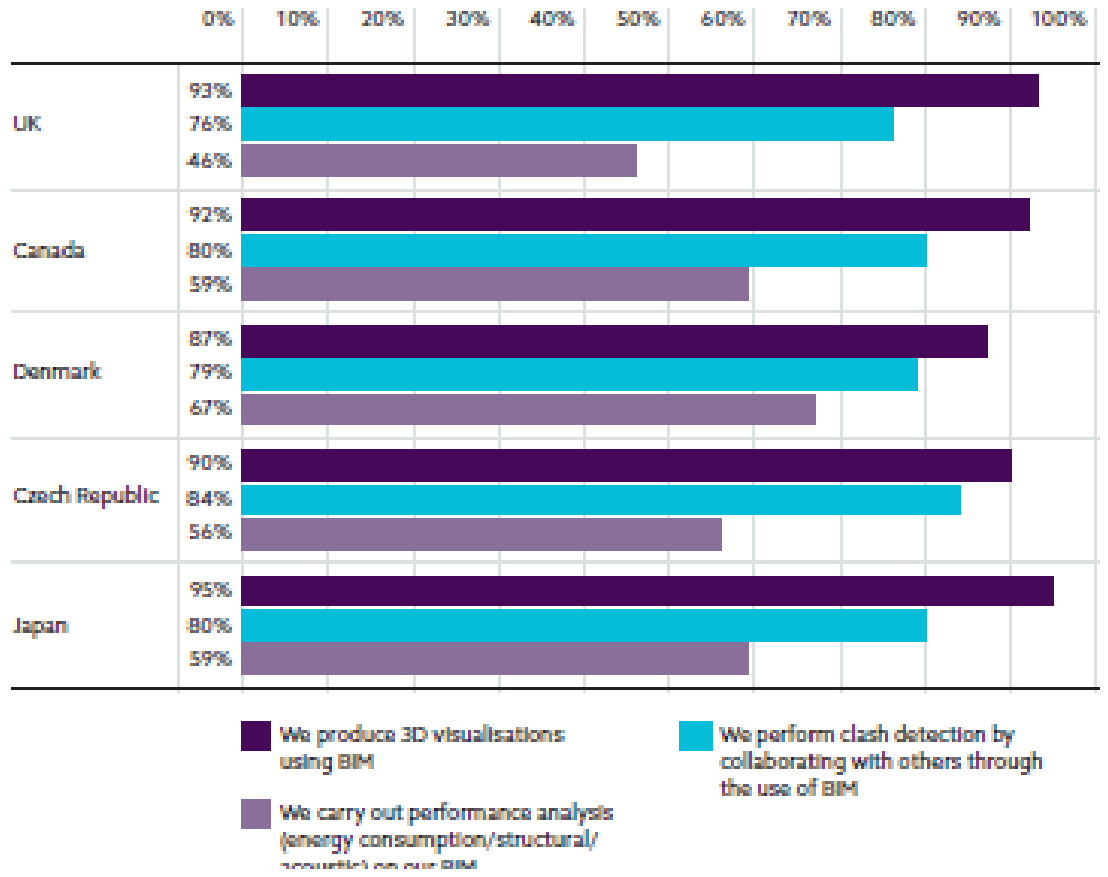

Figure 2.8. Current Uses of BIM (Source: NBS, 2016) 
Return on Investment (ROI) is an important issue which may influence BIM adoption in construction companies. Research shows that the level of engagement and size of the company influences the ROI on BIM (McGraw Hill Construction, 2014). Small size companies with low level of engagement report their ROI as negative or break-even, whereas large size companies with high level of engagement report as very positive. Negative or break-even ROI reports may be due to the impact of BIM investment.

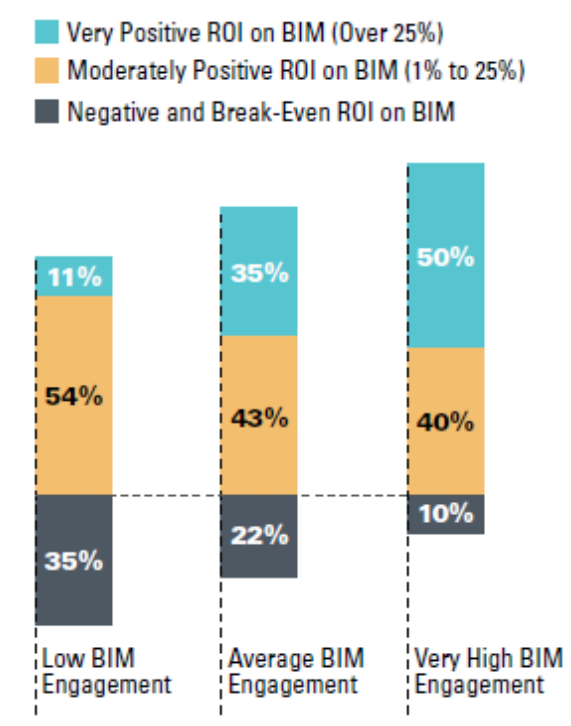

Figure 2.9. Impact of BIM Engagement Level on ROI (Source: McGraw Hill Construction, 2014)

\subsubsection{Legislation Actions}

BIM adoption has been mandated by some governments and some institutions around the world. In this section, some examples of current BIM initiatives will be explained. 


\subsubsection{United Kingdom:}

In 2011, the government declared that it would require "fully collaborative 3D BIM (with all project and asset information, documentation and data being electronic) as a minimum by 2016” (UK Cabinet Office, 2011). This means a minimum of Level 2 BIM will be required on “centrally procured public projects” (Designing Buildings Wiki, 2015). Vision for 2025 is to reduce costs by 33\%, reduce greenhouse gas emissions in built environment by $50 \%$, accelerate delivery of construction projects by $50 \%$ and increase exports of construction products and materials by 50\%. BIM implementation is an important part of this vision (Department for Business, Innovation, \& Skills, 2013).

\subsubsection{Singapore:}

Singapore has been encouraging BIM implementation since 2010. As a part of Construction Productivity Roadmap, BIMs of architectural and engineering projects of all new building projects larger than $5000 \mathrm{~m}^{2}$ have to be submitted electronically (Cheng, 2012).

\subsubsection{United States:}

National BIM Standard (NBIMS-US) has been developed in 2007, and recently the $3^{\text {rd }}$ version of NBIMS-US has been published (NIBS, 2015). The aim of this document is to provide a common ground for BIM implementation.

US General Services Administration (GSA) which is responsible for public building projects requires spatial program validation via BIMs as a minimum (GSA, 2015). Institutions in U.S. such as MIT Department of Facilities (2012), and U.S. Department of Veterans Affairs (2010) mandates submissions of BIMs in their construction projects. 


\subsubsection{Australia:}

National standards for BIM were developed in Australia in 2015. BIM implementation will be required in national government procurement for built environment projects in July 1, 2016; and territory governments as well as private sector is encouraged to require BIM for procurement (RICS, 2014).

\subsubsection{China:}

Investments in infrastructure to adopt BIM have been made in China. To speed up the adaptation process, National 12th Five Year Plan for 2011-2015 has included BIM, and a BIM framework has been formulated (RICS, 2014).

\subsubsection{Hong Kong:}

BIM implementation has been encouraged in Hong Kong since 2006 (Housing Authority, 2016). Documents to support and standardize BIM implementation such as user guides, library components design guides, etc. have been published by Housing Authority, although implementation is not required yet.

\subsubsection{Netherlands:}

Central Government Real Estate Agency (2014) in Netherlands mandates delivery of BIMs in public building projects. BIM standard specifying the qualities of BIM deliverables is developed and published in 2012 (Rijksgebouwendienst Ministry of the Interior and Kingdom Relations, 2012).

\subsubsection{Norway:}

Four large Norwegian public building clients and owners have signed a joint statement and required BIMs in their projects since 2013 (BuildingSMART, 2013). 
According to this joint statement, open standards (IFC in this case) should be used in delivery.

\subsubsection{European Union:}

The European Parliament has been encouraging its members -28 EU countries, to adopt BIM in public procurement processes since 2014 (Autodesk PR, 2014). The aim of European Union Public Procurement Directive (EUPPD) is to use BIM in all publicly funded construction projects by 2016. 


\section{CHAPTER 3}

\section{BIM IMPLEMENTATION PLANS AND STANDARDS}

Business process reform to adopt BIM can be performed in two levels: (1) industry-wide changes in business practice, (2) changes in individual organization (Smith \& Tardif, 2009). To enable industry-wide business changes, standards development is crucial. There are several standards and guidelines published by different institutions around the world. They are either national/regional guidelines to support BIM transition or institutional standards that outline the rules to follow for building projects within the institution. Therefore, contents of these documents vary depending on the target audience. Some documents focus on the implementation process in a detailed manner, while some focus on what information the deliverables should have.

buildingSMART initiated a project to catalogue standard and guideline documents in 2013, and currently 81 documents have been listed (Marie, 2015). The project is still on progress and cannot provide a structured comparison among these documents yet. 81 documents listed there include the chapters of the same document. When this list is studied, it is seen that there are only 55 resources referred to. Since the scope of this thesis is only BIM execution process, only 23 documents which focuses on BIM execution process have been reviewed. Detailed content matrix can be found in Appendix A. Content details are compiled below to provide general information. The intent of this study is to facilitate adoption and implementation of BIM processes in construction companies. Considering possible phases that a construction company could participate in a building project depending on the contract type, content of previous studies have been reviewed focusing on design and construction phases only.

Contents of reference documents are categorized under four groups: (1) scope of implementation, (2) infrastructure, (3) contracts, (4) implementation processes. "Scope of implementation” defines the general decisions on BIM implementation, such as BIM mission and vision of the company, projected goals and uses of BIM, and the project phases of implementation. "Infrastructure” includes technological and organizational assets of the company to enable and support BIM implementation. "Contracts” explains 
the suitable project delivery method for BIM implementation and the key subjects to include in the contract documents. "Implementation processes" includes the subjects to address while project execution.

\subsection{Scope of Implementation}

\subsubsection{Organizational BIM Mission and Vision}

Mission and vision statements facilitate organizations to understand the existing state of the organization and to guide them to achieve their future desired state. Bart and Baetz (1996, 1997; 1995) state that clearly defined mission statements "have strong positive relationship on improving the performance" and "the standards of behavior within the organization”. Specific to BIM processes, mission and vision statements identify the backbone for further decisions. BIM Project Execution Planning Guide V2.1 (Computer Integrated Construction Research Group, 2011), BIM Planning Guide for Facility Owners V1.02 (Computer Integrated Construction Research Group, 2012) and Autodesk BIM Deployment Plan (Autodesk Inc., 2010b) suggest that defining organizational BIM mission and vision statements and aligning them with organizational vision enhance the productivity of organization.

A BIM mission statement should refer to the concept of using BIM instead of only referring to the existing operations of the organization. It may emphasize the organization's eagerness to benefit from technological developments related to the services it provide, to deliver innovative solutions in their projects, etc. An example BIM mission statement of a construction company might be as follows: "X Company provides operational excellence and innovative solutions by means of technology and efficient collaboration, and consistently outperforms its competitors in a rapidly evolving construction industry."

On the other hand, a vision statement should clearly define future desired state. It has to increase the motivation and give inspiration to the participants for the project execution and the project has to be conducted to accomplish this vision statement. To clarify the vision statement, quantitative targets or a deadline to achieve them might be included. An example BIM vision statement might be as follows: "The vision of $\mathrm{X}$ 
Company is to minimize risks of the project, to be able to compete in international construction industry and to rank among top 500 construction companies in the world in the next ten-year period by dint of integrating BIM processes to our projects.”

\subsubsection{BIM Goals and BIM Uses}

BIM Goals are one of the most important aspects of the BIM execution plans in the literature. They help define the specific requirements of the project. It may be challenging to identify the distinction between BIM as a process to be implemented to accomplish specific goals and the software applications to be chosen to author the process, as companies try to execute BIM for the first time. So significant consideration is required to define BIM Goals which could be satisfied by the software applications (Canada BIM Council, 2014)

BIM Goals enhance projected accomplishments of the project and improvements for the company's services. Epstein (2012) states that goals provide a general approach to remain competitive by providing profitability, efficiency, openness to new business opportunities, etc. Therefore the focus may not only be on the project deliverables, but also the vision statement of the company. It is important that they should be "specific, measurable, attainable, realistic and timely” (Computer Integrated Construction Research Group, 2012). Setting key performance indicators (KPIs) for each goal could help evaluate the performance at the end of the project (The Centre for Contsruction IT, 2013).

The purpose of this study is to guide construction companies in developing their own BIM implementation plans. While defining goals, construction companies could consider the motivation of implementing BIM within their organizations. New targets such as working with new clients, serving new types of deliverables, extended scope of work could help finding the goals (Kensek, 2014). Some possible goals for design and construction projects for construction companies could be

- Review design progress,

- Quickly asses cost associated with design changes,

- Eliminate field conflicts,

- Increase field productivity,

- Track progress during construction, (Computer Integrated Construction Research Group, 2011) 
BIM Uses are defined as “A method of applying building information modeling during a facility's life-cycle to achieve one or more specific objectives.” in National Building Information Modeling Standard-United States (NIBS, 2015). (“BIM Uses” will be used as a term with a capital "U" from this point on in this document.) Since the goals support the future desired state of the organization and BIM Uses are for achieving these BIM Goals, the BIM Goals should be considered carefully while defining the BIM Uses. BIM Execution Planning Guide suggests that keeping in mind the end use of the data that will be produced is crucial to the project success (Computer Integrated Construction Research Group, 2011). Therefore, it is necessary to monitor the process during the data production and revise the BIM Uses, and even BIM Goals, due to the desired end-state of the project information. Some sample of BIM Uses are given below (Canada BIM Council, 2014):

- 3D Coordination

- Quality Control Checks

- Site Utilization Planning

- Building System Analysis

BIM Execution Planning Guide (Computer Integrated Construction Research Group, 2011) has defined a procedure for selection of BIM Uses. First, BIM Uses should be prioritized according to the project needs. Then, it is suggested that responsible parties and necessary resources of BIM Uses should be specified clearly to evaluate the possibility of achieving the specified BIM Use. Ranking the capabilities of each responsible party and resource will show whether additional resources or competencies will be required. Evaluating the priority level of each BIM Use, existing capabilities and additional requirements to have, will help the team to determine which BIM Use to proceed with. This selection procedure can reduce the project risks by eliminating unnecessary or irrational BIM Uses for the project.

Another thing suggested while identifying BIM Uses is to consider them with relation to BIM deliverables and associated team members (author and users) (The BIM Guide Workgroup, 2013). Authors create the specified BIM deliverable, and users work on that deliverable without authoring rights. While doing so, it should be kept in mind that one person may have multiple roles (British Standards Institution, 2013). These considerations provide hints towards information exchange plan for later stages. 


\subsubsection{Project Phases}

BIM implementation process may comprise of several phases from design to demolition. This study is limited to design and construction phases of building projects.

BIM implementation plans can be created and executed for any phase of the project according to the contract type. The content of the plan such as BIM Uses, modeling methods, information exchange procedure, and deliverables can be adjusted to the phase's requirements. Detailed explanations for each phase are given below.

Two types of models that are most frequently referred to in the literature are design and construction models. Since Design-Bid-Build projects are often built in construction projects, construction companies may include creation of these models in their BIM plans. Design model is generated by designers and consultants for not only design coordination but also tender documents. Construction models are generated by contractor for construction purposes (Kensek, 2014; The BIM Guide Workgroup, 2013). Design models are coordination models which can be used to identify interferences to be resolved before tender documents are created, whereas construction models are for developing the model for the updates done during construction and fabrication. Construction models would end up being an as-built model to be used in facilities management phase when the project is completed.

The content, authors and the intended uses of the models that could be created by BIM Team throughout a construction project can be found below as a summary table. 
Table 3.1. Model Content and Uses of Project Phases (Source: Singapore BIM Guide V2.0)

\begin{tabular}{|c|c|c|c|c|}
\hline $\begin{array}{l}\text { Stages/ } \\
\text { Disciplines }\end{array}$ & $\begin{array}{l}\text { Architectural } \\
\text { Design }\end{array}$ & $\begin{array}{l}\text { Structural } \\
\text { Design }\end{array}$ & MEP Design & Intended Use \\
\hline $\begin{array}{l}\text { Conceptual } \\
\text { Design }\end{array}$ & $\begin{array}{l}\text { Topo, } \\
\text { Massing, } \\
\text { Site Elements, } \\
\text { Site Boundary, } \\
\text { Levels, } \\
\text { Location, } \\
\text { Orientation }\end{array}$ & (Optional) & (Optional) & $\begin{array}{l}\text { Site Planning, } \\
\text { Location of the building(s) on the } \\
\text { site, } \\
\text { Starting situation for renovation } \\
\text { project, } \\
\text { Investigation, } \\
\text { Visualization, } \\
\text { Design options, } \\
\text { Investment analysis, } \\
\text { Preliminary energy simulation, } \\
\text { Alternate spatial designs, } \\
\text { Scope management, } \\
\text { Investment calculations, } \\
\text { Energy simulation, } \\
\text { Finalised spatial requirements for } \\
\text { structures and MEP systems. }\end{array}$ \\
\hline $\begin{array}{l}\text { Preliminary } \\
\text { Design }\end{array}$ & $\begin{array}{l}\text { Building } \\
\text { elements with } \\
\text { nominal } \\
\text { dimensions } \\
\text { and details }\end{array}$ & $\begin{array}{l}\text { Load-bearing } \\
\text { structures, } \\
\text { Proposed } \\
\text { structural } \\
\text { system and } \\
\text { basic structure }\end{array}$ & $\begin{array}{l}\text { MEP } \\
\text { schematics }\end{array}$ & $\begin{array}{l}\text { Definition of building elements, } \\
\text { Comparison of building element } \\
\text { and structural alternatives, } \\
\text { Management of quality } \\
\text { information, } \\
\text { Preliminary dimensioning of } \\
\text { structures, } \\
\text { MEP analysis, } \\
\text { Visualization. }\end{array}$ \\
\hline $\begin{array}{l}\text { Detailed } \\
\text { Design }\end{array}$ & $\begin{array}{l}\text { Building } \\
\text { elements with } \\
\text { actual } \\
\text { dimensions } \\
\text { and details }\end{array}$ & $\begin{array}{l}\text { Frame } \\
\text { structures, } \\
\text { Joints, } \\
\text { Foundations, } \\
\text { Joining to } \\
\text { foundations, } \\
\text { Penetrations } \\
\text { and } \\
\text { reservations } \\
\text { connections. }\end{array}$ & $\begin{array}{l}\text { Service areas } \\
\text { of MEP } \\
\text { systems, } \\
\text { Central units, } \\
\text { Ducts, } \\
\text { Pipe work, } \\
\text { Terminal } \\
\text { devices, } \\
\text { Switchboards, } \\
\text { Cable routes, } \\
\text { Lighting } \\
\text { fixtures, } \\
\text { Penetrations } \\
\text { and } \\
\text { reservations }\end{array}$ & $\begin{array}{l}\text { Dimensioning of structures to the } \\
\text { precision required for tenders, } \\
\text { Definition of MEP systems, } \\
\text { Quantity take-off, } \\
\text { Penetration and reservation } \\
\text { design, } \\
\text { Energy simulation, } \\
\text { Visualization, } \\
\text { Combined services design. }\end{array}$ \\
\hline Construction & $\begin{array}{l}\text { Model used to } \\
\text { extract } \\
\text { construction } \\
\text { information }\end{array}$ & $\begin{array}{l}\text { Model used to } \\
\text { extract } \\
\text { construction } \\
\text { information }\end{array}$ & $\begin{array}{l}\text { Model used to } \\
\text { extract } \\
\text { construction } \\
\text { information }\end{array}$ & $\begin{array}{l}\text { Detailed design information for } \\
\text { construction, } \\
\text { Prefabricated element design, } \\
\text { Production planning. }\end{array}$ \\
\hline As-built & $\begin{array}{l}\text { Updated detail } \\
\text { model as per } \\
\text { actual site } \\
\text { conditions }\end{array}$ & $\begin{array}{l}\text { Updated detail } \\
\text { model as per } \\
\text { actual site } \\
\text { conditions }\end{array}$ & $\begin{array}{l}\text { Updated detail } \\
\text { model as per } \\
\text { actual site } \\
\text { conditions }\end{array}$ & $\begin{array}{l}\text { Information to be handed over } \\
\text { for FM (maintenance and repair, } \\
\text { space and occupancy } \\
\text { management) }\end{array}$ \\
\hline
\end{tabular}




\subsubsection{Conceptual Design Phase:}

Conceptual Design Phase is led by an architect and the participation of engineering teams is optional to study the potential design solutions for the project according to the owner's requirements. BIM use could be beneficial in this stage for site planning, investment analysis, preliminary energy simulation, defining spatial requirements for structures and MEP systems, visualization, etc. (The BIM Guide Workgroup, 2013).

\subsubsection{Preliminary Design Phase}

Preliminary design phase is the first stage of the design process. The Chamber of Architects in Turkey (2011) indicates that this phase for a construction project determines the project scope, needs, and objectives of the owner; and it starts with signing a contract with architect. The architect is responsible for collecting the necessary documents for the site, agreeing on the design and construction procedure with the owner, and preparing a conceptual design. According to the conceptual design, which shows the approximate size of the building, construction type, spatial organization and comparative alternatives, architect requests offers from several potential stakeholders.

Essentials of the phase do not differ in BIM implementation process, but BIM process brings along several advantages to the preliminary design phase. Input data about site, needs, and requirements is gathered from the owner and architect starts to work on design ideas. Simplified models of design alternatives that includes low level of detail could be used to perform preliminary energy simulation iterations, early cost estimation, etc (Indiana University, 2015). These efforts lead the owner and the project team to project and investment decisions. When decisions are made, BIM team proceeds to the design phase.

Besides more analyzed decisions, Jernigan (2007) claims that the difference between traditional and BIM process is the opportunity to change the focus of the design phase. In traditional process, the control and dominance is in the architect's hands, she/he designs the project which tries to fit into the owner’s needs. However, BIM approach may 
provide more collaborative environment where the architect and the owner can communicate better.

\subsubsection{Detailed Design Phase}

Detailed design phase ensures the details of the project that is studied in the preliminary design phase. Traditional detailed design phase for a construction process is led by an architect. Architectural projects are coordination projects, and the architect works as a coordinator who organizes and checks the engineering projects of the structural, mechanical, electrical engineers, and ensures that the projects meet the requirements of zoning laws and procurement procedures of electricity, gas, water, etc.

The Chamber of Architects in Turkey (2011) states that detailed design phase projects should:

- Include precise site plans that are appropriate to the zoning laws,

- Confirm that the ground level of the site and its neighborhood is correctly associated,

- Include the surveying information and state the precautions if necessary,

- Include the procurement information of electricity, gas, water, telephone, etc.,

- Include the safety precautions like lightning conductor, fire prevention,

- Show the heating, cooling and ventilation principles,

- Indicate the building materials,

- List the spatial elements,

- Include the report that indicates the information mentioned above,

- Include all floor plans, at least two sections, elevations that are different from each other, and detail drawings.

Architect and engineers collects the tenders for design projects. Those tenders and projects are presented to the project owner. When owner grants approval, architect coordinates the design team to proceed to construction phase.

BIM process cannot change the basic requirements of detailed design process, but can change the system of meeting the requirements. First, architect may not be the only leading actor of the process. Instead, BIM leader position is needed to develop a BIM plan for the project. Architect may also fit in that position as long as she is capable of 
managing a BIM implementation process. Not only detailed design phase deliverables but also cooperation and reporting procedures should be identified clearly while developing a plan (Senate Properties, 2012). Since the collaboration will not proceed through 2D drawings like in traditional design phase, each part of implementation plan should be designed to facilitate an effective coordination among team members.

As the level of detail increases in detailed design phase, the design review and improvements are possible. Detailed architectural and engineering design models could be used for clash detection, energy calculations, cost estimation, etc. Therefore, modeling should be an iterative process and needs to be managed well. The reporting process must be tight, and the project should be updated due to the changes. Thus, the inspection process of building information models will provide a higher quality realization with fewer errors (Senate Properties, 2012).

Constructability studies evaluate the design on whether it can be built. They are of significant importance in design phase. They help discover and fix design problems that would otherwise be noticed only during construction requiring changes that result in time and financial losses. Related to constructability, Hardin (2009) states that architects may choose "to use BIM to create design intent documentation" or to create "accurate" models to benefit from BIM. He orders the reasons for choosing the latter as follows:

- "First, an architect rarely regrets creating more accurate documentation, and as modeling proficiency increases, the ability to model quickly facilitates additional information in the process.

- Second, working toward a collaborative and interoperable system of using BIM is the future. Although some software limits the comprehensive capabilities of BIM because of a lack of interoperability, the future of BIM is moving toward a virtual, buildable model.

- Third, emulating actual construction in modeling becomes a useful tool for the construction manager building it. ”

Design deliverables are another important aspect of the design phase, because building permits must be granted before the construction phase. 2D drawings are still regulatory for those permits in Turkey. When project is approved by the owner and design team, 2D drawings must be prepared and submitted to associated authorities. In traditional project implementation processes this paper-based mode of communication, due to the desire to start the construction phase as quickly as possible, may result in constructability 
problems in design that are hard to detect (Eastman et al., 2011). If the construction permit is obtained without detecting those problems, the design is corrected on site whenever it is possible, but often, the team has to return to the design phase, which results in unnecessary loss of time and finances (Eastman et al., 2011).

When the design is ready to proceed to the construction phase, preparation for the construction phase should be organized (Senate Properties, 2012). This process includes reviewing the constructor's role in BIM process, arranging procurement documentation, and finally relinquishing the model to the contractor.

\subsubsection{Construction Phase}

Construction phase projects need to include higher level of detail than the design phase projects. When project is approved by owner to proceed to construction phase, design team works to elaborate on the details of the design to generate contract documents that hold and increased level of information. This information should include specifications for all materials, and installation method of each component in detail (The Chamber of Architects of Turkey, 2011). Additionally, since construction projects show precise details of the projects, contractors might use them for exact quantity takeoffs and cost estimation.

Hardin (2009) suggests constructors to create construction model to track the workflow, even if the building information model of the project was not created during the design phase. He states this new model will shorten the coordination procedure by providing a better understanding of the design and project, and an opportunity to make beneficial changes before starting to work at the construction site. The alternative ways of creating these models would be explained in modeling procedure and information exchange and collaboration headings (Section 3.4.4).

It is important to note that each design change, which is done during the construction phase, must be updated in the building information model (Senate Properties, 2012). Reporting procedure must be correspondingly tight between construction site and BIM leader, in order to avoid the errors and omissions due to miscommunication. 


\subsection{Infrastructure}

\subsubsection{Organizational Roles and Responsibilities}

Since BIM implementation implies a new process, the roles of the participants also change. Developing a "BIM Team” is suggested in most of the BIM implementation guidelines and standards. The roles and responsibilities of each member should be clearly defined. It is important to evaluate the starting capabilities of the BIM team, and to develop a plan either to train the team or to recruit new members. Definition of BIM Team and the roles within Team are given in this section. The roles may vary depending on the size of the company and/or unique requirements of the project. There are many organizational roles defined in the literature. A comprehensive overview of these roles is given by Barison and Santos (2010). The most common roles (BIM Leader, technical leader, and modeling staff) are explained below.

\subsubsection{BIM Team}

BIM Team involves several individuals who cooperate to accomplish project goals throughout implementation. The Team might either be formed from the existing employees of the organization by training them for BIM implementation or be outsourced (Epstein, 2012). In both cases, it is important to describe the roles of these individuals. There are essential roles defined in the existing BIM implementation plans such as BIM manager/leader/champion, technical leaders/coordinators, modeling staff (AEC UK Initiative, 2012; Computer Integrated Construction Research Group, 2011, 2012; MIT Department of Facilities, 2012; U.S. Department of Veterans Affairs, 2010). Regardless of project requirements or the size of company, it is important to note that defining new roles to implement BIM requires more than adding new software names to the job descriptions (Joseph, 2011). Hiring authority within the company should be aware that BIM implementation leads to a more collaborative working environment and that the participants have to have a better understanding of construction processes as well as the vision of the company. 
Epstein (2012) suggests that since BIM process covers the life of a project, the participants, and their roles within the BIM Team change from phase to phase such as design, construction, occupancy and demolition. Since this study focuses on the predesign, design and construction phases, only these will be discussed. According to Epstein (2012), the owner has a leading role in the planning phase team, and architects and their consultants give the owner assistance in decision-making. Figure 3.1 shows the relationships among participants of the planning phase team.

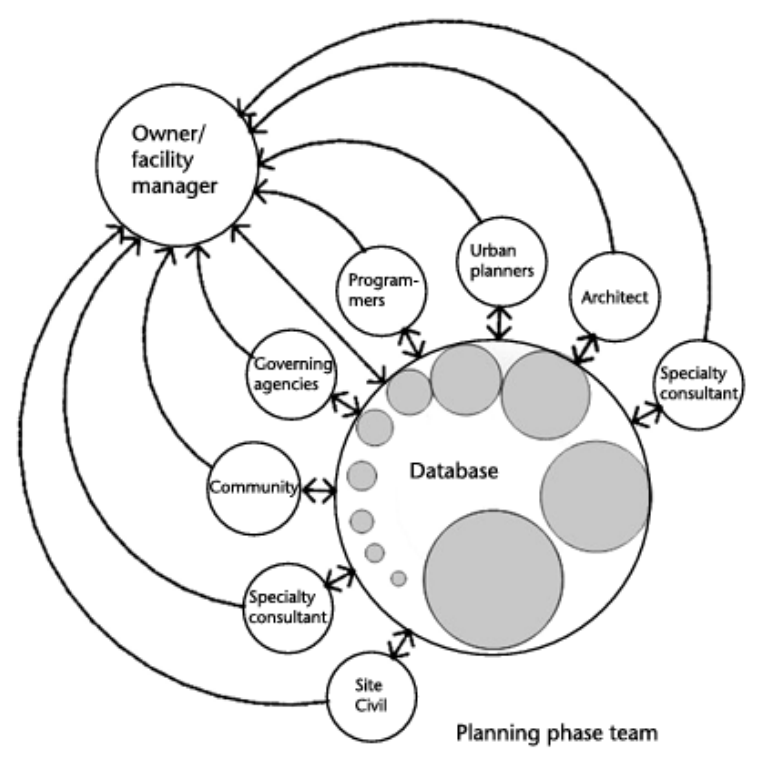

Figure 3.1. The Planning Phase Team (Source: Epstein 2012)

During design phase, the BIM Team is led by the architect (Epstein, 2012). She/he works as a coordinator between the owner and the consultant engineers and controls the process and checks whether the requirements of the owner is met. This relationship among stakeholders would provide a flexible environment to fix possible problems in early phases of the project due to the fast feedback opportunity from different disciplines. A generic summary of relationship among stakeholders in design phase is shown in Figure 3.2 (Epstein, 2012). 


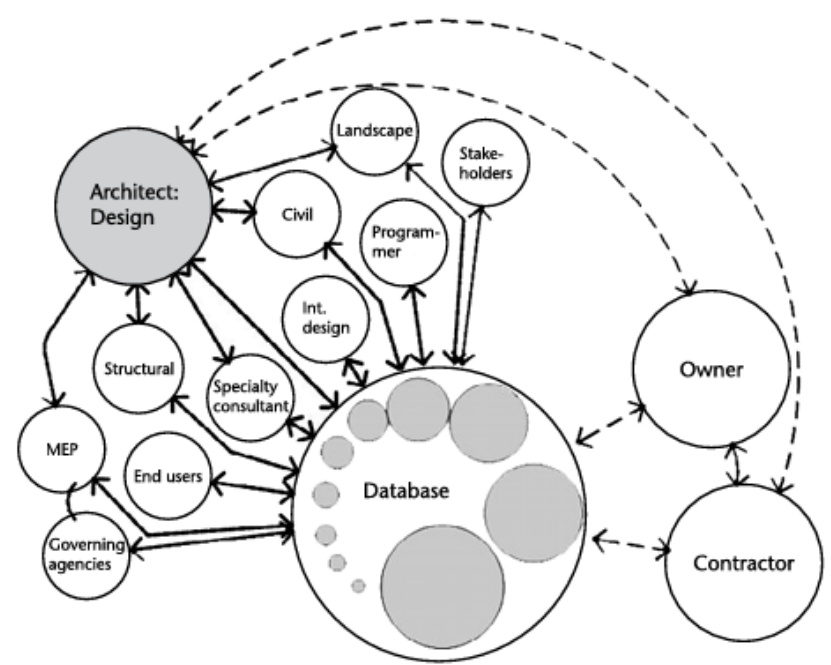

Figure 3.2. The Design Phase Team (Source: Epstein 2012)

The construction phase team that Epstein (2012) suggests consists of architect(s), constructors, fabricators (if necessary), and owner. Ideally "symbiotic relationship" (Epstein, 2012) among stakeholders would facilitate the BIM process, and help the BIM team to take more healthy decisions. Figure 3.3 shows the relationship of stakeholders in construction phase.

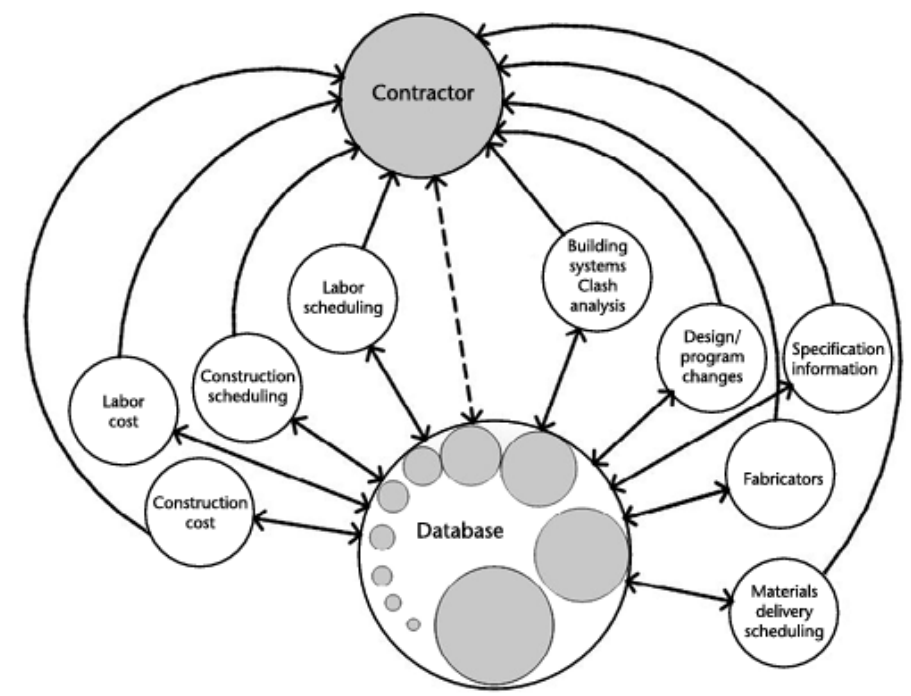

Figure 3.3. The Construction Phase Team (Source: Epstein 2012) 
The term "database" in the diagrams refers to the information sharing and collaboration environment in BIM process. Further information will be given in the “Information Exchange and Collaboration Procedure” (Section 3.4.4).

\subsubsection{BIM Leader}

BIM leader is one of the positions that is frequently suggested in BIM implementation plans, although various titles are used by different sources such as "BIM Coordinator” (Senate Properties, 2012; The Centre for Contsruction IT, 2013), “BIM Champion” (Computer Integrated Construction Research Group, 2012), and “BIM Manager” (AEC UK Initiative, 2012; U.S. Department of Veterans Affairs, 2010). BIM leader is a project manager who has sufficient BIM knowledge and experience in BIM .as well as in project management (Senate Properties, 2012). The level of this knowledge and experience may vary according to project complexity.

BIM leader is responsible for developing the BIM implementation plan for the project, defining project uses based on project requirements (Senate Properties, 2012) coordinating modellers, design consultants, and sub-contractors(Construction Industry Council, 2015), checking the accuracy and quality of the model (Epstein, 2012), using models for coordination, constructability, cost studies, etc. (The Centre for Contsruction IT, 2013) reporting the status of BIM, measures taken, dealing with possible problems that might be faced (Senate Properties, 2012). BIM leader is also the major contact person and The Veterans Affairs BIM Guide charge BIM leader with being responsible for keeping in touch with official issues (U.S. Department of Veterans Affairs, 2010).

Additional to developing BIM implementation plan, BIM leader must be capable of understanding the modeling process. As Jernigan (2007, p. 80) states there is a need for someone who is responsible for seeing the big picture, realizing inconsistencies even in the modeling process and managing them correctly.

\subsubsection{Technical Leaders}

BIM implementation process requires professionals from various disciplines to work together. The need for reliable coordination increases the importance of technical 
leaders. Technical leaders are responsible for coordinating their teams in terms of meeting project requirements and cooperating with other disciplines (AEC UK Initiative, 2012; Senate Properties, 2012; U.S. Department of Veterans Affairs, 2010), and charting BIM training plan for modeling staff (AEC UK Initiative, 2012; U.S. Department of Veterans Affairs, 2010), and quality assurance of building information modeling (Senate Properties, 2012). Technical leaders report to BIM leader.

\subsubsection{Modeling Staff}

Modeling staff is responsible for building the information model of the project. They report to their technical leaders. They are not necessarily already skilled employees for BIM modeling (AEC UK Initiative, 2012). For the companies that are implementing BIM process for the first time, required number of current employees may be chosen, and trained for BIM processes. This training process might be solved by either external or internal sources, like employing technical experts or hiring them for a short period of time(Epstein, 2012). It is beneficial for the project, if those chosen employees are open to innovations, otherwise there might be a resistance to change due to the strength in continuity and stability (Reddy, 2011). Training the employees does not mean that they just learn new software, but they need to understand the process of implementing a project differs from the previous 2D-based project implementation. In this way, they can adapt and even contribute to the process.

There may be other positions in the Team depending on the Team and project size. Kensek (2014) suggests that annotators and detailers could be added to the Team if necessary.

\subsubsection{Training Plan}

Training the employees for BIM implementation process requires a plan. First, current employees must be evaluated on what their capabilities are, and what level it is aimed for them to be achieved (Autodesk Inc., 2010a). This can be done by technical leaders. The content of the training plan has to be identified according to target capabilities. Then, the number of employees, who will be trained, should be determined, 
and the training authorities for this process should be chosen, and the appropriate training schedule should be set for the project (Epstein, 2012).

Olatunji (2011) suggests to create 2-step training program: (1) start-up training prior to implementation to prepare the Team for implementation, (2) in-line training which includes continuous training to keep the knowledge of the Team up-to-date in the fast pace era of information. He adds that training program should clearly structure the context and content to be taught. The resources to be used and the method to follow for training should be defined. Additionally, duration of the program has to be set relation to the implementation schedule of the company.

Commercial training services may be one option. This could lead to faster results in adoption of the software and staff could get help from the instructors while designing the modeling and information exchange procedures during the courses. However, this might be an expensive solution for small size companies that do not have adequate financial resources. In these cases can use books, online training documentation which are provided by BIM software developers such as Autodesk, Graphisoft, etc., online education websites which provides online resources for reasonable prices, and blogs on BIM can be used (Kensek, 2014). There are also several user groups/forums where BIM users share experiences. Once the company gains experience, internal education resources could be prepared for new members of the BIM Team.

Training process cannot change the project implementation of the company immediately, because BIM implementation requires more than software training. Once the Team members have been trained on specific software, processes to accomplish BIM Uses must be designed. This could take time. Therefore instead of changing the whole operation to BIM, implementing BIM in pilot projects could "provide time to learn the new processes and tailor to the needs of the firm” (Epstein, 2012).

Epstein (2012) remarks that only maintaining a process that is carefully designed leads to high quality of work; the employees should develop a process first, and then develop the speed. Otherwise, illusion of fast adaptation to BIM process might jeopardize future opportunities, because it could create a resistance.

Training should not be limited to the beginning of transition to BIM. The technological developments are constant in AEC industry. So seminars/webinars not only in the expertise areas, but also cross-disciplinary areas could be beneficial to keep up with the latest state of the practice (Kensek, 2014). This way companies could revise their 
processes, BIM Uses and services they provide, and increase their level of competitive power.

\subsubsection{Technological Infrastructure}

BIM requires an IT environment made up of software, hardware, system configuration and networks that will support all of the targeted BIM Uses. There may be dozens of unique combinations of technological infrastructure that a company may choose from commercially available products. To choose the optimum solution possible for a company, in-depth analysis must be done to determine which software can perform the required BIM Uses. Interoperability issues between selected software applications and other parties, information exchange options, server setup, network access, required budget for software licenses, hardware and time for adaptation, etc. should all be considered (Autodesk Inc., 2010a; Computer Integrated Construction Research Group, 2011; Eastman et al., 2011). During the BIM implementation, technological infrastructure updates must be analyzed very thoroughly. A testing phase has to be carried out to have all parties mutually agree on changes (Senate Properties, 2012).

In AEC industry there is a tendency to purchase upfront software licenses, and then spend less on training. Training, consulting and integration expenses of BIM implementation, however, are typically five to ten times that is spent on software licenses (Reddy, 2011). Therefore it is important to define desired BIM Uses, required personnel and training plan, before investing on any technological infrastructure to avoid inefficient outcomes during the adaptation process. These decisions would help clarify the number of software licenses to purchase, the time required to train the number of employees, whether to outsource some of the work to be done and so on.

For construction companies that do not plan to process any building information during construction can take advantage of free viewer applications that most 3D modeling software provide (The Associated General Contractors of America, 2005). This way they can still benefit from 3D information from designers without an investment, however, this would limit dramatically the possible outcomes of the models.

Software investments are not the only costs for an appropriate BIM infrastructure. Purchasing of hardware to enable an effective work environment should also be considered. It is recommended to invest in the fastest hardware that the company can 
afford (Kensek, 2014). Teams will need to work on files that include large amounts of information. Delays in processing the information or crashes on the system could cost much more than hardware investment. Moreover, shared workspaces and central databases should be configured for information exchange processes (The Centre for Construction IT, 2013). The details of these could be identified according to the information exchange protocol that the company will define.

\subsection{Contracts}

Delivery method selected for a project can leverage BIM usage depending on how BIM is implemented.

One of the most common delivery methods, design-bid-build method, may seem like it is not suitable for BIM implementation due to the segmented structure of the project execution. But BIM can decrease the workload and the associated costs of requests for information during the bidding phase, if all parties are willing to implement and benefit from BIM. Otherwise the only party who will be using BIM could be the design team without the realization of the benefits because of other parties. (Kensek, 2014)

Due to the amount of information created and utilized in the process, BIM implementation may nourish if a high-level of cooperation is obtained. Integrated Project Delivery (IPD) and Design-Build methods are suggested as convenient types of contracts for projects in which BIM is implemented (Computer Integrated Construction Research Group, 2011). When it is not possible to select one of these methods, having contracts with the stakeholders showing that they are capable and willing to participate in the project by taking on the required responsibilities for BIM implementation has significant importance. Standard contracts companies used in previous projects may need to be updated for BIM projects. Contracts should cover BIM implementation plan with roles and responsibilities for BIM Team and stakeholders, BIM processes, tools that would be used with agreed versioning information, BIM schedule and deliverables (Kensek, 2014), information exchange procedures, model management and intellectual property rights (IPR) (Computer Integrated Construction Research Group, 2011).

Data ownership is a contractual subject that is stated in the literature as a potential risk factor unless it is determined precisely (Azhar, 2011). Definitions with a distinction between authorship and ownership depending on the information transmission among 
parties could help avoid controversies. AIA suggests in the document E203-2013 that copyright of the digital data belongs to the transmitting party, however once the data is transmitted, ownership of the data does not exist (AIA, 2013a). This definition could avoid duplication or co-ordination errors throughout the project implementation (Construction Industry Council, 2015)

The transmission of the data is inevitable during project implementation. Therefore the usage of the data is another important issue to be addressed in the contracts. It is suggested that receiving party can process the data only according to the authorized uses that the project includes (AIA, 2013a), and the sharing procedure of the model has to be identified if $3^{\text {rd }}$ parties such as subcontractors need to work on the model (Senate Properties, 2012). It is also suggested to create a table for digital data protocol (Table 3.2) to identify which data would be transmitted to be used in which authorized use throughout the project implementation (AIA, 2013b).

Table 3.2. Digital Data Protocol Table (Source: The American Institute of Architects)

\begin{tabular}{|c|l|l|l|l|}
\hline Digital Data & $\begin{array}{c}\text { Digital Data } \\
\text { Format }\end{array}$ & $\begin{array}{c}\text { Transmission } \\
\text { Method }\end{array}$ & $\begin{array}{c}\text { Authorized } \\
\text { Uses }\end{array}$ & Notes \\
\hline Project Agreements and Modifications & & & & \\
\hline Project Communications & & & & \\
\hline General Communications & & & & \\
\hline Meeting Notices & & & & \\
\hline Agendas & & & & \\
\hline Minutes & & & & \\
\hline Requests for Information & & & & \\
\hline Architect's Supplemental Instructions & & & & \\
\hline Architect's Preconstruction Submittals & & & & \\
\hline Schematic Design Documents & & & & \\
\hline Design Development Documents & & & & \\
\hline Construction Documents & & & & \\
\hline Contract Documents & & & & \\
\hline Architect's Drawings & & & & \\
\hline
\end{tabular}

(cont. on next page) 
Table 3.2. (Cont.)

\begin{tabular}{|c|l|l|l|l|}
\hline Digital Data & $\begin{array}{c}\text { Digital Data } \\
\text { Format }\end{array}$ & $\begin{array}{c}\text { Transmission } \\
\text { Method }\end{array}$ & $\begin{array}{c}\text { Authorized } \\
\text { Uses }\end{array}$ & Notes \\
\hline Architect's Specifications & & & & \\
\hline Contractor's Submittals & & & & \\
\hline Product Data & & & & \\
\hline Submitted by Contractor & & & & \\
\hline Returned by Architect & & & & \\
\hline Shop Drawings & & & & \\
\hline Submitted by Contractor & & & & \\
\hline Returned by Architect & & & & \\
\hline Subcontractor's Submittals & & & & \\
\hline Product Data & & & & \\
\hline Submitted by Subcontractor & & & & \\
\hline Returned by Contractor & & & & \\
\hline Shop Drawings & & & & \\
\hline Submitted by Subcontractor & & & & \\
\hline Returned by Contractor & & & & \\
\hline Modifications & & & & \\
\hline Requests for Proposal & & & & \\
\hline Architect's Order for a Minor Change & & & & \\
\hline Proposals & & & & \\
\hline Construction Change Directives & & & & \\
\hline Change Orders & & & & \\
\hline Project Payment Documents & & & \\
\hline Notices and Claims & & & \\
\hline Closeout Documents & & & \\
\hline Record Documents & & & \\
\hline Operations and Maintenance Manual & & & \\
\hline
\end{tabular}

Data security is another subject that is suggested to be stated in the contracts. Data loss/damages or misuse by inside or outside sources should be prevented by Teams using user access protocols (U.S. Department of Veterans Affairs, 2010). 


\subsection{Implementation Processes}

\subsubsection{Project Information}

Project information is referred in most of the guidelines and standards as a first step of BIM implementation. Basic information such as project name, address, description, etc. should be included the project information part as well as more detailed information like project phasing, approximate area information, key stakeholders and their contact information, key BIM personnel, etc. (AEC UK Initiative, 2012). It can be presented in a table which could be used as an identity tag of the project after completion. A sample project information table is given in Table 3.3.

Table 3.3. Sample of Project Information Table

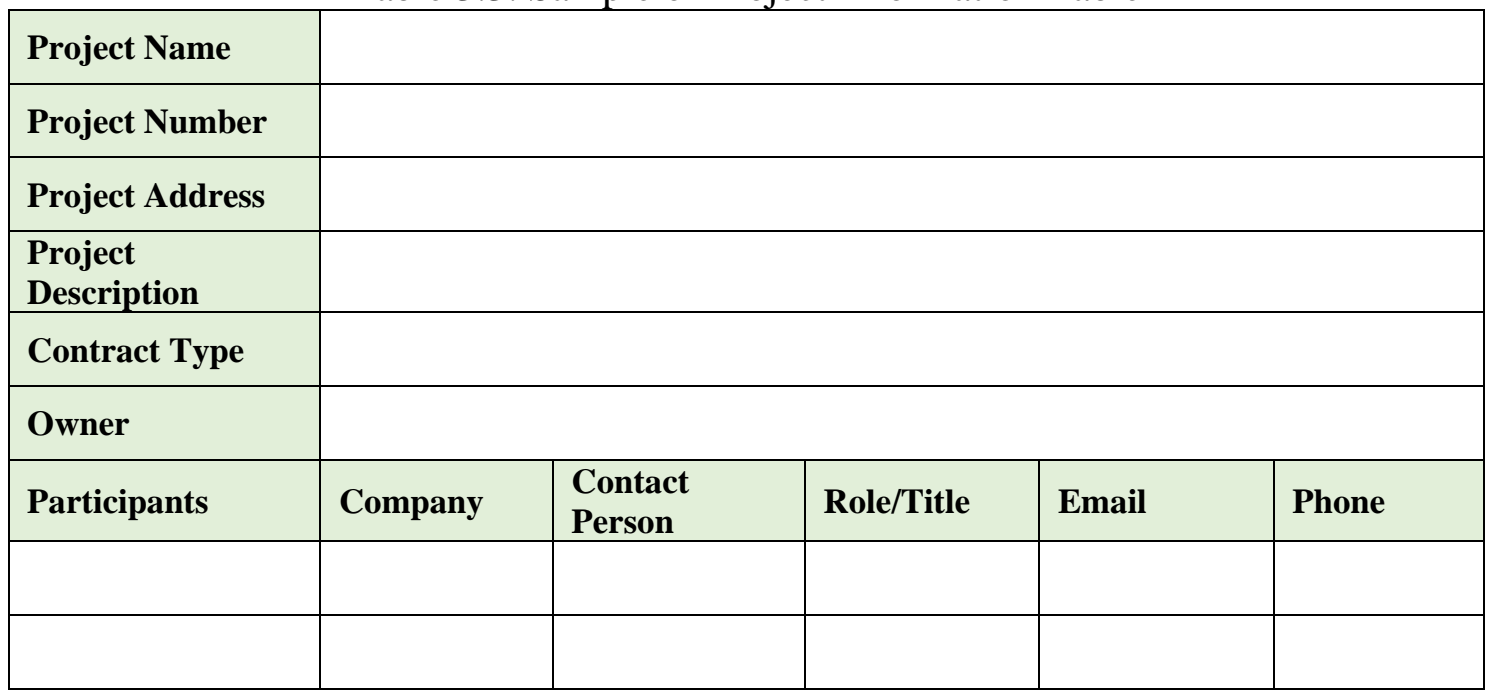

\subsubsection{Project Schedule and Milestones}

Project schedule lists activities of the project systematically, identifying milestones. Components of project schedule in BIM implementation process may vary due to the preferences on developing it. Some may choose to develop the schedule for each phase of the project (Senate Properties, 2012), whereas some may choose only to indicate the estimated start and finish dates of the phases (Autodesk Inc., 2010a). 


\subsubsection{BIM Project Execution Process}

Project execution processes are suggested to be organized in 2-level process maps (Computer Integrated Construction Research Group, 2011). First level focuses on the big picture of project implementation where main steps, stakeholders and information exchange topics are identified. Second level identifies each step to take to accomplish each BIM Use. Details of these two process maps are given below.

\subsubsection{BIM Overview Map}

BIM Overview Map graphically visualizes the BIM implementation process. To create a BIM Overview Map there are four things to consider (Computer Integrated Construction Research Group, 2011). First is to identify potential BIM Uses that can be beneficial for the project. If a BIM Use is needed to be performed at different phases of the project, it should be added to the map where needed. Second is to define the sequence of BIM Use that fits the project implementation. Third is to assign each BIM Uses to responsible parties. Responsible parties may consist of multiple teams/groups that have to work cooperatively during the process. Last is to define information exchanges. These may occur on an internal database or via file transfer. A sample BIM Overview Map of a laboratory building, which is designed and presented (Computer Integrated Construction Research Group, 2011) is given in Figure 3.4.

In Figure 3.4 the circles at the left and right sides of the diagram (middle part of the sheet, in the "BIM USES" section) refer to the start and end-points of the overall process. The rectangles, which are connected by arrows between start and end-points indicate design phase information on the top left corner, activity name in the middle, responsible party on the bottom left corner, and name of the detailed map related to this activity on the bottom right corner. Information exchange contents of each activity are shown at the bottom part of the table in the "Information Exchange" section. 


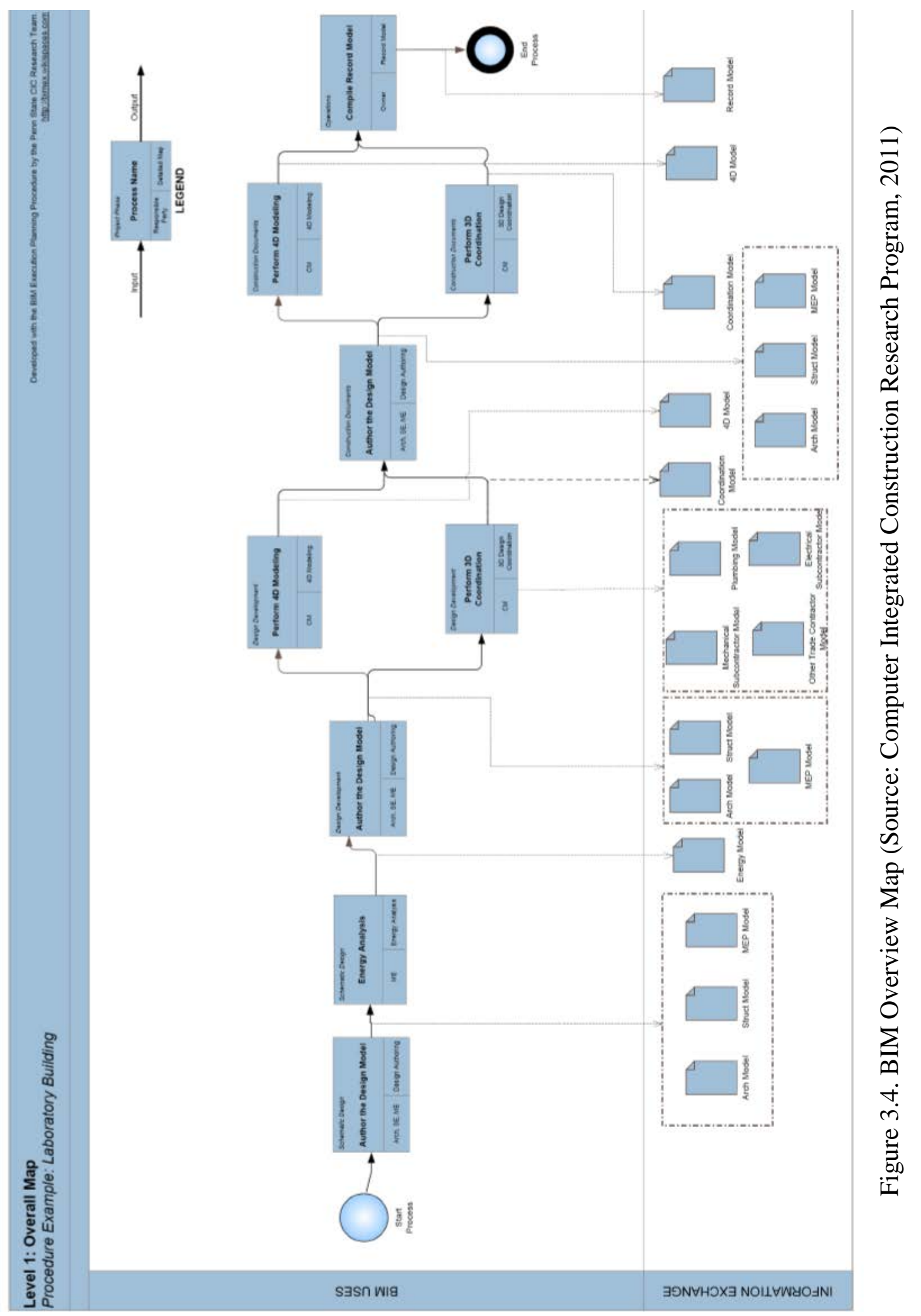




\subsubsection{Detailed Process Map}

BIM Overview Map draws a big picture for the BIM implementation process within the company, whereas Detailed Process Map defines specific steps to take for each BIM Use identified. Companies have unique processes and procedures, therefore it is recommended to customize process maps. An example can be seen in Figure 3.5 (Computer Integrated Construction Research Group, 2011).

These maps are designed to consist of three layers of information (Computer Integrated Construction Research Group, 2011). First layer contains 'Reference Information' that defines the internal and/or information channels required to execute that particular BIM Use. Second layer contains 'Process' information that defines the sequence of activities required to perform the BIM Use. The last layer shows 'Information Exchange' requirements among activities with respect to the direction of flow of information for that BIM Use.

Creating a detailed process map would help the company/team to determine a roadmap for BIM Use implementation. Five-step procedure to structure information while creating a detailed process map could be used as follows (Computer Integrated Construction Research Group, 2011). First step is to divide a BIM Use into individual processes noting their importance and order in the project implementation. Second is to define dependencies and connections between processes. Third is to add 'Reference Information' that defines what is the required to perform that activity, 'Information Exchange' and 'Responsible Party' information to each activity. Fourth is to specify decision points to verify whether the goal is met. Last is to review and refine the map and archive it for future projects. 


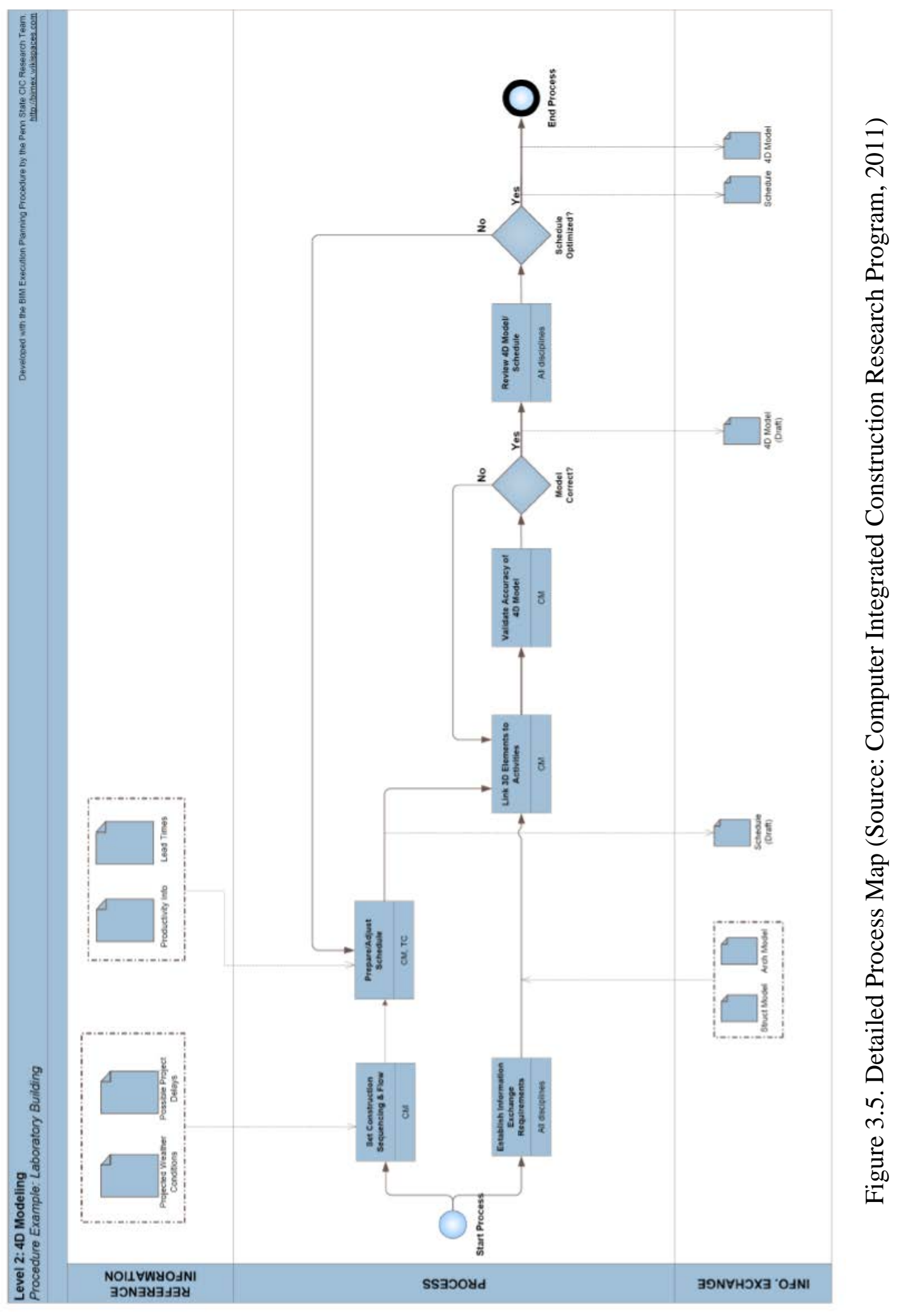




\subsubsection{Information Exchange and Collaboration Procedure}

Information exchange procedure is an important aspect of BIM implementation process. Collaboration is an essential part of BIM and since the collaboration procedure depends on information exchange, information exchange procedure must be studied carefully. It has multiple dimensions. Platform, data environment and formats along with human interactions have to be identified. Systematic approach that covers all these aspects should be designed prior to implementation to maximize the efficiency and minimize errors.

Collecting the data in a common platform is one of the essential aspects of the information exchange process. PAS 1192-2 (British Standards Institution, 2013) names this concept as "Common Data Environment (CDE)". CDE is an online source of information where graphical and non-geometric data associated with the building project is collected and managed by multi-disciplinary teams. It can use project servers, extranets, cloud-based servers, etc. depending on the project teams' preferences.

Strategies of working collaboratively on BIMs in CDE should also be considered. Two common ways are using single monolithic and federated domain models (Kensek, 2014).

Single model means different disciplines creating parallel models or copies of the same model. It is theoretically the ideal version of BIM which starts at the very beginning of the design process and continues to be developed till the end of construction process and used in facilities management. Gregory P. Luth, PhD, SE, (2012) conducted a study where he utilized a single model from design to construction with a very high level of detail. It is called "HiDef BIM". To implement BIM via a single model, integrated project delivery (IPD) process is required. It provides advantages during cost estimation, bidding and construction operation; however, there are several disadvantages and reasons, summarized by Kensek (2014), why it is difficult to be applied in today's construction practice:

- The division of roles in construction industry, for instance designers need to sign and seal their design which is not applicable in a single model where even subcontractors' detailing is included,

- Interoperability issues among participants. It may not be possible to find compatible software for design, fabrication and/or analytical purposes. 
- The extra cost to combine all types of information from multiple disciplines and participants in a single model file.

- Possible software and hardware deficiencies while working on large projects due to processing huge amounts of data.

- Coordination difficulties requiring extra time to plan and manage among multiple disciplines while adding information which may overlap.

Another way of working in cooperation with multiple teams is to create disciplinespecific models separately, and organize them to be accessible to use whenever needed. These models can be called “federated domain/discipline models” (Kensek, 2014), “container model” (AEC UK Initiative, 2012), or “ composite model” (Hardin, 2009). These models can be derived from one another, linked to one another, used as a basis for one another, absorbed into the other depending on the project's needs (Kensek, 2014). They are the assembly files for coordination and clash detection purposes (Construction Industry Council, 2015). Hardin (2009) expresses that these models provide safer implementation environment because they decrease the risks of mistaken interference like accidental editing, or deleting model elements between BIM Teams. The policies required for linking the files to derive composite models should be documented carefully (Kensek, 2014).

A BIM server or network where team members can access and work on the models simultaneously can be a way of collecting data and collaboration (Kensek, 2014). These servers can be used for both single and multi-models, but due to the disadvantages of single models, multi-models could be a better choice for BIM servers. FTP servers can be an easy-to-use, relatively old, but reliable option that may be used to share models among stakeholders. They prevent interferences by enabling to define rights for read and write, or read-only access to the directories (Cooperative Research Center for Construction Innovation, 2009).

In current construction projects, stakeholders could be spread around the world. Software vendors have been providing cloud-based collaboration platforms where stakeholders from multiple locations can access and share BIMs. The update information of files can also be tracked, reviews can be done, project files can be stored, etc. in these cloud-based platforms.

Data formats to be used in communication is another important aspect of the information exchange process. Proprietary formats and open standards are two options that could be chosen. Proprietary formats may provide a smoother data transfer for 
stakeholders, however open standards such as Industry Foundation Classes (IFC) are encouraged to be used frequently to increase the efficiency in information exchange and support a competitive environment where BIM can flourish (Kensek, 2014; NIBS, 2015; U.S. Department of Veterans Affairs, 2010).

Information handover requirements is another important aspect to consider for the information exchange process. Information is a broad term that could refer to the whole project content. To avoid contradictions during implementation, information should be divided into manageable compartments to accomplish BIM Uses. Authors who create the information and the users who would process them during implementation should be identified to show the authorization rights (Construction Industry Council, 2015). This would define the information exchange directions. The content of the information which includes uses, preferred form and format, metadata requirements and retention process (if required) is also important and need to be listed for each exchange (NIBS, 2015). When the information exchange direction, the inputs and outputs are defined, these requirements could be arranged in a table to visualize the process and to track the progress (Computer Integrated Construction Research Group, 2011). PAS 1192-2 (British Standards Institution, 2013) which provides guidance for authoring and sharing information among stakeholders and PAS 1192-3 (British Standards Institution, 2014) which provides guidance for information management in operational phase of buildings can be used to develop information management strategy.

\subsubsection{Modeling Procedure}

Modeling is the backbone of the BIM implementation process. There are many core concepts related to modeling procedures which could be documented in implementation plan. Frequently referred ones in the existing guidelines and standards are explained below. However a company could elaborate these according to its services and deliverables if it feels the need.

Modeling procedure is basis for information exchange due to the creation of information. Team members from several disciplines work on the same project while each is given access to the required information as an author or a user. Agreed and tested versions of software and file formats are suggested to be defined to facilitate information exchange and avoid latter conflicts (Kensek, 2014). 
Classification system is a crucial aspect of modeling procedure to standardize the structure of information. There are several industry standards like Omni Class, MasterFormat, etc. that may be adopted or used as a basis to create a new one according to the company's services. These classification systems consist of hierarchical tables representing information such as building elements, spaces, construction entities, construction works, phases, products, etc. (NIBS, 2015).

Another crucial aspect of modeling procedure is to define a target level of development (LOD) for the project. LOD is a concept that was first identified in AIA E202-2008 Building Information Modeling Protocol and in its updated definition from AIA G202-2013 specifies "minimum content requirements and associated Authorized Uses for each Model Element at five progressively detailed levels of completeness”. In BIM resources LOD may be referred to as Level of Detail as well and both are interchangeable. However, it is important to note that Level of Detail refers to the level of information included in the components, whereas Level of Development refers to the degree to which components are to be developed (BIMForum, 2013). 5 LODs (LOD 100, LOD 200, LOD 300, LOD 400, LOD 500) are defined as conceptual, approximate geometry, precise geometry, fabrication and as-built information in building components respectively. However, due to the rapid changes in the use of BIM and the requirements of LOD for coordination during BIM implementation, AIA allowed a new study to be conducted by BIMForum in 2013 to update the definitions of LOD and to designate a new LOD named LOD 350 to provide accuracy of coordination among teams. The definitions of these updated 6 LODs is given in Table 3.4. LOD may vary depending on the project requirements. Owner and contractor should agree on this subject, before the implementation starts. (U.S. Department of Veterans Affairs, 2010). While determining the LOD for the project, it is better to keep in mind the BIM Goals and BIM Uses that are set for the project and to consider the possible uses of the model in later phases (Deutsch, 2011).

Table 3.4. LOD Descriptions (Source: BIMForum, 2013)

\begin{tabular}{|l|l|}
\hline LOD & Definition \\
\hline $\mathbf{1 0 0}$ & $\begin{array}{l}\text { The Model Element may be graphically represented in the Model with a symbol or other } \\
\text { generic representation, but does not satisfy the requirements for LOD 200. Information } \\
\text { related to the Model Element (i.e. cost per square foot, tonnage of HVAC, etc.) can be } \\
\text { derived from other Model Elements. }\end{array}$ \\
\hline
\end{tabular}

(cont. on next page) 
Table 3.4. (Cont.)

\begin{tabular}{|l|l|} 
LOD & Definition \\
\hline $\mathbf{2 0 0}$ & $\begin{array}{l}\text { The Model Element is graphically represented within the Model as a generic system, } \\
\text { object, or assembly with approximate quantities, size, shape, location, and orientation. } \\
\text { Non-graphic information may also be attached to the Model Element. }\end{array}$ \\
\hline $\mathbf{3 0 0}$ & $\begin{array}{l}\text { The Model Element is graphically represented within the Model as a specific system, } \\
\text { object or assembly in terms of quantity, size, shape, location, and orientation. Non- } \\
\text { graphic information may also be attached to the Model Element. }\end{array}$ \\
\hline $\mathbf{3 5 0}$ & $\begin{array}{l}\text { The Model Element is graphically represented within the Model as a specific system, } \\
\text { object, or assembly in terms of quantity, size, shape, orientation, and interfaces with other } \\
\text { building systems. Non-graphic information may also be attached to the Model Element. }\end{array}$ \\
\hline $\mathbf{4 0 0}$ & $\begin{array}{l}\text { The Model Element is graphically represented within the Model as a specific system, } \\
\text { object or assembly in terms of size, shape, location, quantity, and orientation with } \\
\text { detailing, fabrication, assembly, and installation information. Non-graphic information } \\
\text { may also be attached to the Model Element. }\end{array}$ \\
\hline $\mathbf{5 0 0}$ & $\begin{array}{l}\text { The Model Element is a field verified representation in terms of size, shape, location, } \\
\text { quantity, and orientation. Non-graphic information may also be attached to the Model } \\
\text { Elements. }\end{array}$ \\
\hline
\end{tabular}

It is suggested to establish a "Model Element Table" (also called "LOD Matrix" by Hardin and McCool (2015)) to identify the LOD of different phases of the project and the responsible party who authors the model in each phase (AIA, 2008). An example of such a table is given in Figure 3.6. This table would be shared with each party to acknowledge everyone's responsibilities and more importantly the LOD of the models they could receive from different parties. Hardin and McCool (2015) notes the risks of unidentified LOD during implementation. There may be several ways to generate contract documents for permits and/or bidding, and it is risky to assume the LOD of the model which the drawings are generated from. Teams could add annotations to specify the details in low LODs. If the receiving party fails to notice these annotations, unnecessary field changes may arise. 


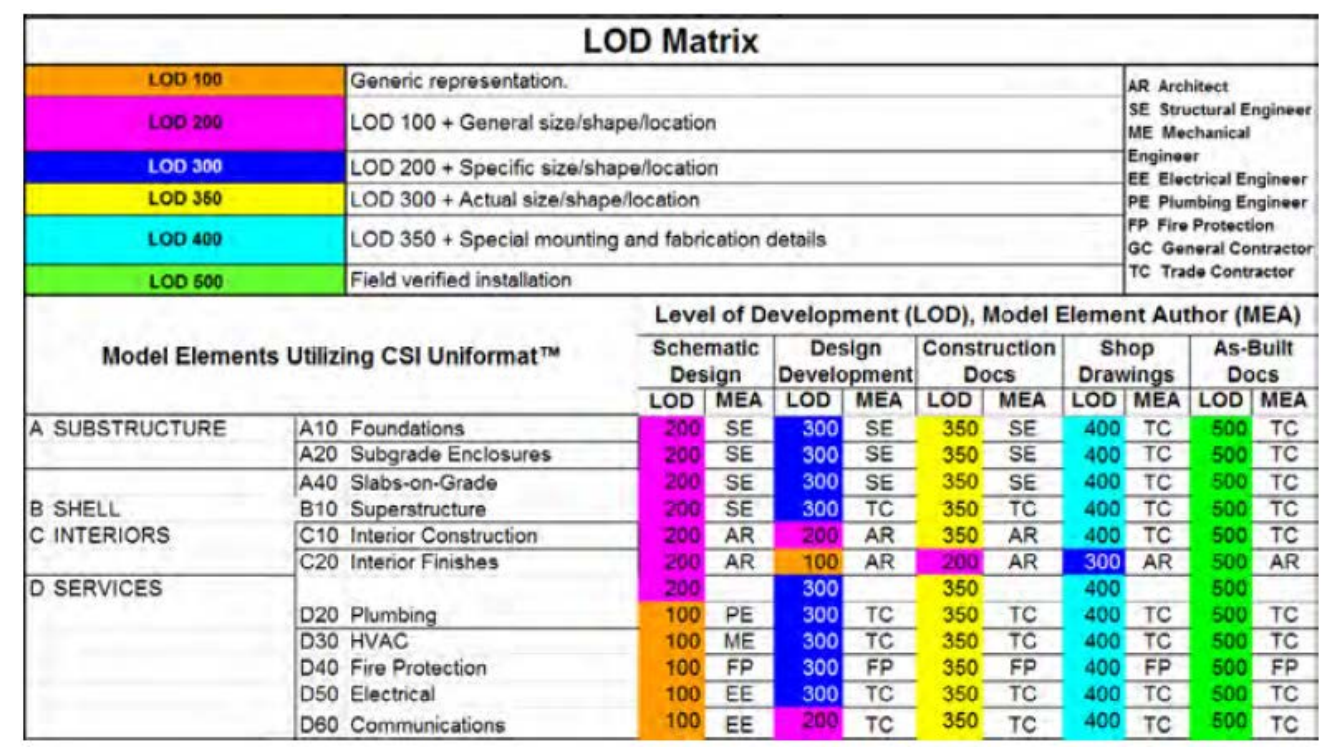

Figure 3.6. Sample of LOD Matrix (Source: Hardin and McCool, 2015)

During early phases of the modeling process, low LODs may cause unintentional conflicts. It is recommended to set proper search sets and/or hide or group particular components that are left to be solved in later phases to save time (The BIM Guide Workgroup, 2013).

Naming conventions are another important aspect affecting cooperation during implementation. The structure for naming is suggested to have 6 fields of information: project name, originator, discipline/system, zone, level, description (Canada BIM Council, 2014). Former three fields are recommended to be included in every project, but latter three are optional fields. Length of the file name may cause problems in accessing files/folders due to the character limit of path definitions. Therefore instead of naming the files with project information in long form, numbers and characters could be used. For instance, architectural project of a multi-storey building could be named as 285674-EXMARCH-R2-18-SUITS.rvt This example file name describes that the file consists of the architectural project (ARCH) model for suits in the 18th floor (18) of the second residential block (R2) of the project named “Hypothetical Residence” (285674) designed by “Example Architecture” company (EXM). Company could create a coding system for each field depending on the stakeholders and project's scope.

Spatial coordination issues also play a role in effective coordination. Measurement system, units, coordination base point and geo-referencing are some of the subjects that should be consistent across the modeling procedure (AEC UK Initiative, 
2015). Model files that include geo-reference information showing the accurate location of the project could use relative coordinates, after coordination among Teams is set (U.S. Department of Veterans Affairs, 2010).

Large file size may interrupt workflow because of hardware deficiencies. It is recommended not to model more than one building in a single file (Construction Industry Council, 2015) and to break the building into number of parts/volumes when the file size is difficult to manage (British Standards Institution, 2013). There may be several ways for dividing the model to provide a productive modeling environment. Some companies may prefer to separate their models into smaller parts, for instance, core and shell, floors, etc. An example for model division per discipline is given in Figure 3.7. An alternative way of decreasing file size to cope with hardware issues may be to avoid adding building data to the model and instead, to include the necessary data in spreadsheets linked to the objects. Another method is to use data-rich 2D objects instead of 3D components where possible (Kensek, 2014). Whichever method is adopted, each stakeholder should follow the same method throughout the modeling procedure (Construction Industry Council, 2015)

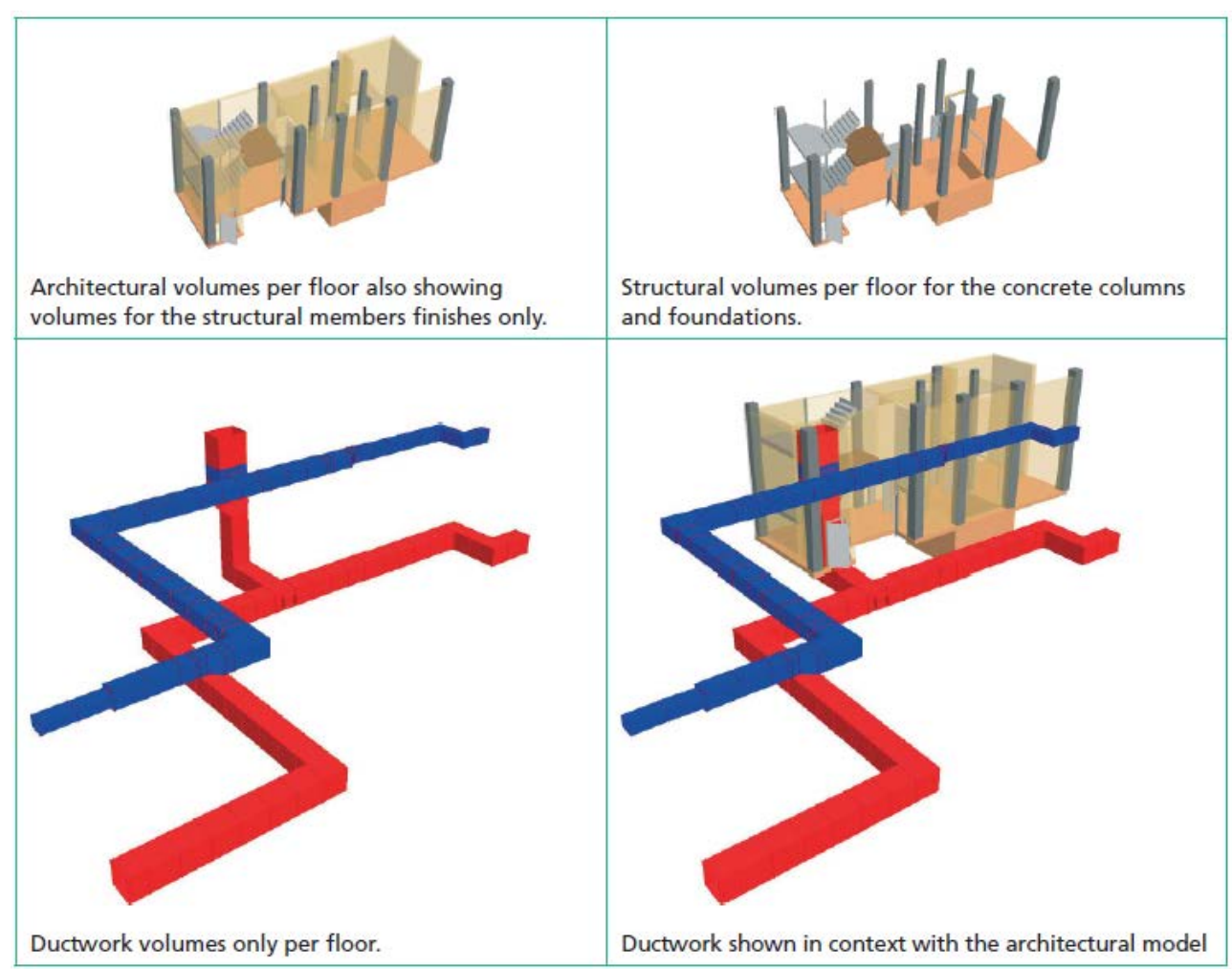

Figure 3.7. Division of Model Example (Source: British Standards Institution, 2013) 
Modeling processes should be identified according to the BIM Uses, and each responsible party should be assigned to appropriate tasks to achieve these BIM Uses (AIA, 2013a). Each party should develop and use the models according to the agreed protocols (LOD, measurement system, division of model, etc.) to facilitate implementation.

Graphic standards are important aspects in AEC industry because communication is mostly based on visual assets. To support communication, presentation styles for both soft copy and hard copy documents are suggested to be created that include layers, line types, line weights, text styles, hatch patterns, annotations, sheet layouts, title blocks, sheet naming, numbering and referencing conventions (Kensek, 2014).

\subsubsection{Communication and Meetings}

Developing an effective communication environment could foster the implementation process. To avoid misunderstandings and disruptions in communication, it is suggested to capture, record and store all electronic communication data including the internal messaging through the collaborative project management systems (Autodesk Inc., 2010a).

Modes of communication such as face to face meetings, video conferences, phone calls, and emails among stakeholders may vary due to the geographical limitations where teams are located, or the information that would be exchanged through communication. To accelerate the communication process, it is recommended to develop a communication sheet that includes not only contact person and the contact information but also software and version that is used by the contact with file exchange format information for sending BIM files (Hardin \& McCool, 2015). Example of such a communication sheet is given in Table 3.5 .

Table 3.5. Sample Communication Sheet (Based on a contact sheet example from Hardin \& McCool, 2015)

\begin{tabular}{|l|l|l|l|l|l|}
\hline $\begin{array}{l}\text { Company } \\
\text { Name }\end{array}$ & $\begin{array}{l}\text { Contact } \\
\text { Person }\end{array}$ & $\begin{array}{l}\text { Phone } \\
\text { Number }\end{array}$ & E-mail & Software/Version & $\begin{array}{l}\text { File } \\
\text { Formats }\end{array}$ \\
\hline $\begin{array}{l}\text { Jane Doe } \\
\text { Architects }\end{array}$ & Jane Doe & $\begin{array}{l}\text { Office: ... } \\
\text { Cell: ... }\end{array}$ & janedoe@jda & Revit 2015 & RVT, DWG, IFC \\
\hline & John Doe & $\begin{array}{l}\text { Office: ... } \\
\text { Cell: ... }\end{array}$ & johndoe@jda & $\begin{array}{l}\text { Navisworks } \\
\text { Manage 2015 }\end{array}$ & NWC \\
\hline
\end{tabular}


Meetings are essential part of communication. Meetings focused on BIM implementation should define the BIM Goals and BIM Uses according to the experiences of parties and individuals involved in the project (Computer Integrated Construction Research Group, 2011). Project schedule in terms of the required start and completion dates of tasks and release schedule of the models as well as the responsible parties (Autodesk Inc., 2010a; Senate Properties, 2012), and the frequency of the meetings with the attendees to review the process and facilitate the communication and coordination between parties (AEC UK Initiative, 2012). There may be task-specific meetings such as construction coordination meetings, clash detection meetings, etc.(U.S. Department of Veterans Affairs, 2010). The meetings may be either face-to-face or virtual (e.g. video conferencing). The minutes of meetings should be shared with each associated party afterwards and included in the communication data as well.

\subsubsection{Minimum BIM}

Utilizing BIM software and applications may not mean implementing BIM. To identify the distinction between benefiting from BIM technology and executing BIM, NBIMS-US (NIBS, 2015) defines a Minimum BIM standard. There are two alternative ways of identifying the maturity level of the implementation 1) via the Tabular BIM Capability Maturity Model Matrix, where users highlight their level of implementation to find out whether they fit into the minimum BIM definition of NBIMS-US; 2) via the Interactive Capability Maturity Model (I-CMM) where users can choose their interests from an interactive table format and calculate their maturity level of implementation. Minimum BIM requirements to evaluate via Tabular BIM Capability Maturity Model Matrix can be seen in Figure 3.8, and a sample view from I-CMM can be seen in Figure 3.9 .

Other than these two methods, there are commercially available tools to evaluate the BIM maturity level, e.g. BIMe, VDC Scorecard/bimSCORE, etc. whose intended users vary from AEC to O (operations) (NIBS, 2015). 


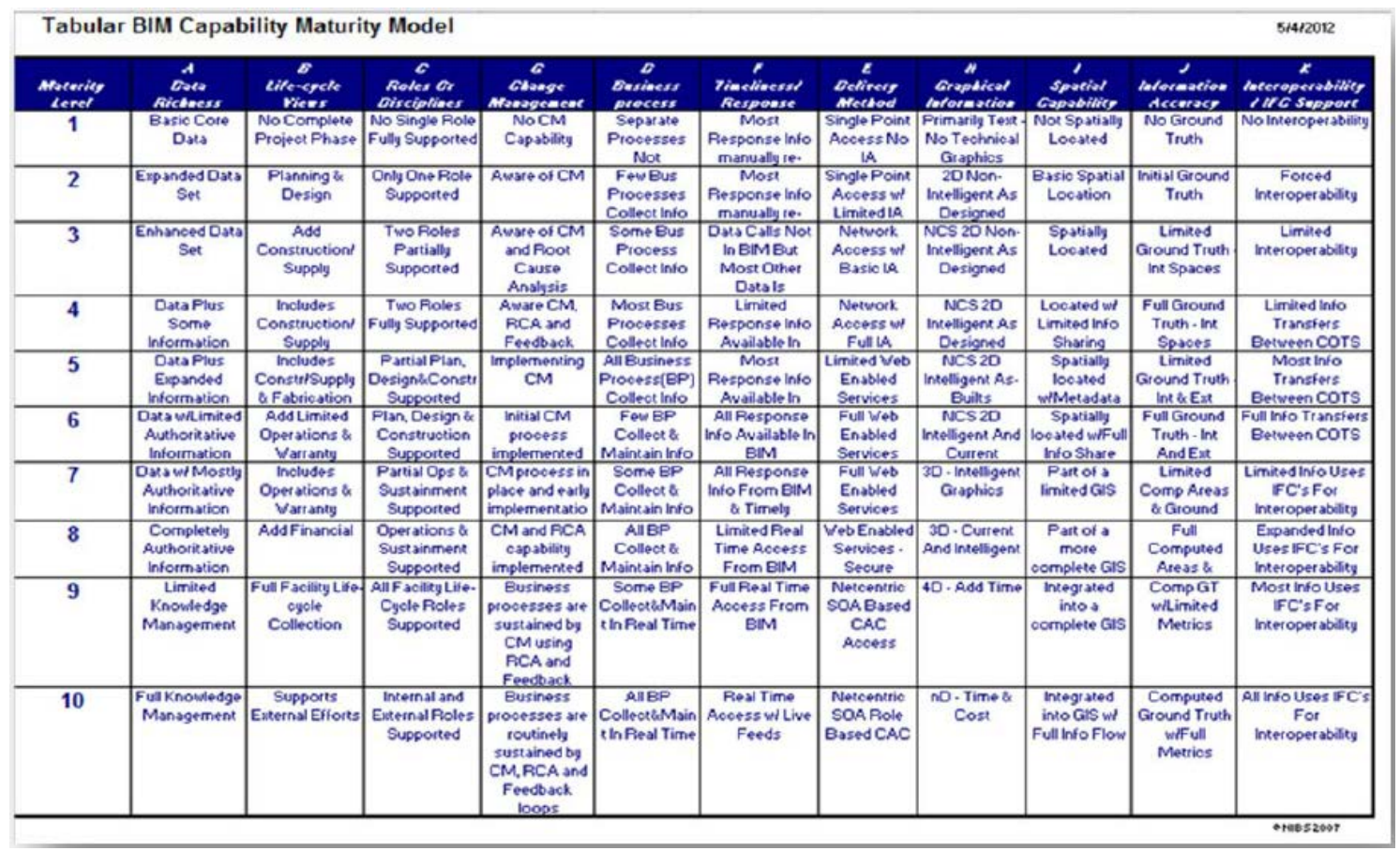

Figure 3.8. Minimum BIM Diagram for Tabular BIM Capability Maturity Model Matrix (Source: National Institute of Building Sciences, 2015)

\begin{tabular}{|c|c|c|c|c|}
\hline \multirow[t]{15}{*}{ ONIBS 2012} & \multicolumn{4}{|c|}{ The Interactive BIM Capability Maturity Model } \\
\hline & Area of Interest & Weighted Importance & Choose your perceived maturity level & Credit \\
\hline & Data Richness & $84 \%$ & Data Plus Expanded Information & 4.2 \\
\hline & Life-cycle Views & $84 \%$ & Add Construction/Supply & 2.5 \\
\hline & Change Management & $90 \%$ & Limited Awareness & 2.7 \\
\hline & Roles or Disciplines & $90 \%$ & Partial Plan, Design\&Constr Supported & 4.5 \\
\hline & Business Process & $91 \%$ & Some Bus Process Collect Info & 2.7 \\
\hline & Timeliness/Response & $91 \%$ & Data Calls Not In BIM But Most Other Data Is & 2.7 \\
\hline & Delivery Method & $92 \%$ & Limited Web Enabled Services & 4.6 \\
\hline & Graphicallnformation & $93 \%$ & $3 D \cdot$ Intelligent Graphics & 6.5 \\
\hline & Spatial Copability & $94 \%$ & Basic Spatial Location & 1.9 \\
\hline & Information Accuracy & $95 \%$ & Limited Ground Truth - Int Spaces & 2.9 \\
\hline & Interoperability/IFC Support & $96 \%$ & Most Info Transfers Between COTS & 4.8 \\
\hline & & \multirow{2}{*}{ 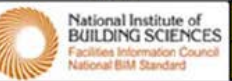 } & Credit Sum & 40.0 \\
\hline & & & Maturity Level & Minimum BIIM \\
\hline
\end{tabular}

Figure 3.9. Sample of I-CMM (Source: National Institute of Building Sciences, 2015)

\subsubsection{Deliverables}

Project deliverables have to be considered by project owner and team in advance of project implementation and may be specified in contract. Changing the requirements of the deliverables during the implementation might cause delays in project completion 
since model editing may take longer time than creating the model from scratch (Eastman et al., 2011).

Project deliverables may depend on the protocols or standards based on the country and region where the project is constructed. The project parties must check the legal obligations they have to fulfil. In Turkey, 2D drawing sets are still obligatory and must be presented to obtain building permits. However, project owners may additionally require designers and constructor to submit coordination files, model files, reference and support files, reports, renderings, analysis, etc. according to specific templates that they designed with predefined views, plot settings, etc. (Canada BIM Council, 2014; U.S. Department of Veterans Affairs, 2010).

\subsubsection{Project Validation}

BIM implementation does not change the review process in the traditional project delivery to confirm the design/project. Major conflicts and errors should be identified by quality assurance procedure (The Associated General Contractors of America, 2005). The assurance procedure should address the data to be handed over to the participants stated in BIM implementation plan, time period to verify the competency, and quality metrics for verification process (NIBS, 2015). The example for a validation checklist for ensuring that the project is ready for completion is defined by BIM Committee in United Kingdom (AEC UK Initiative, 2015)

- It is advised that all drawing sheets and extraneous views be removed from the BIM.

- If contractually pressured to deliver a model containing sheets then the sheet borders should be swapped for a transmittal border.

- Model file has been audited, purged and compressed.

- File format and naming conventions conform to project Data Exchange protocols,

- Data segregation conforms to the agreed project BIM methodology,

- Model files are up-to-date, containing all users’ local modifications,

- Model files are all independent,

- Any linked reference files have been removed and any other associated data required to load the model file is made available, 
- Model is correctly assembled through visual inspection,

- Any changes since the last issue are communicated to the project team.'

Project owners may require space and program validation, clash detection, accuracy of fabrication models, spatial coordination reports, and/or security data to verify the competency at the end of the project (U.S. Department of Veterans Affairs, 2010). If that is the case, data requirements should be agreed upon implementation. There are analysis applications available in the market that the stakeholders could benefit from in which they could check the model structure, space compliance, clash detections, version comparison, code compliances, or set their own rules to perform custom analysis (Cooperative Research Center for Construction Innovation, 2009).

\subsubsection{Archiving the Project}

Information models do not only serve during design and/or construction phases, but also facility management. Therefore archiving procedure should be designed considering the potential model usages throughout the life-cycle of the project. Kensek (2014) categorizes BIM data into two groups: 1) “process data streams (dynamic)” which are constantly shared and transformed, 2) “archival repositories (static)” which are archived data of completed projects. According to this categorization, two different types of archive procedures are possible.

Creation of BIMs is a process where multiple stakeholders collaborate in a defined period of time. During the implementation, dynamic data could be created iteratively. To avoid data loss, it is suggested that at milestones of the project, a complete version of models and all associated data can be archived to specific archive folders (AEC UK Initiative, 2012).

Archival repositories, on the other hand, could be stored in specific folders after project completion. The type of archival files could be considered in diverse context. For instance, inventory models that show the starting point of the project for renovation projects have an importance on archiving process, since they carry historical information of the project that may be used for checking (Senate Properties, 2012). As-built models are another important type of models that could be stored in archive folders to be used in facilities management phase. Even if the project is not updated according to the construction process, design models may be still beneficial for later uses. 
The format of the archive files are important aspects that need to be carefully dealt with by companies. Institutions or project owners may require submissions to be in PDF format which does not support carrying data-rich environment of BIMs. Companies should consider different options for archiving the BIMs they created to make them available when needed. The fast-paced developments in technology make it difficult to foresee the formats that would exist in the next decade. Even if the company continues to use the same software over many years, versioning problems may arise due to the compatibility issues related to the software itself. Therefore non-proprietary file formats may be a better option for archive files rather than the proprietary file format to enable maintaining the data up-to-date throughout the life-cycle of the building project (Cooperative Research Center for Construction Innovation, 2009). 


\section{CHAPTER 4}

\section{CASE STUDY: BIM IMPLEMENTATION FOR QUANTITY TAKEOFF AND COST ESTIMATION PURPOSES}

In this chapter, a case study on the BIM implementation process at a large construction company in Turkey (LC) with the BIM Uses of quantity takeoff (QTO) and cost estimation (CE) is presented. LC is a leading player in construction industry and is ranked in the Top 250 Global Contractors list of 2015 (ENR, 2015) operating in general building, heavy industry and infrastructure projects around the world. The name of the company and the case studies will be kept confidential throughout the study. As LC is a construction company that only participates in construction phase, BIM has been utilized to create 4D and 5D building models to effectively manage design and construction, and to handover the as-built BIMs to be utilized in operations and maintenance phase

Since BIM implementation is not mandated in Turkey by government or institutions, there is an absence of BIM standards and guidelines to follow. Each organization has to develop its own BIM implementation plan, as it is the case at LC. Organizational level BIM implementation processes have been designed to be utilized at LC's projects. In this chapter, this implementation plan and the unique challenges of the design and execution of this plan are identified and explained.

\subsection{Interviews}

A qualitative study was conducted to review the current practice at LC. The study was performed as half structured theme interviews. The focus of the study was on BIM implementation to perform QTO and CE in construction planning and management phase. The BIM Team with its six members were interviewed to collect information about the development of the BIM implementation plan, the current practice within the company and lessons learned throughout the implementation that improved efficiency. 
Interview questions were grouped under three subjects; 1) BIM execution procedure to perform QTO and CE, 2) adaptation to the new process within the BIM Team and the organization, 3) evaluation of current practice and development suggestions. The interview guide used in the interviews and a list of the interviewees are presented in Appendix B.

BIM implementation plan was developed to perform QTO and CE BIM Uses and tested in six projects: a school, a residential building, two office buildings and two commercial buildings.

\subsection{BIM Implementation Strategy at LC}

BIM implementation at LC was started as top-down strategy to adapt to the paradigm shift that is ahead of the AEC industry, although BIM implementation has not become a statutory obligation in Turkey yet. There was no established BIM protocols available. Therefore the company had to work on their own BIM implementation plan. The pilot BIM Uses of QTO and CE were chosen to determine the possible advantages to support construction planning and management.

Planning of the BIM implementation could be grouped in two categories as preimplementation and implementation phases in LC. Pre-implementation phase includes unwritten managerial decisions that made implementation possible. Decisions on BIM Uses, roles to be recruited, infrastructure components to be selected and purchased were made at pre-implementation phase planning. These topics are not included in the drafted BIM implementation plan, although they were discussed thoroughly by BIM Leader and associated managers in the company.

BIM implementation phase, on the other hand, includes a drafted plan to guide the BIM Team through implementation procedures. The contents of it includes the scope of the plan, definitions, naming conventions, project file structure, modeling procedures for performing QTO and CE, reporting procedure for QTO, and procedures for file sharing and archiving of the project. Each Team member is expected to follow this plan during project execution.

The development of the implementation plan took about four months to finalize. During this period of time, the technological infrastructure was upgraded due to necessary performance improvements, processes to accomplish BIM Uses were reviewed and 
improved, and the core BIM Team tested the processes in pilot projects. When the plan was approved to produce accurate outcomes, BIM implementation was expanded into other departments of LC.

Detailed information on pre-implementation and implementation phase planning in LC will be given in the following sections.

\subsubsection{Pre-implementation Phase:}

BIM implementation required initial preparations to provide the necessary comfortable working environment with its technical and organizational aspects. BIM Uses that determine the development of the implementation plan, human resources for implementing BIM in the projects, and technical components of the implementation were considered in this phase plan.

BIM implementation process was planned to perform accurate QTO and CE to support the construction phase. QTO and CE are vital for the execution of construction projects due to the existence of financial limitations. Although, precise and straightforward estimation approaches have potential to enable competitive advantage for firms, probable delays and mistakes might still lead to financial losses or failures. To avoid these risks, BIM-based QTO and CE techniques were chosen to replace the previous application of QTO and CE that depended on manual calculations based on 2D drawings.

The BIM Team within the company was chosen by BIM Leader who has handson experience of 10 years with BIM, project and construction management. BIM Leader was responsible for developing the implementation plan along with technical leaders and coordinating with the project stakeholders throughout the project. The Team consisted of technical leaders for architecture, structural and mechanical engineering who have 3 to 5 years of BIM experience, modelers and visualization specialists who have 1 to 5 years of 3D modeling experience. At the beginning, the number of Team members was intentionally kept low to practice and improve the BIM implementation plan and its processes before expanding the implementation to the whole company. The Team executed only pilot projects according the BIM implementation plan until the maturity of the implementation was approved. 
The BIM Uses were defined as QTO and CE, and the infrastructure needed to perform these was evaluated. Literature and current practices in construction industry was reviewed to determine the state-of-the-art technology and methods used. BIM authoring software was needed to create models. Various commercial BIM authoring exist. Allplan was selected to create architectural and structural models, and Revit MEP was selected for mechanical system models because of the economic advantage they provide to the company and the technical support services that their resellers offer. The current version of these software applications that is utilized at LC is Allplan 2016, and Revit 2015.

Three major BIM-based methods to perform QTO and CE is summarized by Eastman et al. (2011) as follows: “(1) export building object quantities to estimating software, (2) link the BIM tool directly to the estimating software, (3) use a BIM quantity takeoff tool”. Rather than utilizing BIM tools, the first method relies on the spreadsheets or external database when carrying out quantity takeoff. Second method deals with the incorporation of the model with the estimating tools in which it operates with the aim of associating the BIM data with additional construction activities, equipment, labor, and material. Third method is similar to the second method; it uses a BIM tool that can import BIM data for QTO process. There are several BIM tools available in the market such as Vico Software, DProfiler, Tocoman iLink that can be utilized to support these methods. The estimation tools mentioned above are commercially available. Besides financial costs of utilizing these tools, they also require developing an information exchange process between BIM authoring tool and QTO tool, as well as a training the Team members in performing QTO.

Several research on QTO and cost estimation processes have been carried out. Forgues et al. (2012) tested various BIM based cost estimation tools and workflows and identified the challenges of these e.g. necessary adjustments in cost databases, information exchange requirements addressing different phases of the project. Le et al. (2014) suggested an ontology-based work item inference system that extracts BIM data from IFCXML files to eliminate cost estimators' subjectivity. Ma et al. (2011) proposed frameworks that enable generating bill of quantities from IFC data; and developed a process map and algorithms for a semi-automatic and specification-compliant model that uses IFC data as a prototype of a BIM-based software application (Z. Ma, Wei, \& Zhang, 2013; Z. Ma, Zhang, Wu, Wei, \& Lou, 2010). Firat et al. (2010) explored the principles for performing model-based QTO. Elbeltagi et al. (2014) proposed a fragmented cost estimation model that can also monitor the construction process. Nadeem et al. (2015) 
suggest a new form of representation for bill of quantities that combine reports with 3D views of the associated geometries. Cheung et al. (2012) proposed a knowledge based tool to evaluate the design alternatives and incorporate cost estimation in early stages of the project to support decision making processes. Aram et al. (2014) proposed a knowledge-based QTO and cost estimation framework that infers object properties.

The BIM Leader evaluated the alternative methods to perform QTO and CE. Academic studies provide theoretical background for automated QTO and cost estimation processes. However, they could not provide a practical approach for businesses to adopt. Using an additional BIM QTO and/or CE tool was not perceived as a viable option due to the difficulty in finding/selecting the combination of software that suits the project requirements in different phases of the project (Forgues et al., 2012). Although pilot projects had been selected to implement BIM in the construction phase, the implementation phases might vary in future projects. It is evident that the implementation plan may need to be revised multiple times to suit the unique requirements of each project, so switching to a new BIM tool or re-designing the whole process according to the project phase could mean wasting time and energy for the BIM Team. Another concern over using a new BIM tool to perform QTO and CE was the lack of ability to apply QTO rules to the model (Zhiliang \& Zhenhua, 2012) and possibility of data losses during the importexport process while exchanging information between BIM tools (Monteiro \& Martins, 2013).

The objective of the Team was to establish platform-free procedures to automate BIM-based QTO and perform CE to preclude deficiencies of using additional BIM tools that are addressed in the literature. The company had already been using a construction planning and execution tool which offers CE solutions as well as an enterprise resource planning (ERP) system for its projects. Instead of purchasing and adopting a new software for QTO and CE, it was decided to develop a BIM implementation plan that enables integration between the BIM authoring software and the systems used in-house. The modeling and reporting procedure is designed to accomplish this objective. The details are explained in the next section. 


\subsubsection{Implementation Phase:}

Implementation phase plan is developed to guide employees who participate in this phase. Written documents are not the only sources of information for employees. For the employees who are new to the process in LC or have lack of experience in BIM implementation, training is provided by the technical leaders of each discipline to accelerate adoption. Use of software was included in the training program as well as the modeling procedures designed by the Team. As the implementation phase plan was tested on pilot projects with successful outcomes, existing employees of the company from different departments have been given a structured 5-day training to expand the BIM implementation within the company. Support for implementation and technical issues is still provided by the core Team.

The structure of the implementation phase plan gives very detailed explanations of generating files from scratch, 3D model creation according to the defined building structure, embedding cost information to the 3D building model from the cost database, obtaining QTO reports from building models, file sharing and archiving procedures.

\subsubsection{File Naming Conventions:}

File naming conventions have great importance on effective communication both during and after project implementation. LC has developed a comprehensive 8-field naming structure to be used in all of its projects in Turkey. The structure is explained in Tables 4.1 - 4.4.

Table 4.1. File Naming Convention in LC

\begin{tabular}{|c|c|c|c|c|c|c|c|c|c|c|c|c|c|c|c|c|c|c|c|c|c|}
\hline \multicolumn{3}{|c|}{ Field 1} & \multicolumn{4}{|c|}{ Field 2} & \multicolumn{3}{|c|}{ Field 3} & \multicolumn{2}{|c|}{ Field 4} & \multicolumn{2}{|c|}{ Field 5} & \multicolumn{2}{|c|}{ Field 6} & \multicolumn{4}{|c|}{ Field 7} & \multicolumn{2}{|c|}{ Field 8} \\
\hline \multicolumn{3}{|c|}{ 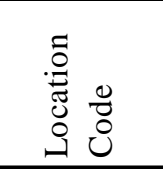 } & \multicolumn{4}{|c|}{ 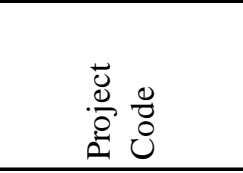 } & \multicolumn{3}{|c|}{ 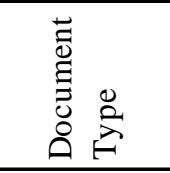 } & \multicolumn{2}{|c|}{ 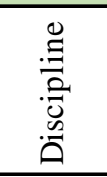 } & \multicolumn{2}{|c|}{ 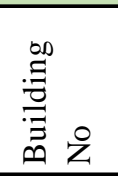 } & \multicolumn{2}{|c|}{ 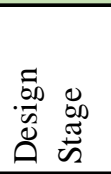 } & \multicolumn{4}{|c|}{$\begin{array}{l}\text { 岌 } \\
\text { 志 } \\
\text { 言 }\end{array}$} & \multicolumn{2}{|c|}{ 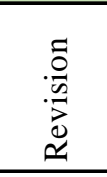 } \\
\hline \multicolumn{3}{|c|}{ 3-digit } & \multicolumn{4}{|c|}{ 4-digit } & \multicolumn{3}{|c|}{ 3-digit } & \multicolumn{2}{|c|}{ 2-digit } & \multicolumn{2}{|c|}{ 2-digit } & \multicolumn{2}{|c|}{ 2-digit } & \multicolumn{4}{|c|}{ 4-digit } & \multicolumn{2}{|c|}{ 2-digit } \\
\hline 1 & 2 & 3 & 4 & 5 & 6 & 7 & 8 & 9 & 10 & 11 & 12 & 13 & 14 & 15 & 16 & 17 & 18 & 19 & 20 & 21 & 22 \\
\hline
\end{tabular}


Field 1 - Location Code is abbreviated by using first three letters of the city where the project is executed, e.g. "IST" for Istanbul or "IZM" for Izmir.

Field 2 - Project code represents the code that is generated in SAP. If the file does not belong to any existing project, this field should be named as “ 0000 ”

Field 3 - Document Type indicates the format of the document.

Table 4.2. Document Type List

\begin{tabular}{|l|c|}
\hline Document Type & Abbreviation \\
\hline Drawing & DWG \\
\hline Letter & LET \\
\hline Correspondence & COR \\
\hline Issue & ISS \\
\hline Standard & STD \\
\hline Request for Information & RFI \\
\hline Request for Action & RFA \\
\hline
\end{tabular}

Field 4 - Discipline code represents the discipline that the model is created by.

Table 4.3. Discipline Abbreviations List

\begin{tabular}{|l|c|}
\hline Discipline & Abbreviation \\
\hline All Disciplines & AD \\
\hline Master Plan & MP \\
\hline Architectural & AR \\
\hline Civil & CI \\
\hline Electrical & EL \\
\hline General/Not Discipline Specific & GN \\
\hline Interior Design & ID \\
\hline Infrastructure & LS \\
\hline Land Survey & LA \\
\hline Landscaping & ME \\
\hline Mechanical & PL \\
\hline Plumbing & PQ \\
\hline Prequalification & \\
\hline
\end{tabular}


Field 5 - Building No indicates the individual buildings in the project such as A1. B2, etc. If there is only one building in the project, the code should be 00 .

Field 6 - Design Stage represents the relevant stage of the project. If the file is not issued for any of these stages, the field should be filled in as "AA".

Table 4.4. Design Stage Abbreviations List

\begin{tabular}{|l|c|}
\hline Design Stage & Abbreviation \\
\hline Concept Design & CD \\
\hline Preliminary Design & PD \\
\hline Detailed Design & DD \\
\hline Issued for Construction & FC \\
\hline Shop Drawings & SD \\
\hline As-Built Drawings & AB \\
\hline
\end{tabular}

Field 7 - Number and Field 8 - Revision indicates the given number of the file and the revision. These fields should be consistent throughout the project to facilitate cooperation and communication among team members.

\subsubsection{Project File Structure}

In each project, setting the file structure within the BIM authoring tool is crucial for correct progress. It determines the base values for model creation. The number of floors below and above ground level, floor heights according to their locations in the project, slab and foundation thicknesses, and the number of filesets to be generated within the model are the settings that LC had identified to be compulsory in its projects. Each fileset that is structured within the Allplan model file is used in LC to import into reference drawing files from design phase and create building model on separate filesets depending on their own level. The filesets for building model are organized according to disciplines: structural building elements on top, and architectural building elements below. If the project has more than one building, then the reference files are grouped on top, as it can be seen in Figure 4.1 with the filesets named 100-110, and filesets for each building's structural and architectural building elements are grouped under it, with the 
filesets named 111-120. This file organization gives the Team the flexibility to work on the reference files and building information model they create without interfering with each other through the options for changing the status of each fileset individually to activate, edit or reference only.

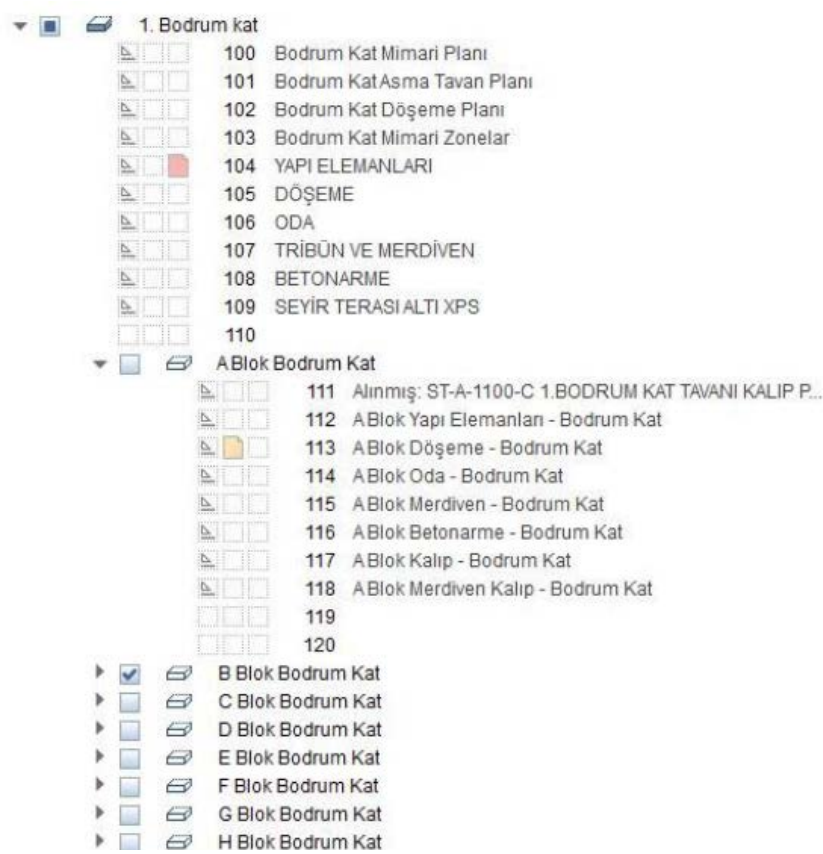

Figure 4.1. Fileset Structure that Groups Reference Files and BIM

\subsubsection{Roadmap for $Q T O$ and CE}

BIM-enabled QTO and CE require a systematic data creation and rules to process BIM data. Rules of engagement for processing BIM data to perform QTO and CE that were defined by the Team in LC are:

- Geometries have to represent building elements accurately.

- Rules and constraints associated with modeling procedure and performing QTO must be defined to enable calculating correct amounts of quantities from the model.

- Non-geometric data must be assigned to each building element to achieve informative and correct QTO reports and enable for performing CE. 
Non-geometric data must represent 3 types of information according to QTO and CE procedures at LC.

Naming: Each building element must have a relevant name. This is required not only for QTO process but also for procurement process.

Cost code: Each building element must be assigned an 8-digit cost code from the cost database used by LC (called CCD for the rest of this study).

Recipe: Attributes such as calculation type, type of work, material, etc. must be assigned accurately.

Modeling procedure, as well as the QTO and CE processes have been developed to fulfill these rules of engagement. The details of these subjects are presented in associated sections below.

\subsubsection{Assigning Cost Database}

In Turkey there are several cost databases provided by different government agencies. The most comprehensive construction cost database is provided by "The Ministry of Environment and Urbanization” (this database is called BYND in this document) and is updated annually. This database includes over sixty thousand cost items (called POZ in Turkish) that includes assemblies, equipment, material, material losses, and transportation in the same database. It provides guidelines for quantity takeoff procedure as it gives detailed descriptions of the cost items by identifying its sub-workpackages, measurement units, and estimated costs. There is a fee-based web search mechanism provided by the agency for the estimator to search and find the proper POZ for their takeoff. It is a compressive database requiring extensive estimating experience and familiarity that LC has. However contractors do not prefer to utilize BYND except for public building projects due to the unrealistic unit prices it offers (Ocal, Tat, \& Erdis, 2004). To enable more accurate CE, the 8-digit cost database that is utilized by LC is organized in a very similar manner to CSI MasterFormat 16-division with unit costs provided from either historical data or subcontractors/vendors.

Prior to implementation, cost items have to be listed and grouped according to construction and materials required for the building projects. These lists should be organized in spreadsheet format to import as an XML file to the project as a cost database. 
The cost items carry object property information such as line weights, layers, trade, priority rate, hatching, etc. that are generated based on CCD.

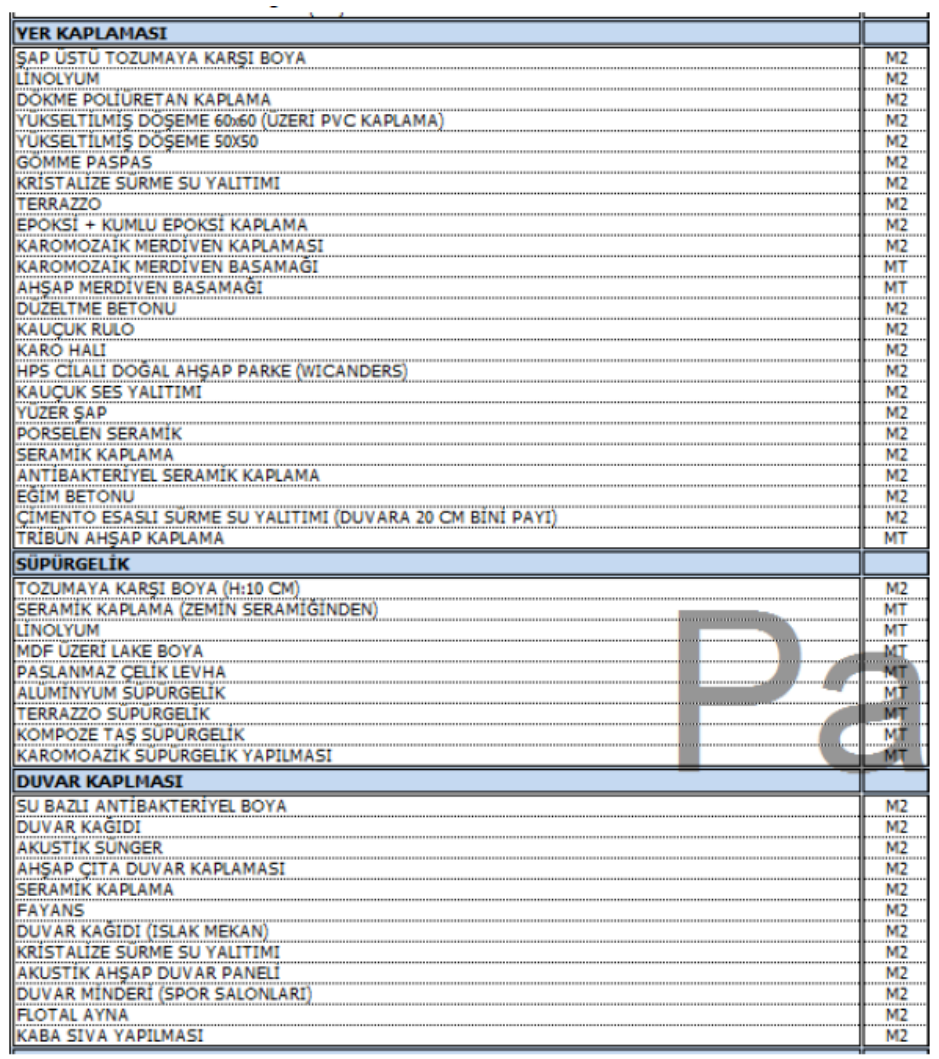

Figure 4.2. Sample of Cost Item List

\subsubsection{Modeling Procedure:}

LC is a construction company that outsources design projects. The modeling procedure begins when the building permit is obtained. Building information models are created by using design projects, either in 2D or 3D format, as a basis for the model creation. The modeling procedure in the BIM implementation phase plan focuses on construction phase only.

Design phase models may have been created by the design team during relevant phases. However these models mostly do not carry the required information to conduct automatic QTO and CE. BIM Use that design teams utilized in their projects was mostly visualization in the case of LC. The submitted models to the BIM Team included 
duplications in geometries, and do not carry cost information that the QTO and CE processes require.

The BIM Team had created modeling templates to be used in each LC projects to increase efficiency of the implementation process. QTO reports can be generated from BIMs automatically by means of these templates, therefore it is critical to assign attributes in the templates correctly to each building object. The templates include non-geometric information such as settings for material, layering, priority rate, calculation modes and height for most of the building elements. These non-geometric information, also called "attributes", are to be assigned to "Quality" section of the objects. "Name" is one of the most important attributes that each element has. Each element is given an appropriate name defining the type of it, and if it names a structural element, the very same name from the structural project is given to facilitate construction progress control on site. Allplan cannot search for structural elements according to their locations on structural grid. To eliminate this shortcoming, the Team assigns “Architectural Material” attribute showing the locations on structural grid. Cost item from the cost database related to the building element is assigned to "Material” properties of the element. "Trade” information is where the type of work such as concrete work is assigned to the object. "Calculation Mode" identifies in which unit quantities should be calculated and "Priority" defines the rate that controls the behavior of each object in the case of interaction with other building elements. Intersecting parts of objects with lower priority rates would be subtracted from the objects with higher priority rates. These attributes helps the Team not only in automatically generating the QTO reports, but also facilitating the construction progress control on site by enabling filtering options with reference to the non-geometric information that is embedded to the building elements. 


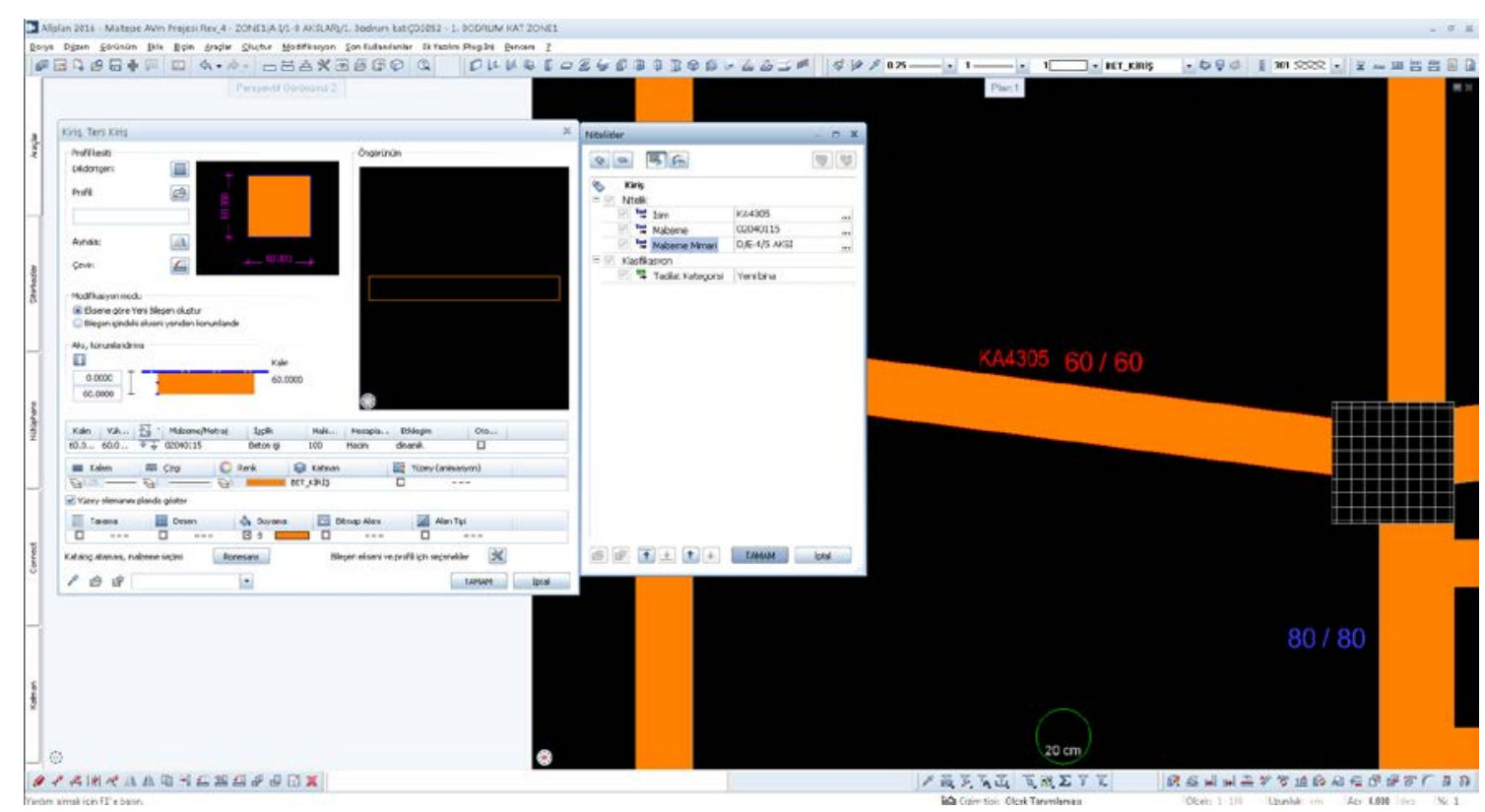

Figure 4.3. Object Attributes in Allplan

Modeling process begins after the file is set and the required templates are assigned to the model. The first elements to be modeled are the structural components according to the structural design project. Foundations, structural walls, columns, beams, and slabs are modeled. The reinforcement inside load-bearing elements is not modeled at LC to decrease modeling time. The Team can get acceptable reinforcement QTO by using information from previous projects on the ratio of concrete/formwork number of floors, and floor heights. Exterior walls, interior walls, doors, windows, tags, and stairs are added to the model after structural components. The reason for this sequence is to determine the heights of the walls respective to the beams and slabs, and to avoid any duplications in the faces of the geometries which could lead to erroneous results in QTO and CE. The finishing works such as rooms, suspended ceilings, vertical surfaces (for wall covering materials), floor covering materials, baseboards, trimmings, etc. are added lastly to the model.

While creating the model, it has significant importance to follow the rules that are defined to generate QTO reports automatically. Formwork QTO requires a special set of rules for model creation. All structural elements should be modeled in a way that all the faces must touch each other without overlapping and/or having gaps between them. Column heights should be aligned with the top of the slabs. Beams should be aligned to the columns without any overlapping; and slabs should be created in between the columns and beams without intersecting. Only cost item associated with concrete work must be 
assigned to all of these objects. The details of the calculation rule will be given in the Reports section.

Most of the geometries in the building projects are modelled using default object creation tools in Allplan with some exceptions. The QTO reports of concrete stairs can be generated correctly with the default stair tool; QTO reports of formwork for stairs, however, are generated according to German standards which is not appropriate for Turkish construction industry when the default stair tool is used to generate the geometry. The Team designed an alternative way of modeling for stairs to automate correct QTO report of formwork for stairs. They are modelled as solid geometries instead of using default stair tools in the software, then they are converted to slabs and relevant cost items are assigned to them. A similar approach is followed when creating ramps or nonorthogonal reinforced concrete structural elements. This process takes longer to model, but provides more accurate results in the reports.

Another building object that requires an alternative way of modeling to perform accurate QTO is the reinforcement in walls. The Team developed a modeling procedure using column and beam tools (depending on the direction) to create them. Assigning a higher priority rate to these objects than the walls in which they are located subtracts the reinforcement amount from the wall even if the wall geometry is overlapping with the reinforcement geometry and leads to an accurate QTO.

BIMs for mechanical, electrical and plumbing (MEP) projects are created by the Team according to the design projects. The software used for these models is Revit MEP 2015. As the structural and architectural models progress, MEP projects are modeled by using those models as a base. MEP model generation is designed in a more simplistic way than other disciplines. All building elements are modeled with default tools and nongraphic information are not assigned to any object. 


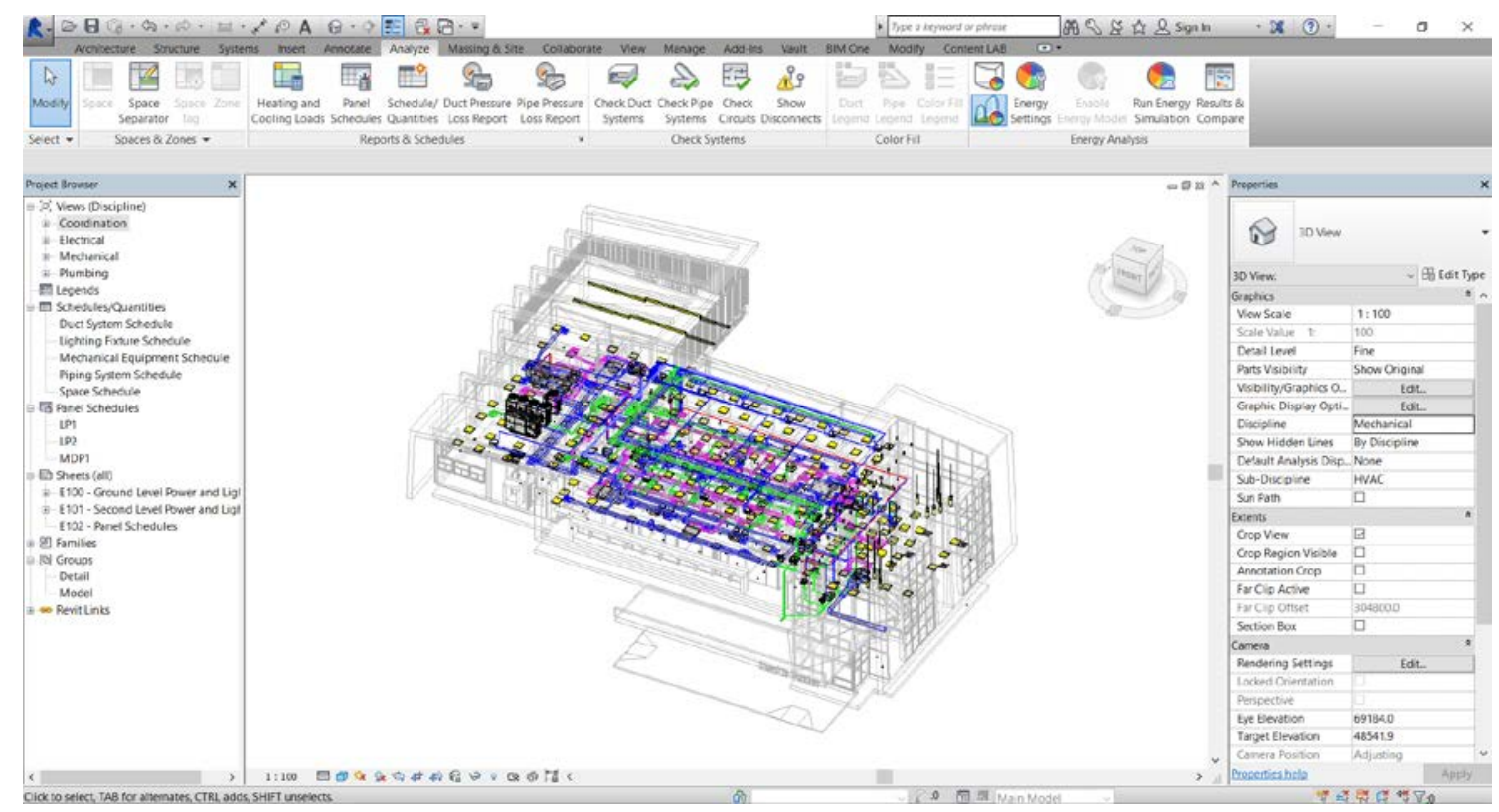

Figure 4.4. Screenshot of a MEP model in Revit MEP

The coordination between disciplines necessitates a defined origin point in the model. After each discipline creates its own models, these models are linked in Autodesk Navisworks to create a composite model to perform clash detection. The Team realized that file size of these composite models could be excessive when Revit families that are distributed by manufacturers are used. To eliminate this problem, the objects from these families that are used in the MEP model are exported individually. When the models are linked together, the interferences are examined. They are solved among disciplines in meetings that are held weekly or bi-weekly depending on the workload. The composite model that includes models of various disciplines enables the Team to solve the interferences in the design before construction begins.

Modeling procedure is not limited to planning and managing construction phase. During construction, all design changes that take place on site are updated in BIMs. When the project is completed, the Team has the as-built models ready to be used in the FM phase.

\subsubsection{Reports}

Properties that can be directly quantified from the model (i.e. lengths of walls, number of doors or windows) require a relatively simple process in QTO. For instance, 
MEP projects' reports are generated in Revit MEP with default QTO tools. Formwork QTO, however, is referred to as a problematic issue in the literature due to the lack of abilities to calculate accurate quantities in some of the BIM tools (Monteiro \& Martins, 2013), or the high-level of attention or the rules it requires in modeling phase to avoid duplicated volumes of structural elements (Barak, Jeong, Sacks, \& Eastmant, 2009; Z. Ma et al., 2013). The BIM Team had experienced BIM-based QTO and CE tools to get the reports from the model they created. Those formwork QTO reports had confirmed that they may be subjected to deviations. The deviations may be small and may be considered unimportant, e.g. $0.4 \mathrm{~m} 2$ /floor. But in high-rise projects, even small amounts of deviations on each floor could be problematic. Therefore the Team focused on eliminating this problem.

Modeling procedure is designed to avoid any duplications as it is explained in modeling procedure section. It enables generating formwork QTO from BIM authoring software according to the rules that are developed by the Team in Visual Web Developer (VWD) which means that the $3^{\text {rd }}$ party QTO tools are eliminated. The user-friendly interface of VWD enabled creating the report templates according to the existing templates of LC. The formulization needed for formwork developed in VWD by assigning associated attributes of structural elements to the required fields. The defined limitation for this rule is to include only the concrete building elements in the calculation. The rule deducts the touching rear faces of the structural elements such as slabs or beams where there would not be a formwork to pour concrete on the construction site. Sample of report template that was created in VWD can be seen in Figure 4.5.

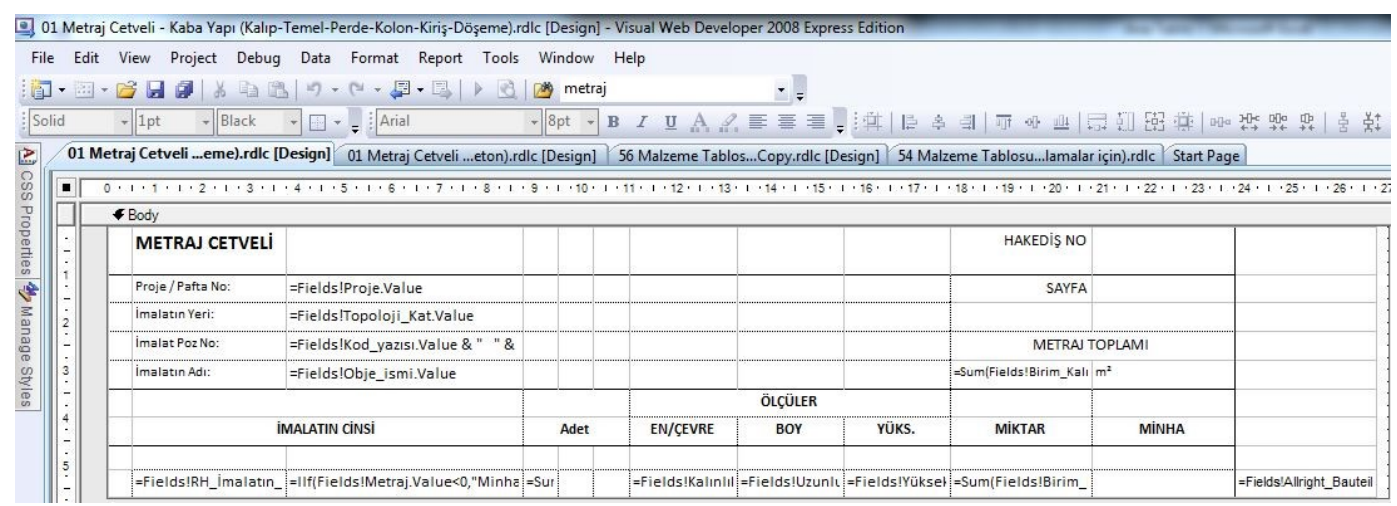

Figure 4.5. Sample of Report Template for Formwork QTO Created in VWD 
Modeling procedure has a direct effect on QTO reports. BIMs which are visually the same with each other could generate different QTO reports depending on the modeling procedure. For instance, the plan views of these examples are the same (Figure 4.6). There are two structural walls on the right and the bottom, and a column on top left-hand corner; beams are located in between these vertical structural elements. The difference between these two examples is the way the slab is drawn.

In the first example, slab (D1) is drawn in between columns, beams and structural walls, which top level of each element is the same. The perspective view is given inFigure 4.7. Under these circumstances, total concrete QTO would be equal to $40.68 \mathrm{~m} 3$, and formwork QTO would be $240.92 \mathrm{~m} 2$ (Figure 4.8).

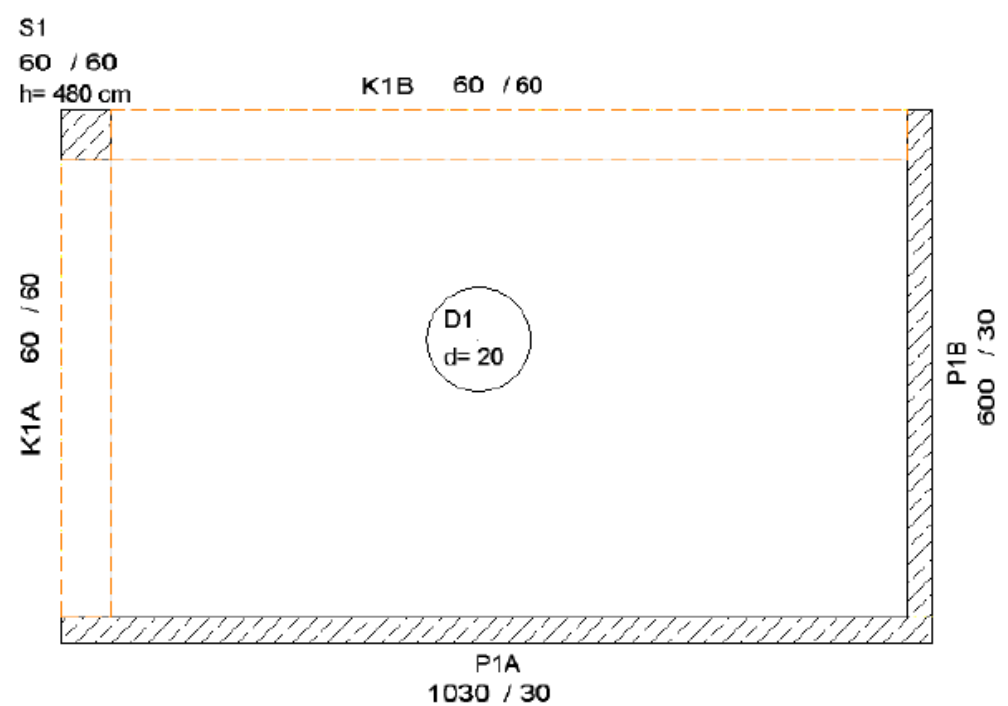

Figure 4.6. Plan View of QTO Example

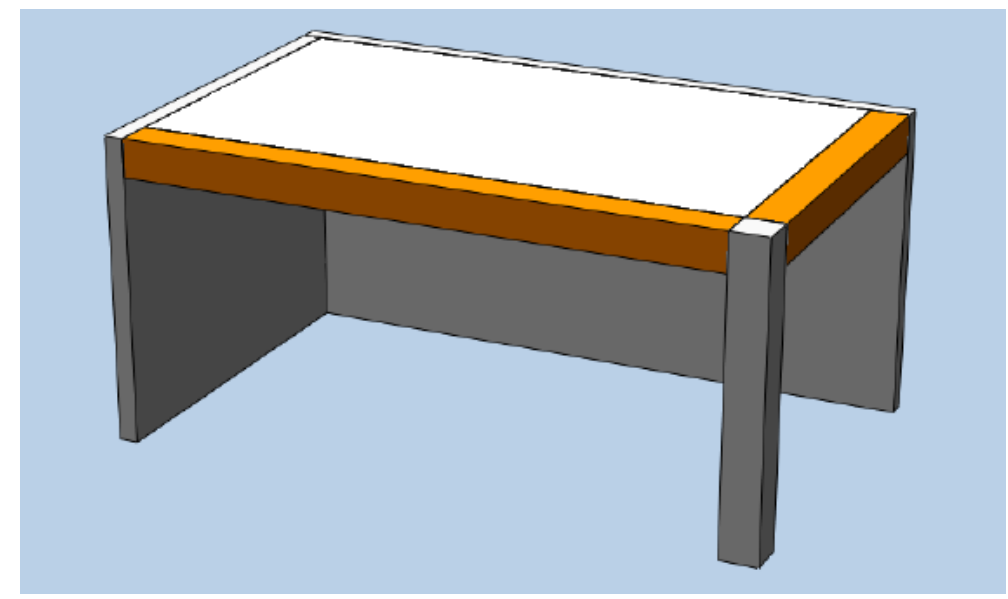

Figure 4.7. Perspective View of Example 1 


\begin{tabular}{|c|c|c|c|c|c|c|}
\hline E $14 \mid$ & $-1>$ & | & 国 & $100 \%$ & 012 & \\
\hline Kat & Kot & Malzeme & Obje ismi & Özet Yaz & Beton & Kalıp \\
\hline \multicolumn{7}{|c|}{ Zemin kat } \\
\hline Zermin kat & 4,60 & 02030115 & Döşeme & Beton - Betonarme Döşerre & $10,15 \mathrm{~m}^{2}$ & $50,76 \mathrm{~m}^{2}$ \\
\hline Zernin kat: & 4,60 & 02040115 & Kiriş & Beton - Betonarme Kirşler & $5,33 \mathrm{~m}^{x}$ & $23,68 \mathrm{~m}^{2}$ \\
\hline Zemin kat & 4,60 & 02050115 & Kolon & Beton - Betonarme Kobn & $1,73 \mathrm{~m}^{3}$ & $10,80 \mathrm{~m}^{2}$ \\
\hline Zemin kat & 4,60 & 02060115 & Duvar & Beton - Betonarme Perde Duvarlar & $23,47 \mathrm{~m}^{3}$ & $155,68 \mathrm{~m}^{2}$ \\
\hline \multicolumn{5}{|r|}{ Toplam: } & $40,68 \mathrm{~m}^{3}$ & $240,92 \mathrm{~m}^{2}$ \\
\hline
\end{tabular}

Figure 4.8. QTO Report of Example 1

In the second example, slab is drawn on top of other structural elements; the heights of column, structural walls and beams are $20 \mathrm{~cm}$ shorter than the first example although the total height of the example stays the same. The perspective view is given in Figure 4.9. Total concrete and formwork QTO would be same as the previous example (Figure 4.10).

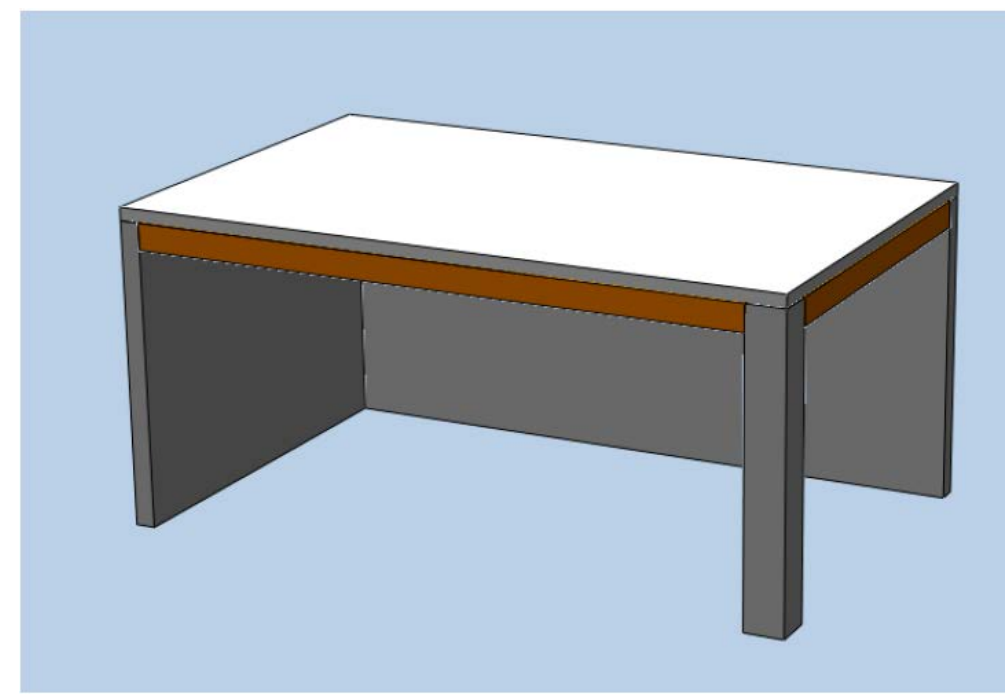

Figure 4.9. Perspective View of Example 2 


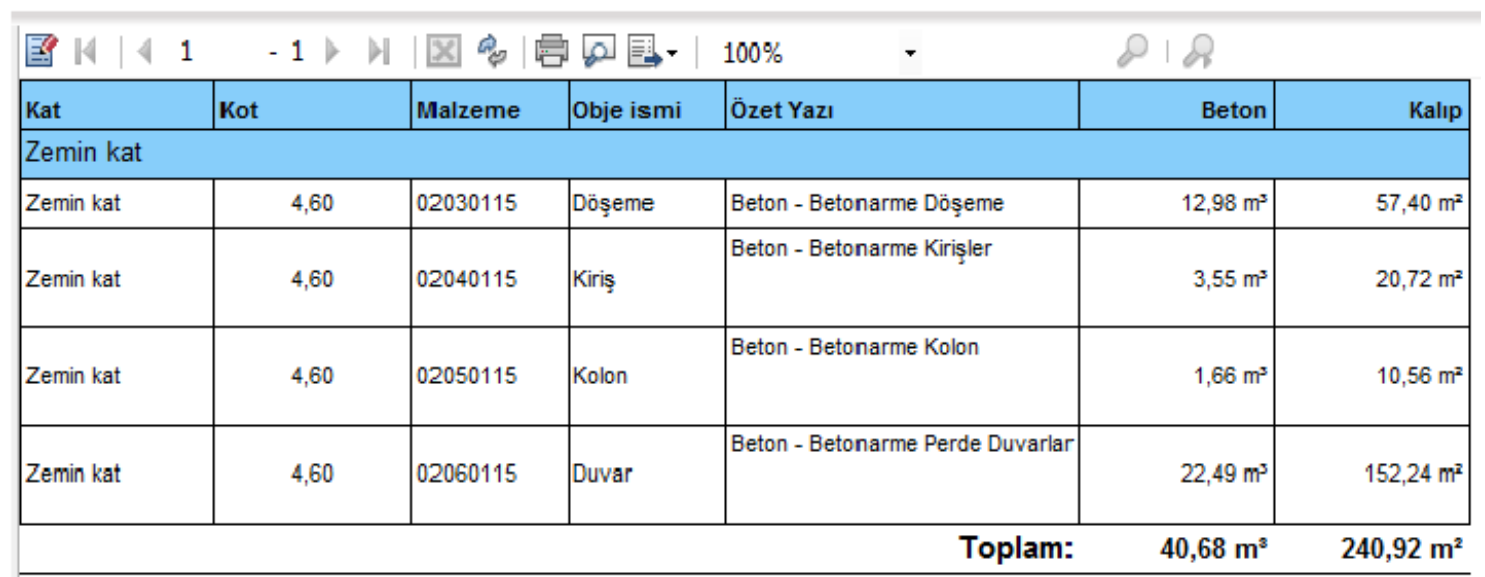

Figure 4.10. QTO Report of Example 2

The difference between these two examples lies in the individual QTO amounts of each building element. For instance, there is a $6.64 \mathrm{~m} 2$ difference in formwork QTO of the slab, and $2.83 \mathrm{~m} 3$ difference in concrete QTO of the slab. These could be seen trivial as long as the total amounts are correct, however, they may cause site managers problems of organization of the construction. Therefore it is important to pay attention to modeling procedure while creating the BIMs.

Besides formwork QTO, concrete, partition walls, door/window and finishing works QTO reports are all generated from BIMs. Creating the layout and the content of these reports were influenced by the coordination between the office and the construction site. Partition wall QTO reports, for instance, represented the total amount of the walls with the cost item information and the name of each wall indicating the location of the wall on the project, when the Team first designed the report. Construction crew asked to add the information showing the amounts of the openings on the walls. Then the report updated to provide this information to the construction site to facilitate construction.

The attributes assigned to the building elements are all used in the reports. This provides the people at the construction site with a working environment where they control the construction process from both the QTO reports and the scheduling documents. The scheduling documents can be monitored through the composite models in Navisworks where the related details will be given in scheduling section. 


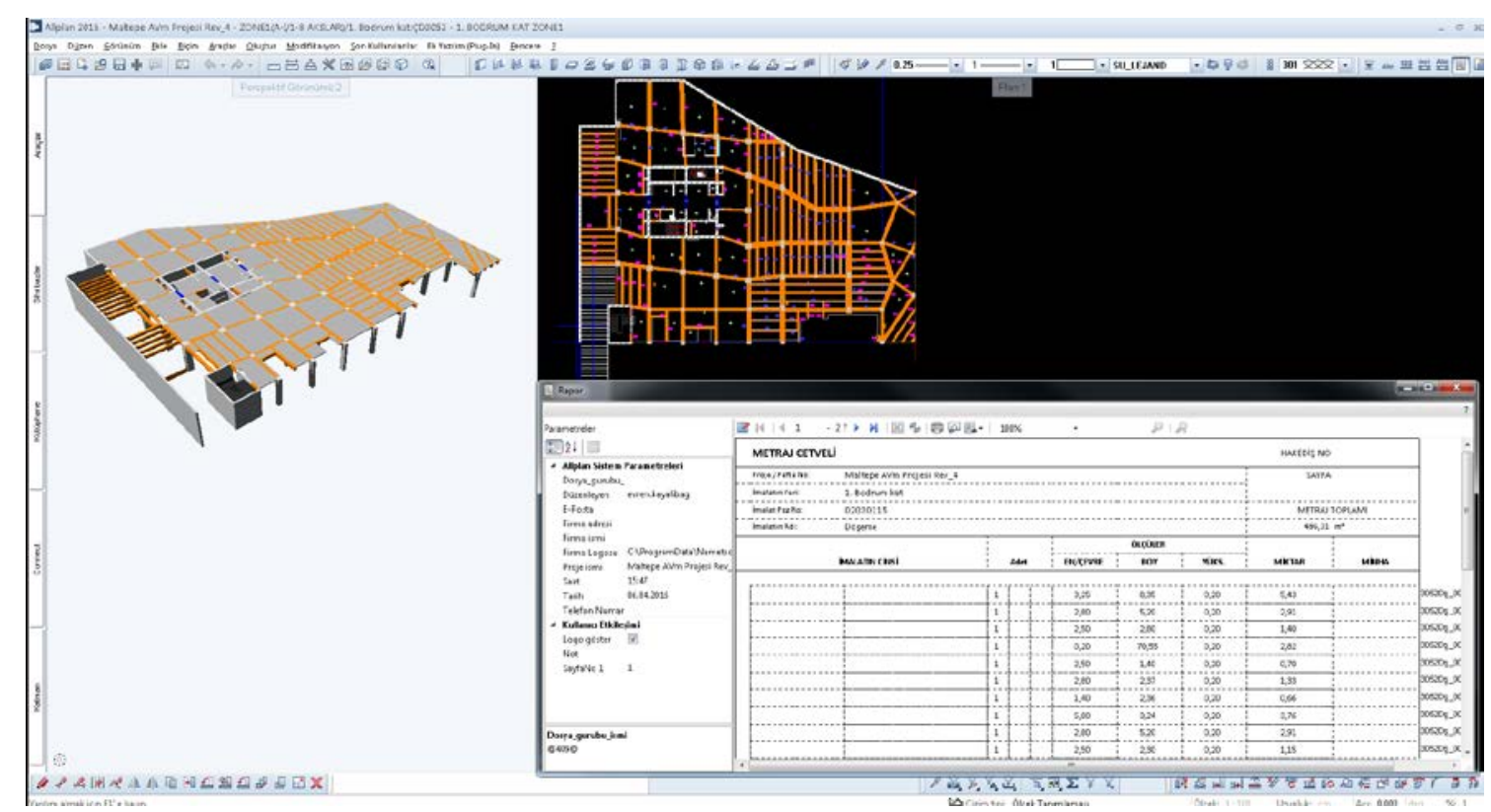

Figure 4.11. QTO Report in Allplan

\subsubsection{Information Exchange and Collaboration:}

An enterprise content management (ECM) platform called OpenText is deployed at LC to manage information exchange related to project implementation. The utilization of the product is not limited to information exchange process during BIM implementation; but throughout the project's life-cycle. Starting from the project inception, all internal correspondence, building permit documentation from design teams, BIMs, construction phase documentations, and archives of the project at the end of the construction and BIM implementation to be used in FM phase are managed and stored in the content repository of OpenText.

In the case of BIM implementation, architectural and structural models are created in Allplan. Therefore there is no need to convert the architectural and structural projects into any other file formats to collaborate. The Team access the models via BIM server for the modeling process of architectural and structural projects. MEP projects, however, are created in Revit MEP. Architectural, structural and MEP projects are all merged into Navisworks to perform clash detection tests and scheduling. 


\subsubsection{Scheduling:}

Project scheduling provides "virtual simulation of the construction process from its beginning to its end, with location, resources, and progress information” (Mubarak, 2015). Due to the amount of information required to develop project schedule, extensive experience on sequencing, constructability, and CE is required which the Team had. The procedure for project scheduling has been developed by the Team as follows.

3D model from BIM authoring software and the project schedule developed in Primavera P6 or MS Project are imported into the Navisworks TimeLiner. Since the modeling procedure creates hierarchical groupings by assigned attributes such as type of works, cost codes, or materials, the activities and the tasks under them could be assigned to the building elements from the 3D model. Activities and tasks are not created from scratch for each project. Most of the construction works are repetitive; and activities and tasks can be adopted from previous projects while developing project schedules. Each task could be customized from the information it can carry, for instance, name, status, planned start/end, actual start/end, task type, attached geometry, etc. The tasks could be grouped according to the type, e.g. temporary, construct, demolish, etc. which defines the representation style that would be used in simulation phase.

Selection sets which ease the selection of building objects in 3D model are created. These sets could be created either by Selection Tree tool available in Navisworks TimeLiner or by selecting objects manually to group the objects in a logical manner to ease the task assignment to the objects. Some of the selection sets that the Team utilizes include object or trade type such as concrete works, partition walls which are grouped according to the location of the objects. Once the selection sets and tasks are created, they are assigned to each other to create the schedule. Example of the task assigning process to the selection sets is given in Figure 4.12. 


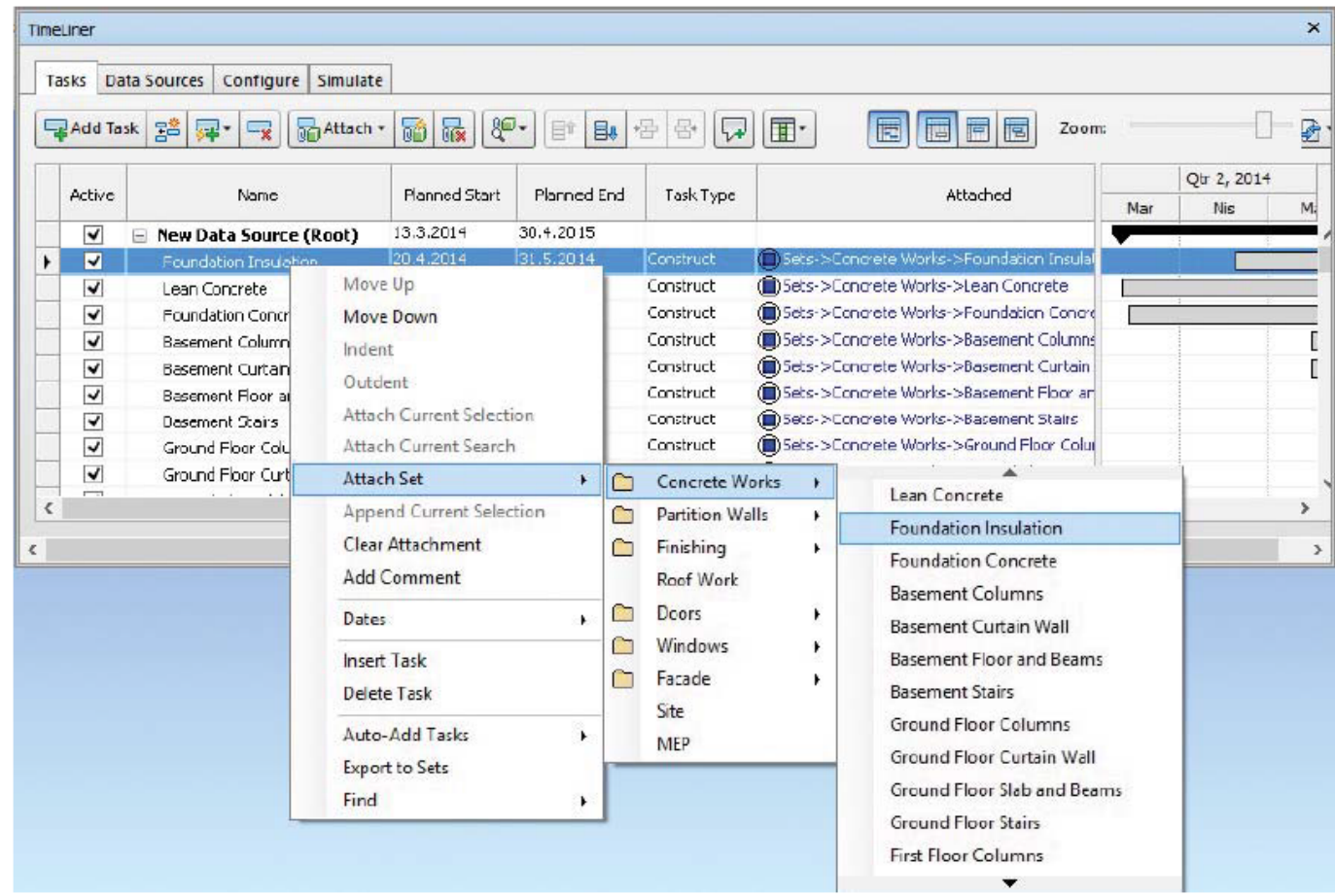

Figure 4.12. A Snapshot of Assigning Selection Sets to Tasks (Source:Mubarak, 2015)

Simulation of the project schedule could be generated when the schedule is completed in Navisworks TimeLiner. It can simulate the construction process from start to end, and the Team customize the simulation settings depending on the project requirements like limiting the simulation to be within defined intervals.

\subsubsection{Cost Estimation:}

Scheduling is followed by CE. The aims of the Team while developing the CE procedure for the case studies were:

- Designing a system that is not too sophisticated to implement,

- Defining problems and early warnings,

- Conducting performance analysis,

- Delivering a tool for management to use.

As it is stated in Reporting section, QTO reports are created in Allplan, because of the deviations in formwork QTO when it is generated from $3^{\text {rd }}$ party QTO tools. Therefore the reports from Allplan in spreadsheet format are utilized in CE process. Cost items and materials are represented in these reports associated with building objects. 
The reports from Allplan and project schedule from Primavera P6 are both linked together in RIB iTWO platform which is utilized in 5D construction planning and execution. The tasks from project schedule include activities which associated resources should be assigned to. Resource information of equipment, labor and material relating to activities - in other words, assemblies, may resemble recipes for cooking. Catalogs for these resources are needed and uploaded to ERP system to be utilized. The costs of resources can be consolidated from these catalogs. Assembly example is given in Figure 4.13. Unit costs and QTO information is hidden in this example due to confidentiality. Each assembly includes unit costs of resources they comprise. Each subcontractor is also identified in the ERP system to be assigned to the assemblies. This allows the Team to search for each unit costs individually when a change is required.

Cost items assigned to building elements in 3D model are shown in QTO reports which facilitates assigning the resources to objects. Even though the $3 \mathrm{D}$ model is not linked to iTWO, the QTO reports are, which means any changes to the model would update the CE procedure.

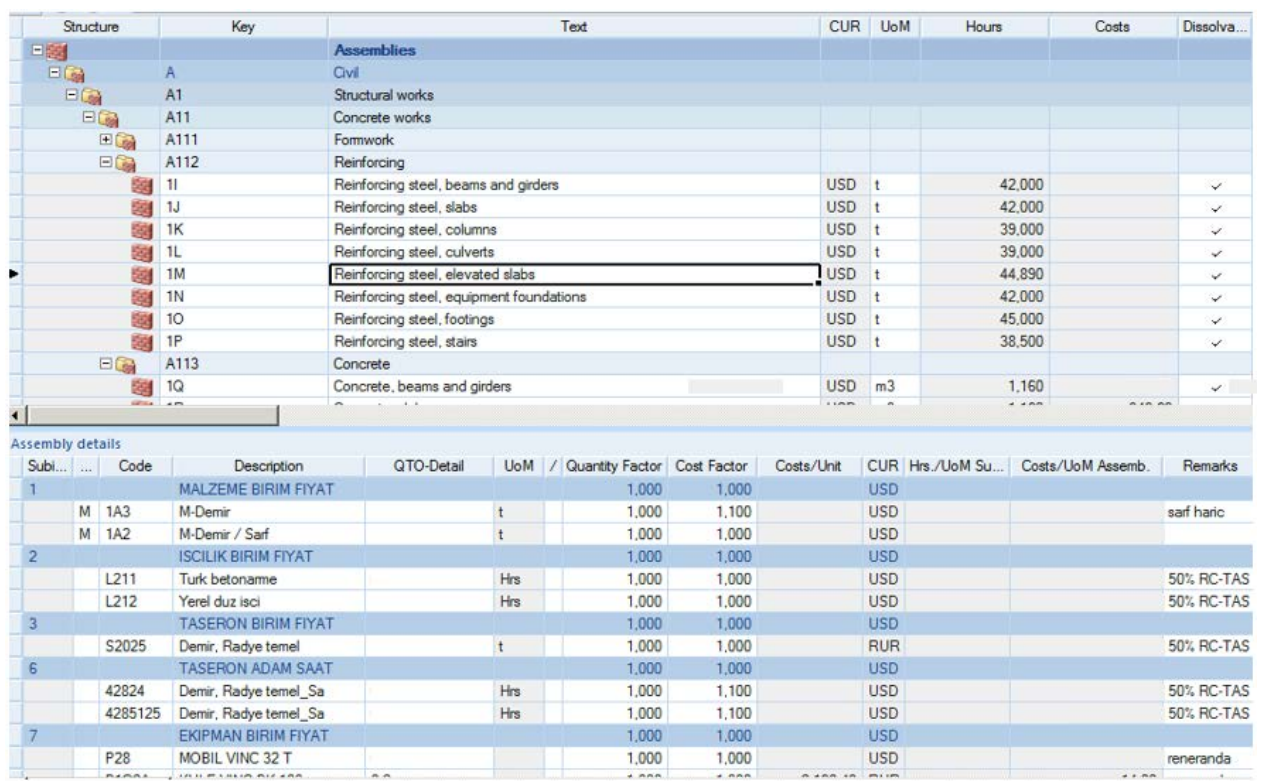

Figure 4.13. Assembly Example

Erroneous cost information would lead to miscalculations. To eliminate possible human errors associated with the information provided by the project stakeholders, 2D coding structure for CE are designed to be used at LC. Each task is given a budget cost 
and a cost code together. Budget code represents the activity and the cost code represents the resources to perform the activity. Example of a 2D coding structure is given in Figure 4.14.

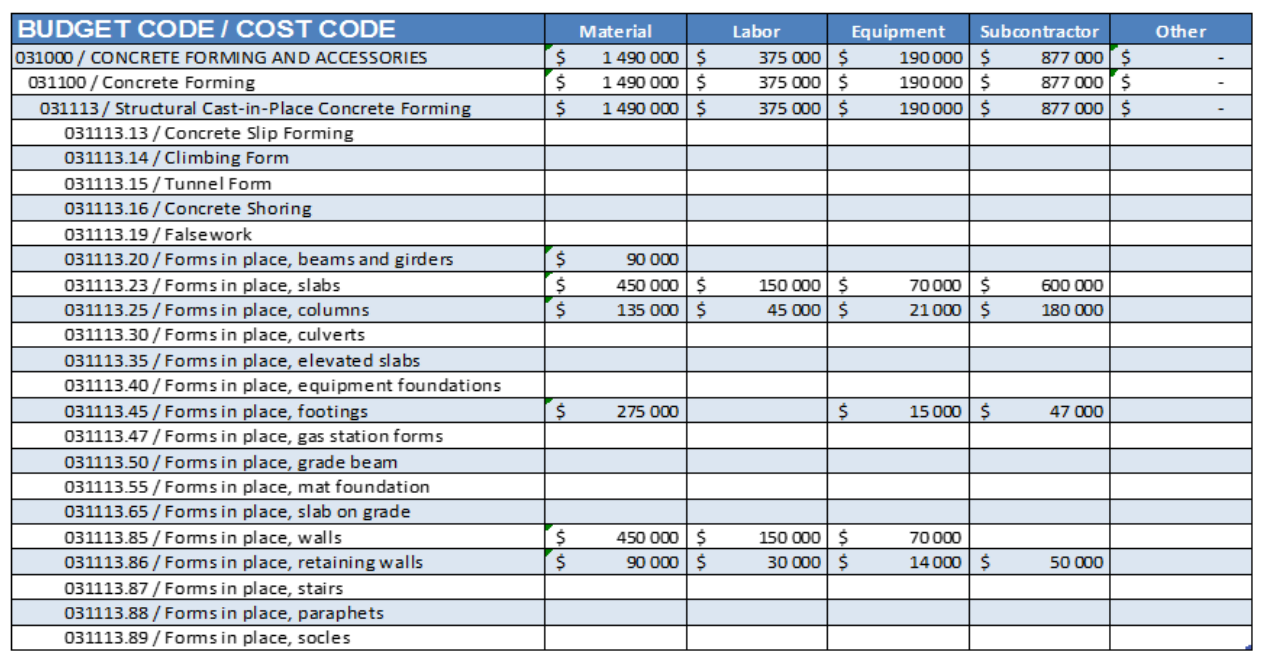

Figure 4.14. 2D Cost Code Structure Example

All cost items related to both the project schedule, and also indirect costs of the construction such as salaries, accounting, central charges, etc. are compiled from ERP system. Therefore a comprehensive CE is obtained by using BIM-based methods. Once the $\mathrm{CE}$ reports are generated, they are submitted to managers to be reviewed according to the target costs. If the estimation exceeds target costs, the model is revised again to alter properties of building elements such as materials.

The graph that summarizes the overall process to perform QTO, and CE is given in Figure 4.15. 


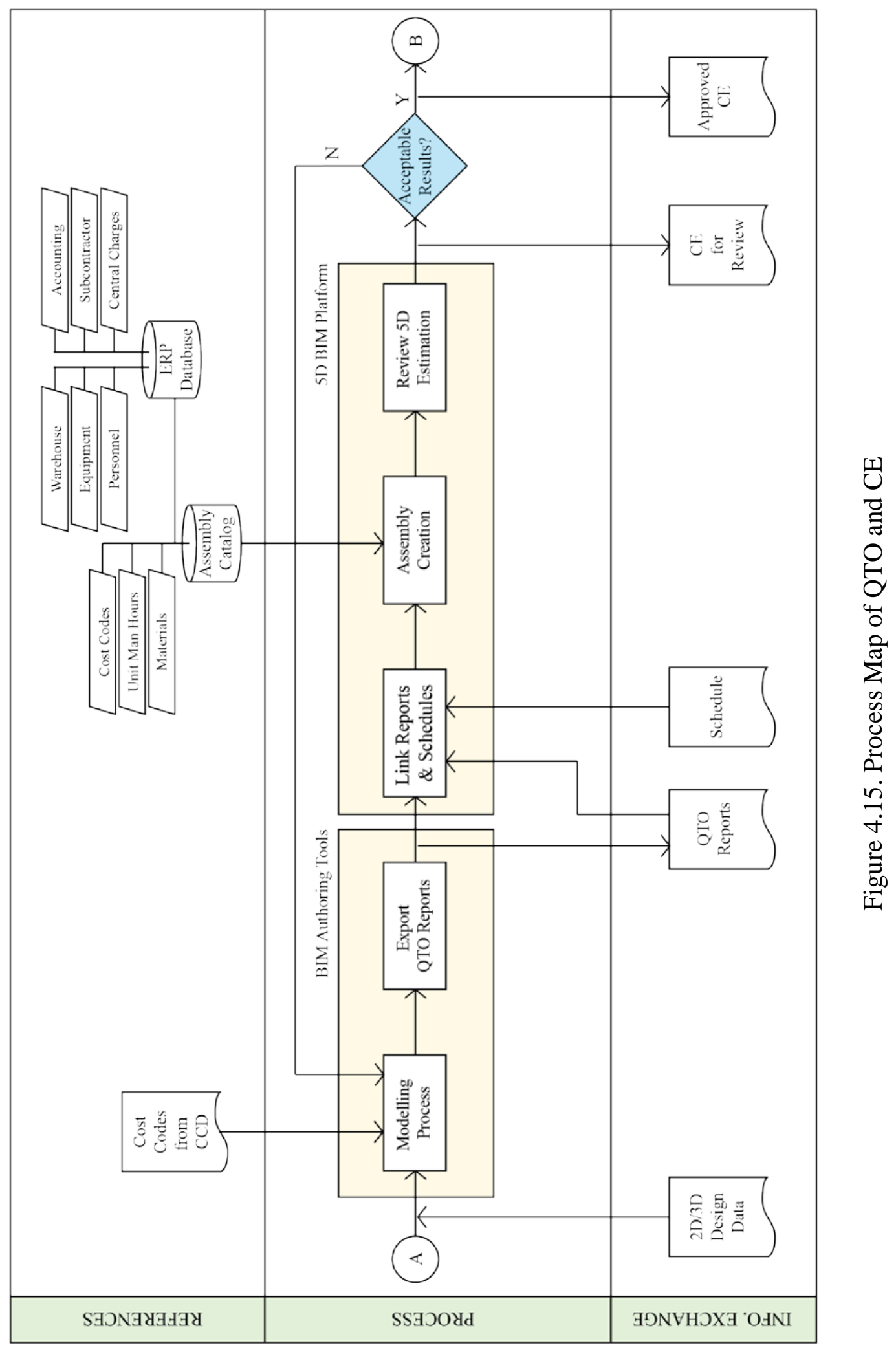




\subsubsection{Performance Evaluation:}

Earned Value Management (EVM) is applied to measure the performance of cost and schedule during the construction phase. Indicators of cost and schedule progress are required to track the performance. Schedule performance index (SPI) and cost performance index (CPI) are two concepts that are utilized in the case studies for performance evaluation. SPI "measures the progress to date against the progress that was planned" and CPI "measures the value of the work completed against actual cost" (Heldman, 2009).

Monthly evaluations are conducted to calculate time and cost variances. Periodical installed quantities from the model, and periodical actual accrual cost reports that includes accounting, personnel, warehouse closings, and subcontractor billing are required to be created monthly This is a repetitive process till the end of the construction. SPI and CPI are calculated according to the monthly reports. Therefore the performance of scheduling and CE can be monitored, and early warnings may be created whenever needed. The outputs of these reports can be customized regarding the level of detail of information on budget and schedule they represent.

\subsubsection{Lessons Learned:}

The Team learned important lessons from the six projects they carried out while implementing BIM to perform QTO and CE and support construction site work. Competitive environment of AEC industry in Turkey, lack of standardization, and human factor in BIM implementation were some of the most influential and key factors to be dealt with.

Competitive environment of AEC industry in Turkey has a major impact on BIM implementation process that the Team encountered. The project owners demand from constructors to complete construction projects in the shortest period of time possible. Under these circumstances, it is hard for construction companies to accomplish designing BIM implementation plan that is proved to produce accurate and effective results. Even if they manage to implement BIM, they may limit the aimed BIM Uses. For instance, the BIM Uses that were chosen at LC were only QTO and CE, whereas there were many 
other BIM Uses that could be benefited during the construction phase such as field/manage tracking, digital fabrication, etc.

Lack of standardization of information in Turkey also constitutes a major shortcoming in AEC industry. Common methods of standardization that are utilized abroad such as MasterFormat, OmniClass, etc. are not utilized in Turkish AEC industry. Even the most comprehensive construction cost database, BYND, is not utilized except for public building projects. Each construction company develop its own construction cost database based on its own historical data. For instance, CCD is developed and utilized in the projects of LC. This prevents establishing a collaborative environment among companies.

BIM adoption could be an expansive process for the companies due to the infrastructure and process design investments. The implementation plan has been designed at LC to minimize required resources as much as possible. For instance, instead of purchasing new BIM-based QTO software application, the Team identified necessary rules and restrictions in Allplan to conduct accurate QTO reports. Additionally the Team gave precedence to evaluate the software applications that the company already had prior to any purchase of new software.

The human factor is also an important challenge to deal with. Construction crew showed a strong bias towards not adopting BIM procedures. The reports that were generated to facilitate construction progress were distrusted at first. Although the Team provided accurate QTO reports which had been utilized on site, some professionals from the site had reported misleading opinions on BIM implementation. This bias decelerated the integration of BIM procedures at the construction site.

One of the reasons of the bias against BIM implementation was inadequate training programs at the company that had been given by software vendors. Due to the instructors' lack of knowledge of construction, the construction crew could not get satisfactory answers to their questions related to construction phase, which led negative opinions on BIM implementation. The Team, which comprises of technical leaders who have hands-on experience of construction, was able to develop a BIM implementation plan that met the quality requirements of the company in spite of the existing bias their colleagues had.

Communication between the Team and construction site has a crucial role in facilitating construction planning and management. When BIMs are ready to generate information to support the construction crew, the updates in documentation can take place 
effectively as long as there is a strong communication. All QTO reports, for instance, had been generated according to the existing reporting templates of the company and updated during the implementation due to the requests from the construction crew to facilitate the transition. This provided a similar environment for the construction crew without major changes in their existing procedures and also gave them a chance to improve their tracking procedures by embedding links to QTO items that direct them to the building elements on the model in Navisworks.

The human factor in BIM implementation is not limited to the construction crew. Expanding the implementation within the company by increasing the number of members of BIM Team could be also challenging as the Team experienced during case studies. When the implementation plan was tested to provide accurate results, the size of BIM Team was intended to expand. New employees with BIM experience were recruited. Open-minded individuals become part of the Team, whereas some of the new employees could not fit into the Team because of the resistance they put up to new processes and workflows.

In Turkey, most construction projects are started to be built before the design process is completed. The design problems are realized on site and often increase costs of the projects and waste resources. Design companies could not invest in developing customized BIM implementation plans to benefit from BIM due to their financial deficiencies and generally utilize BIM tools for visualization and drawing generation purposes. This situation disrupt the continuation of utilization of BIM throughout project's life-cycle. Construction companies re-create the design projects according to their own implementation plans to perform aspired BIM Uses as it happened in this case study.

The Team tested utilization of 3D models that were created by design teams during the project implementation. This testing process showed the Team that the modeling procedure is significantly important to accomplish BIM Uses defined at the beginning of the project. Design teams utilized 3D models for visualization purposes only. The models received had too many duplications and problems in geometry which cause erroneous QTO reports. Inspecting all of the problems in the models were impossible for the Team due to the excessive time required, while the construction site was waiting for information to rely on. That is why the Team re-models each project according to the modeling procedure defined in BIM implementation plan when the building permit is obtained. 
Detecting interferences in design projects through clash detection tests provides savings in terms of time, resources and money. However, studying design projects via BIMs also provides valuable savings as well. The Team models the projects not only from architecture, structure and MEP projects, but also the design solutions that subcontractors offer. In one of the high-rise building projects, the Team detected a design problem related to the structural system of the curtain wall and interior partitions. Detecting the problems prior to construction enabled the Team to alter the design of the curtain wall with the subcontractor which led to a considerable amount of savings in time and resources. 


\section{CHAPTER 5}

\section{CONCLUSION AND RECOMMENDATIONS}

\subsection{Implementing BIM}

AEC industry has been dealing with low labor productivity rates, and high consumption levels of raw materials and energy for decades. Technological advancements have helped other industries to overcome similar challenges. Such advancements could also improve productivity rates and decrease consumption levels in AEC industry, despite its fragmented nature and lack of coordination and communication.

Paper-based communication which dominates current business practices is one of the reasons for the rework in construction process, and lack of collaboration and/or coordination among project stakeholders. It is difficult to detect errors and omissions until they are discovered at the construction site. Although efforts have been addressed to eliminate the deficiencies of paper-based modes of communication by electronic file sharing systems, these only help improve the delivery time of the information, not reduce the errors in project delivery.

$\mathrm{BIM}$ is an emerging concept which demonstrates promising results in reducing rework and cost in AEC industry. Beyond requiring the adoption of new software programs, BIM is developing and executing new interacting processes and workflows to manage digital data addressing the whole life cycle of a project from conceptual design to demolition. It requires high levels of collaboration among stakeholders from the conception of projects. It shifts the workload of stakeholders from construction phase to early design phases which have considerable positive effect on cost of the changes.

The collaborative business practice that BIM promises and the heavy amount of information that the models contain require a well-designed execution process to enable maximizing the benefits. However designing the execution process is an iterative and expensive procedure due to the resources to be allocated to find optimal solutions to multifaceted subjects of BIM implementation, such as acquiring appropriate infrastructure, developing efficient procedures, etc. To facilitate this, formal documents 
such as BIM guidelines and standards are published by various organizations around the world. The contents of these documents vary depending on their targeted audience and defined scope of BIM implementation they intend to support.

BIM implementation in Turkey is a relatively new concept that has been gaining importance. There is a need to develop an industry-wide national guideline. However, in the absence of BIM guidelines and standards to follow, companies that aim to implement BIM have to research BIM execution processes and develop their own customized execution plans for achieving their targeted BIM Uses. In the competitive environment of construction industry, allocating resources for the development of this plan is challenging.

\subsection{Literature Survey}

In order to facilitate BIM adoption, information on BIM execution processes is collected and structured as part of this study. A comprehensive literature review of publications on BIM execution process and BIM guidelines and standards has been conducted. Contents of these documents were studied and a content comparison matrix is created (Appendix A). 57 individual subjects on BIM execution that are gathered from these documents are categorized under four headings, i.e. scope of implementation, infrastructure, contracts and implementation process. These headings define a structure for implementation plans and comprise of interdependent subjects that could be used to draw a framework for planning the execution process.

First heading, scope of implementation, includes managerial decisions to design implementation process. These decisions should identify the concept of BIM implementation, projected accomplishments, and methods to achieve these and project phases to perform BIM Uses.

Second heading, infrastructure, comprises of organizational and technical aspects. Organizational aspects include assigning roles and responsibilities and designing a training plan within the company. Technical aspects refer to software, hardware and system configuration decisions.

Third heading, contracts, is important when companies collaborate with each other on a project. Data ownership, transmission of data and data security subjects should be clarified in contracts to eliminate risks related to BIM implementation. 
The last heading, implementation process is multi-faceted. A schedule that identifies the milestones or a detailed scheme for the implementation process is needed. Sequence of BIM Uses, information exchange procedures and responsible parties can be visualized in a flowchart. Information exchange and collaboration strategies should also be specified. These include decisions on technology platforms such as extranets, servers, etc.; model management methods such as utilizing a single model or composite model; data formats and information handover requirements. Backbone of the implementation process is the modeling procedure. Data generation details such as classification of information, file naming conventions, level of development of models, etc. should be identified and agreed by all project stakeholders to foster effective project implementation and collaboration. Project deliverables are another aspect of implementation process which has a direct effect on data creation process and have to be identified prior to implementation. Validation and archiving procedures are also important aspects which require a timeline and specifications to be followed.

\subsection{Case Study}

A case study on BIM implementation in Turkey has been conducted as part of this study. The significance of the case study is based on the fact that that the execution process was an organizational decision of LC and they had to specify their own execution process. The catalog created in this study was utilized by LC to determine their own customized BIM execution plan. This BIM execution plan was tested in six building projects. Semi-structured interviews were conducted to get insights into this BIM execution process in Turkey.

The BIM execution process of LC was designed in two phases: Preimplementation and implementation phases. In the pre-implementation phase the scope of implementation was determined. In the implementation phase included a drafted BIM standard of the company as well as a 5-day structured internal training program.

In this case study, the goal of LC was to carry out are quantity takeoff and cost estimation processes utilizing BIM. To carry out these two tasks, a BIM Team was formed by the BIM Leader. Technical infrastructure required for these purposes was set up, and processes to implement them were designed. Drafted BIM standard and internal training program were utilized to prepare the BIM Team for implementation. 
BIM implementation process workflow at LC to perform QTO and CE could be summarized as follows: LC works as a constructor and does not design building projects. Therefore BIM implementation starts when building permit is obtained by design companies and design projects are submitted to LC. First, BIM models are created according to the rules of modeling defined by the BIM Team. Architectural, structural and MEP models are created to perform QTO reports which are generated directly by the BIM authoring tools. These reports are linked to the project schedule. Then assemblies which carry cost and resource information drawn from the ERP database used by LC are created. The project cost is estimated by adding direct costs that are calculated on the assemblies and indirect costs such as accounting, salaries, etc. The estimated cost is reviewed. If the estimated cost exceeds the target cost, the model is revised to alter properties of building elements such as materials.

\subsection{Barriers for BIM Adoption in Turkey}

Insights into BIM execution process in Turkey was gained from the interviews conducted with the BIM Team. Several challenges for BIM implementation in Turkey have been identified which may create barriers for the transition to BIM in the industry.

The Team states that the competitive environment in the construction industry is one of the major challenges. It is not easy for companies to allocate resources to develop unique processes in this environment. Since LC is a large construction company, they were able to pay the associated transition costs. However it may be a significant deterrent for small and mid size companies.

Another challenge is the rush to start the construction at the site. The Team frequently experiences that the construction starts before design is validated. Project owners' demand on project completion on the shortest period of time possible is one of the reasons behind this. The Team states that owners mostly are not aware of the benefits of BIM, do not require BIM deliverables for their project and are reluctant to wait for BIM models to be created. Due to this haste to start construction, design problems are discovered during the construction phase when solving them requires a lot of resources and time. However as the BIM Team observed during the BIM implementation, when projects are evaluated by BIM tools, conflicts and problems can be identified prior to construction resulting in time and cost savings. 
Another challenge is the lack of formal collaboration procedures to foster utilization of BIM information throughout project's life-cycle. Since there is an absence of BIM standards in Turkey, each company develops a customized execution process. The Team experiences that most of the design companies utilize BIM tools only for visualization and documentation generation purposes. Models that are submitted to LC often include several problems such as duplicated geometries. Due to these problems related to models, the Team has been re-modeling the projects to produce reliable construction data after receiving the design projects from the design teams.

Commercialized training services provided by third parties may also be a challenge to overcome. LC had received services from third parties before they decided to develop their own custom execution processes within the company. Some instructors providing training were not experienced in construction processes, but were only experts on software certain applications. They were not able to help in construction specific questions and this created a bias against BIM processes among some of the employees of LC that led to a resistance to change within the company.

Resistance to change either caused by third parties or due to internal bias towards well-known practices is a major challenge of BIM implementation that was encountered at LC. The BIM Team experienced resistance to change especially from construction crew and from the new members of the BIM Team. Communication to explain and remind the desired outcomes of BIM implementation was the key to dealing with this challenge.

Despite these challenges that were encountered during the BIM adoption process, LC found that the designed execution process provided valuable benefits to the company. QTO reports have been generated automatically and accurately from BIM authoring tools, estimated costs can be reviewed and altered faster than traditional methods, and cost and time required to implement accurate projects have been decreased. Thus BIM implementation has been expanded within the company.

In conclusion, the following aspects of BIM execution process need to be carefully planned.

1. Companies should determine the scope of implementation by defining the desired end uses of BIM information. The scope has a direct effect on required organizational and technical infrastructure as well as implementation process to be designed within acquired infrastructure. 
2. Testing the designed process for the accuracy of outputs is essential. Detecting any possible deviations or misleading information in the outputs in pilot projects will avoid wasting resources.

3. Internal training programs have critical importance on improving the BIM execution process. The BIM Teams and other teams that work with the BIM Team can keep up with the technical advances to improve their processes via these training programs. Moreover project owners could be included in these programs to educate them on BIM, its processes and benefits.

4. Tasks should be designed as straightforward as possible to foster learning and execution process. It may take longer to implement new tasks, but everyone in the project should focus on utilizing the new processes to accomplish desired outcomes.

Findings of this case study show that BIM execution initiatives by individual organizations can produce effective and efficient results. These attempts help to increase technical and organizational know-how across the construction industry. As the number of these initiatives increase, best practices in BIM execution process could be established. In the long run, these best practices may lead to industry-wide national BIM guidelines.

\subsection{Limitations}

The limitations of this study include conducting a qualitative study with a single construction company. There is no possibility of comparing BIM implementation processes of multiple organizations. Since the company implements BIM only in construction phase of the projects, it was not possible to study and present the benefits and challenges of BIM implementation throughout the project's life-cycle.

\subsection{Future Work}

Further research is needed for developing a BIM execution process for small and medium sized companies which have limited resources. Another area where more research is needed is the QTO and CE procedures presented in the case study. These processes can be further studied in order to fully automate the procedures. Additionally 
the scope of BIM implementation processes should be extended to cover all phases of the project with regard to lean construction principles. 


\section{REFERENCES}

AEC UK Initiative. (2012). AEC (UK) BIM Protocol Project BIM Execution Plan Retrieved from https://aecuk.files.wordpress.com/2012/09/aecukbimprotocolbimexecutionplan-v2-0.pdf

AEC UK Initiative. (2015). AEC (UK) BIM Technology Protocol: Practical Implementation of BIM for the UK Architectural, Engineering and Construction (AEC) Industry V.2.1.1.

AIA. (2007). Integrated Project Delivery: A Guide.

AIA. (2008). Document E202-2008: Building Information Modeling Protocol Exhibit.

AIA. (2013a). Document E203-2013 Building Information Modeling and Digital Data Exhibit.

AIA. (2013b). Document G201-2013 Project Digital Data Protocol Form.

AIA. (2013c). Document G202-2013 Project Building Information Modeling Protocol Form.

American Institute of Steel Construction. CIS/2. Retrieved from https://www.aisc.org/content.aspx?id=26044

Andre, G. R. (2011). Building Information Modeling (BIM): Special Contract Issues Construction and Engineering Alert. http://www.klgates.com/buildinginformation-modeling-bim--special-contract-issues-10-07-2011/ Retrieved from http://www.klgates.com/building-information-modeling-bim--special-contractissues-10-07-2011/

Aram, S., Eastman, C. M., \& Sacks, R. (2014). A Knowledge-Based Framework for Quantity Takeoff and Cost Estimation in the AEC Industry Using BIM. Paper presented at the The 31st International Symposium on Automation and Robotics in Construction and Mining (ISARC 2014).

Ashcraft, H. W. (2008). Building Information Modeling: A Framework for Collaboration. Construction Lawyer, 28(3). 
Autodesk Inc. (2010a). Autodesk BIM Deployment Plan A Practical Framework for Implementing BIM San Rafael, CA, USA Autodesk Inc. .

Autodesk Inc. (2010b). Organizational BIM Deployment Plan: CA, USA.

Autodesk PR. (2014). European Parliament Directive to Spur BIM Adoption in 28 EU Countries Retrieved from http://inthefold.autodesk.com/in_the_fold/2014/01/european-parliamentdirective-to-spur-bim-adoption-in-28-eu-countries.html\#sthash.Y77d6L0B.dpuf

Azhar, S. (2011). Building Information Modeling (BIM): Trends, Benefits, Risks and Challenges for the AEC Industry. Leadership and Management in Engineering, 11(3), 241-252.

Barak, R., Jeong, Y. S., Sacks, R., \& Eastmant, C. (2009). Unique Requirements of Building Information Modeling for Cast-in-Place Reinforced Concrete. Journal of Computing in Civil Engineering, 23, 64-74.

Barison, M. B., \& Santos, E. T. (2010). An Overview of BIM Specialists. Paper presented at the Proceedings of the International Conference on Computing in Civil and Building Engineering, Nottingham, UK.

Bart, C. K. (1996). High Tech Firms: Does Mission Matter? Journal of High Technology Management.

Bart, C. K. (1997). Industrial Firms and the Power of Mission. Industrial Marketing Management, 371-383.

Bart, C. K., \& Baetz, M. C. (1995). Do Mission Statements Matter? Hamilton, Ontario: McMaster University.

Basic Informations - $\quad$ IFC. (2011). $\quad$ Retrieved from http://www.ifcwiki.org/index.php/Basic_Informations

Beck Technology. Destini Profiler. Retrieved from http://www.becktechnology.com/products/destini-profiler/

Bew, M., \& Richards, M. (2008). The Bew-Richards Ramp. Government BIM Strategy Document. 
BIM Industry Working Group. (2011). A Report for the Government Construction Client Group Building Information Modelling (BIM) Working Party Strategy Paper. Retrieved from

BIMForum (Producer). (2013). Level of Development Specification for Building Information Models

British Standards Institution. (2013). PAS 1192-2:2013 Incorporating Corrigendum No.1 UK British Standards Institution.

British Standards Institution. (2014). PAS 1192-3:2014 Specification for Information Management for the Operational Phase of Assets using Building Information Modelling: BSI Standards Limited.

Brodt, W. (2011). OmniClass. Whole Building Design Guide. https://www.wbdg.org/resources/omniclass.php Retrieved from https://www.wbdg.org/resources/omniclass.php

buildingSMART. (2009). IFC Overview Summary. Retrieved from http://www.buildingsmart-tech.org/specifications/ifc-overview

BuildingSMART. (2013). Is the construction industry ready to meet the requirements of tomorrow? . Retrieved from http://iug.buildingsmart.org/resources/statementsand-guidelines/press-release-from-norwegian-public-clients-1

BuildingSMART. (2014). Model View Definition Summary. Retrieved from http://www.buildingsmart-tech.org/specifications/ifc-view-definition

Canada BIM Council. (2014). AEC (CAN) BIM Protocol V2.0 Implementing Canadian BIM Standards for the Architectural, Engineering and Construction Industry Based on International Collaboration.

Central Government Real Estate Agency. (2014). Building Information Modelling.

Cheng, T. F. (2012). Singapore BIM Roadmap [Press release]

Cheung, F. K. T., Rihan, J., Tah, J., Duce, D., \& Kurul, E. (2012). Early stage multi-level cost estimation for schematic BIM models. Automation in Construction, 27, 6777. doi:10.1016/j.autcon.2012.05.008 
Computer Integrated Construction Research Group. (2011). BIM Project Execution Planning Guide Version 2.1. Pennsylvania, USA: The Pennsylvania State University.

Computer Integrated Construction Research Group. (2012). BIM Planning Guide for Facility Owners Version 1.02. Pennsylvania, USA: The Pennsylvania State University.

ConsensusDocs LLC. 301-Building Information Modeling (BIM) Addendum Arlington, VA: ConsensusDocs LLC.

Construction Industry Council. (2013). Building Information Model (BIM) Protocol Standard Protocol for Use in Projects Using Building Information Models. London, UK.

Construction Industry Council. (2015). CIC Building Information Modelling Standards (Phase One). Hong Kong Retrieved from http://www.hkibim.org/?page_id=3794.

Cooperative Research Center for Construction Innovation. (2009). National Guidelines for Digital Modeling. Qld, Australia.

Crotty, R. (2012). The Impact of Building Information Modelling: Transforming Construction. New York, U.S.: Spon Press.

CSI. UniFormat. Retrieved from http://www.csinet.org/uniformat

Denzer, A. S., \& Hedges, K. E. (2008). From CAD to BIM: Educational Strategies for the Coming Paradigm Shift. Paper presented at the Architectural Engineering Conference (AEI) 2008, Colorado, US

Department for Business, Innovation, \& Skills. (2013). Construction 2025: Industrial Strategy for Construction - Government and Industry in Partnership. Retrieved from

https://www.gov.uk/government/uploads/system/uploads/attachment_data/file/2 10099/bis-13-955-construction-2025-industrial-strategy.pdf.

Designing Buildings Wiki. (2015). BIM Maturity Levels. Retrieved from http://www.designingbuildings.co.uk/wiki/BIM_maturity_levels

Deutsch, R. (2011). BIM and Integrated Design: Strategies for Architectural Practice. Hoboken, New Jersey: John Wiley \& Sons Inc.,. 
Division of State Facilities Department of Administration. (2009). BIM Guidelines and Standards for Architects and Engineers. Wisconsin, USA.

East, B. (2014a). COBie and IFC. Introduction 2 COBie.

East, B. (2014b). Construction-Operations Building Information Exchange (COBie). Whole Building Design Guide. https://www.wbdg.org/resources/cobie.php Retrieved from https://www.wbdg.org/resources/cobie.php

Eastman, C., Teicholz, P., Sacks, R., \& Liston, K. (2011). BIM Handbook: A Guide to Building Information Modeling for Owners, Managers, Designers, Engineers and Contractors: John Wiley \& Sons.

Elbeltagi, E., Hosny, O., Dawood, M., \& Elhakeem, A. (2014). BIM-Based Cost Estimation/Monitoring for Building Construction. Int. Journal of Engineering Research and Applications, 4(7), 56-66.

Elmualim, A., \& Gilder, J. (2014). BIM: Innovation in Design Management, Influence and Challenges of Implementation. Architectural Engineering and Design Management, 10(3-4), 183-199.

ENR, E. N.-R. (2015). The 2015 Top 250 International Contractors 1-100. Retrieved from http://www.enr.com/toplists/2015_Top_250_International_Contractors1

Epstein, E. (2012). Implementing Successful Building Information Modeling: Artech House.

Firat, C., Arditi, D., Hämäläinen, J., Stenstrand, J., \& Kiiras, J. (2010). Quantity Take-Off in Model-Based Systems.". Paper presented at the Proceedings of CIB W78 2010: 27th International Conference.

Forgues, D., Iordanova, I., Valdivesio, F., \& Staub-French, S. (2012). Rethinking the Cost Estimating Process through 5D BIM: a Case Study. Paper presented at the Construction Research Congress 2012: Construction Challenges in a Flat World (ASCE), West Lafayette, Indiana, United States.

GSA. (2015). GSA Building Information Modeling Guide Series V.2.0 Spatial Program Validation. Washington, DC: U.S. General Services Administration.

Gu, N., \& London, K. (2010). Understanding and Facilitating BIM Adoption in the AEC Industry. Automation in Construction, 19, 988-999. 
Hardin, B. (2009). BIM and Construction Management: Proven Tools, Methods, and Workflows 1st edition: Wiley Publishing, Inc. .

Hardin, B., \& McCool, D. (2015). BIM and Construction Management: Proven Tools, Methods, and Workflows (Second ed.): Wiley\&Sons Inc. .

Heldman, K. (2009). Project Management Professinal Exam Study Guide. Indiana Wiley Publishing Inc. .

Holzer, D. (2015). The BIM Manager's Handbook: Guidance for Professionals in Architecture, Engineering, and Construction Best Practice BIM Epart 1. West Sussex, U.K. : John Wiley \& Sons Ltd.

Housing Authority. (2016). Building Information Modelling. Retrieved from http://www.housingauthority.gov.hk/en/businesspartnerships/resources/building-information-modelling/

IFCwiki. (2008, 01.01.2008). Information Delivery Manual (IDM). Retrieved from http://www.ifcwiki.org/index.php/IDM

Indiana University. (2015). BIM Guidelines and Standards for Architects, Engineers, and Contractors: Indiana University.

ISO. (2010). ISO 29481-1:2010 Building Information Modelling -- Information Delivery Manual -- Part 1: Methodology and Format

Jernigan, F. E. (2007). Big BIM Little BIM. Maryland: 4Site Press.

Joseph, J. (2011). BIM Titles and Job Descriptions: How Do They Fit in Your Organizational Structure? Autodesk University 2011.

Jung, Y., \& Joo, M. (2011). Building Information Modelling (BIM) Framework for Practical Implementation Automation in Construction, 20(2), 126-133. doi:10.1016/j.autcon.2010.09.010

Karlshoj, J. (2011). Information Delivery Manuals. http://iug.buildingsmart.org/idms/ Retrieved from http://iug.buildingsmart.org/idms/

Kensek, K. M. (2014). Building Information Modeling: Taylor and Francis 
Kensek, K. M., \& Noble, D. E. (2014 ). Building Information Modeling: in Current and Future Practice John Wiley \& Sons, Inc.

Khosrowshahi, F., \& Arayici, Y. (2012). Roadmap for Implementation of BIm in the UK Construction Industry Engineering, Construction and Architectural Management, 19(6), 610-635.

Kymmel, W. (2008). Building Information Modeling: Planning and Managing Construction Projects with 4D CAD and Simulations: McGraw Hill Construction.

Lee, S.-K., Kim, K.-R., \& Yu, J.-H. (2014). BIM and Ontology-based Approach for Building Cost Estimation. Automation in Construction, 41.

Luth, G. P. (2012). HD BIM and the Future of the AEC Industry. CIFE Seminar CEE320.

Ma, Z., Wei, Z., \& Zhang, X. (2013). Semi-Automatic and Specification-Compliant Cost Estimation for Tendering of Building Project Based on IFC Data of Design Model. Automation in Construction, 30, 126-135.

Ma, Z., Wei, Z., Zhang, X., Shixun, Q., \& Wang, P. (2011). Intelligent Generation of Bill of Quantities from IFC Subject to Chinese Standard. Paper presented at the Proceedings of the 28th ISARC.

Ma, Z., Zhang, X., Wu, S., Wei, Z., \& Lou, Z. (2010). Framework Design for BIM-Based Construction Cost Estimating Software, Cairo, Egypt.

Marie, S. (2015). BIM Guides Project. Retrieved from http://bimguides.vtreem.com/bin/view/Main/

Mazria, E., \& Kershner, K. (2008). The 2030 Blueprint: Solving Climate Change Saves Billions Retrieved from Architecture 2030 website: http://architecture2030.org/files/2030Blueprint.pdf Retrieved from http://architecture2030.org/files/2030Blueprint.pdf

McGraw Hill Construction. (2014). The Business Value of BIM for Construction in Major Global Markets: How Constructors Around the World are Driving Innovation with Building Information Modeling. Retrieved from Bedford, MA:

MIT Department of Facilities. (2012). MIT BIM Execution Plan V3.2. 
Monteiro, A., \& Martins, J. P. (2013). A Survey on Modeling Guidelines for Quantity Takeoff-Oriented BIM-Based Design. Automation in Construction, 35, 238-253.

Mubarak, S. (2015). Construction Project Scheduling and Control (Third ed.). Hoboken, New Jersey: John Wiley \& Sons, Inc. .

Nadeem, A., Wong, A. K. D., \& Wong, F. K. W. (2015). Bill of Quantities with 3D Views Using Building Information Modeling. Arabian Journal for Science and Engineering, 2465-2477.

National Institute of Building Sciences. (2015). National BIM Standard Version 3.0. USA: National Institute of Building Sciences.

NBS. (2013). National BIM Survey 2013. Retrieved from Newcastle:

NBS. (2015). National BIM Survey 2015. Retrieved from Newcastle:

NBS. (2016). International BIM Report 2016 Retrieved from Newcastle:

Nemetschek Company. Allplan. Retrieved from https://www.allplan.com/en.html

NIBS. (2008). United States National Building Information Modeling Standard, Version 1 Part 1 - Overview, Principles, and Methodologies.

NIBS. (2015). National BIM Standard-United States V3.0.

Ocal, M., Tat, A., \& Erdis, E. (2004). Examination of Labor Force Productivity in Unit Price Analysis of Public Works (Bayindirlik Isleri Birim Fiyat Analizlerindeki Isgucu Verimliliklerinin Irdelenmesi). C.U. J. Fac. Eng. Arch., 19(2), 207-217.

Office of Integrated Analysis and Forecasting. (2007). Annual Energy Outlook. Retrieved from Washington, DC:

Olatunji, O. A. (2011). Modelling the Costs of Corporate Implementation of Building Information Modelling. Journal of Financial Management of Property and Construction, 16(3), 211-231.

OpenText Corp. OpenText. Retrieved from http://www.opentext.com/ 
Princeton University Office of Design and Construction. (2012). Princeton University BIM Execution Plan Template. New Jersey, USA.

Race, S. (2012). BIM demystified: Riba Publishing.

Rahman, S. H. A., Endut, I. R., Faisol, N., \& Paydar, S. (2014). The Importance of Collaboration in Construction Industry from Contractors' Perspective ProcediaSocial and Behavioral Sciences, 129, 414-421.

Reddy, K. (2011). BIM for Building Owners and Developers: Making a Business Case for Using BIM on Projects: John Wiley \& Sons.

RIB Software. RIB iTWO. Retrieved from http://www.ribsoftware.com/en/landingpage/rib-itwo.html

RICS. (2014). International BIM Implementation Guide RICS Professional Guidance, Global. London: RICS.

Rijksgebouwendienst Ministry of the Interior and Kingdom Relations. (2012). Rgd BIM Standard V.1.0.1 Rgd BIM Norm. Netherlands: Rijksgebouwendienst.

Roodman, D. M., \& Lenssen, N. (1995). Worldwatch Paper \#124: A Building Revolution: How Ecology and Health Concerns Are Transforming Construction. http://www.worldwatch.org/node/866 from http://www.worldwatch.org/node/866

Samuelson, O., \& Bjork, B. (2014). Adoption Processes for EDM, EDI and BIM Technologies in the Construction Industry. Journal of Civil Engineering and Management, 19(1), 172-187.

Saxon, R. G. (2013). Growth Through BIM. Retrieved from London, UK

Senate Properties. (2012). COBIM: Common BIM Requirements.

Smith, D. K., \& Tardif, M. (2009). Building Information Modeling: A Strategic Implementation Guide for Architects, Engineers, Constructors, and Real Estate Asset Managers: John Wiley \& Sons Inc., .

Steel, J., Drogemuller, R., \& Toth, B. (2012). Model Interoperability in Building Information Modeling. Software \& Systems Modeling, 11(1), 99-109. 
Succar, B. (2009). Building Information Modelling Framework: A Research and Delivery Foundation for Industry Stakeholders. Automation in Construction, 18, 357-375.

The Associated General Contractors of America. (2005). The Contractors' Guide to BIM

- Edition 1 Architectural Engineering and Design Management.

The BIM Guide Workgroup. (2013). The Singapore BIM Guide V2.0. Singapore.

The Centre for Construction IT. (2013). BIM Essential Guide for BIM Execution Plan. Singapore.

The Centre for Contsruction IT. (2013). BIM Essential Guide for BIM Adoption in an Organization. Singapore.

The Chamber of Architects of Turkey. (2011). Contract of Architectural Services and Minimum Cost Rates

Tocoman iLink. Retrieved from http://www.tocoman.com/ilink

U.S. Department of Veterans Affairs. (2010). The VA BIM Guide V1.0.

UK Cabinet Office. (2011). Government Construction Strategy.

Vico Software. Retrieved from http://www.vicosoftware.com/

Weygant, R. S. (2011). BIM Content Developtment: Standards, Strategies, and Best Practices. Hoboken, New Jersey: John Wiley \& Sons Inc., .

Won, J., Lee, G., Dossick, C., \& Messner, J. (2013). Where to Focus for Successful Adoption of Building Information Modeling within Organization. Journal of Construction Engineering and Management, 139(11).

Young, N. W. J., \& Jones, S. A. (2008). Building Information Modeling (BIM) Transforming Design and Construction to Achieve Greater Industry Productivity. Retrieved from Bedford, MA. :

Young, N. W. J., Jones, S. A., Bernstein, H. M., \& Gudgel, J. E. (2009). The Business Value of BIM Retrieved from Bedford, MA. : 
Zhiliang, M., \& Zhenhua, W. (2012). Framework for Automatic Construction Cost Estimation Based on BIM and Ontology Technology. Paper presented at the The CIB W78 2012: 29th International Conference Beirut, Lebanon 


\section{COMPARISON MATRIX OF BIM IMPLEMENTATION PLANS AND STANDARDS}

\begin{tabular}{|c|c|c|c|c|c|c|c|c|c|c|c|c|c|c|c|c|c|c|c|c|c|c|c|}
\hline & 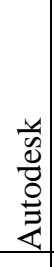 & 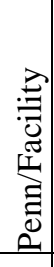 & 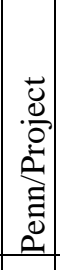 & 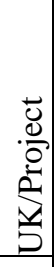 & 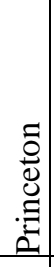 & 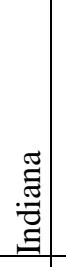 & $\underset{>}{\$}$ & $\begin{array}{c}: \Xi \\
.0 \\
0 \\
0 \\
3 \\
3 \\
3\end{array}$ & $\begin{array}{l}0 \\
0 \\
0 \\
0 \\
\vdots \\
2 \\
\Sigma \\
D\end{array}$ & $\begin{array}{l}\infty \\
D \\
\infty \\
\sum \\
n \\
Z\end{array}$ & $\sum_{0}$ & 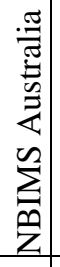 & $\underset{\Xi}{\&}$ & $\underset{\xi}{\xi}$ & $\begin{array}{l}\tilde{J} \\
\vec{Z} \\
\tilde{U} \\
\tilde{U}\end{array}$ & 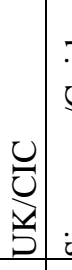 & 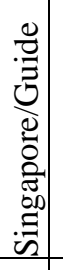 & 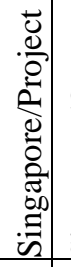 & 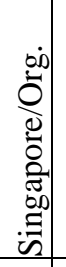 & 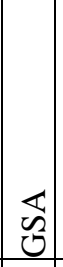 & $\begin{array}{l}0 \\
0 \\
0 \\
0 \\
0 \\
0 \\
0 \\
0 \\
\end{array}$ & \begin{tabular}{|c} 
\\
0 \\
$ن$ \\
$ن$ \\
\end{tabular} & 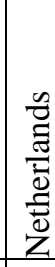 \\
\hline $\begin{array}{l}\text { Project } \\
\text { Information }\end{array}$ & $\bullet$ & & $\bullet$ & $\bullet$ & & & & & & & & & $\bullet$ & $\bullet$ & & & $\bullet$ & $\bullet$ & $\bullet$ & $\bullet$ & $\bullet$ & & \\
\hline $\begin{array}{l}\text { Mission\& } \\
\text { Vision }\end{array}$ & $\bullet$ & $\bullet$ & $\bullet$ & & & & & & & • & & & & & & & & & $\bullet$ & $\bullet$ & $\bullet$ & & \\
\hline Goals & $\bullet$ & $\bullet$ & $\bullet$ & $\bullet$ & $\bullet$ & $\bullet$ & $\bullet$ & $\bullet$ & & $\bullet$ & $\bullet$ & & & $\bullet$ & $\bullet$ & & $\bullet$ & • & $\bullet$ & $\bullet$ & $\bullet$ & $\bullet$ & \\
\hline Uses & & $\bullet$ & $\bullet$ & $\bullet$ & & & & & & $\bullet$ & $\bullet$ & $\bullet$ & $\bullet$ & $\bullet$ & $\bullet$ & & $\bullet$ & $\bullet$ & & $\bullet$ & $\bullet$ & $\bullet$ & \\
\hline Project Phases & & & & $\bullet$ & $\bullet$ & $\bullet$ & & $\bullet$ & & $\bullet$ & $\bullet$ & & & & & & & & & $\bullet$ & $\bullet$ & & \\
\hline $\begin{array}{l}\text { Roles\& } \\
\text { Responsibilities }\end{array}$ & & $\bullet$ & $\bullet$ & $\bullet$ & $\bullet$ & & $\bullet$ & $\bullet$ & $\bullet$ & $\bullet$ & $\bullet$ & $\bullet$ & $\bullet$ & $\bullet$ & & $\bullet$ & & $\bullet$ & $\bullet$ & $\bullet$ & $\bullet$ & • & \\
\hline BIM Team & & $\bullet$ & $\bullet$ & $\bullet$ & • & & $\bullet$ & & $\bullet$ & & - & • & & $\bullet$ & & $\bullet$ & • & • & $\bullet$ & • & • & & \\
\hline Leader & & • & & & $\bullet$ & & $\bullet$ & & $\bullet$ & & $\bullet$ & • & & & & $\bullet$ & • & $\bullet$ & $\bullet$ & $\bullet$ & $\bullet$ & & \\
\hline $\begin{array}{l}\text { Technical } \\
\text { Leaders }\end{array}$ & & $\bullet$ & & & • & & $\bullet$ & & $\bullet$ & & $\bullet$ & $\bullet$ & & & & $\bullet$ & & & $\bullet$ & & $\bullet$ & & \\
\hline Modeling Staff & & & & & & & • & & • & & & $\bullet$ & & & & & & & • & & • & & \\
\hline Training Plan & $\bullet$ & & $\bullet$ & & & & $\bullet$ & & $\bullet$ & $\bullet$ & & & $\bullet$ & & & & & & $\bullet$ & & $\bullet$ & & \\
\hline $\begin{array}{l}\text { Infrastructure } \\
\text { (Technical) }\end{array}$ & - & $\bullet$ & $\bullet$ & $\bullet$ & & - & $\bullet$ & & & $\bullet$ & $\bullet$ & & $\bullet$ & • & $\bullet$ & & $\bullet$ & & $\bullet$ & $\bullet$ & $\bullet$ & $\bullet$ & \\
\hline $\begin{array}{l}\text { Software } \\
\text { Selection }\end{array}$ & • & & $\bullet$ & $\bullet$ & & $\bullet$ & $\bullet$ & • & & $\bullet$ & $\bullet$ & $\bullet$ & $\bullet$ & $\bullet$ & $\bullet$ & & $\bullet$ & $\bullet$ & $\bullet$ & $\bullet$ & • & $\bullet$ & \\
\hline Interoperability & & & & 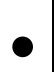 & & & • & & $\bullet$ & $\bullet$ & & & & & $\bullet$ & & & - & & $\bullet$ & & $\bullet$ & \\
\hline
\end{tabular}




\begin{tabular}{|c|c|c|c|c|c|c|c|c|c|c|c|c|c|c|c|c|c|c|c|c|c|c|c|}
\hline & 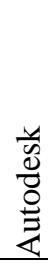 & 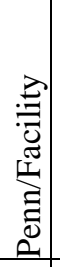 & 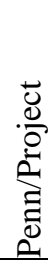 & 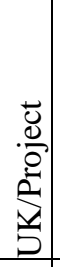 & 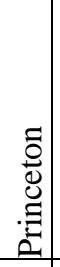 & : & 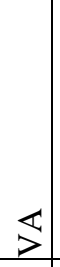 & 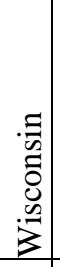 & 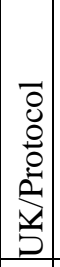 & $\begin{array}{l}n \\
D \\
\infty \\
\sum \\
n \\
n \\
z\end{array}$ & $\begin{array}{c}1 \\
\sum \\
0 \\
0 \\
0\end{array}$ & 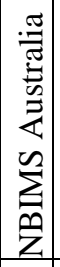 & 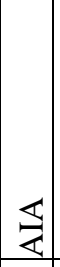 & $\underline{\underline{E}}$ & 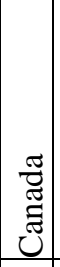 & 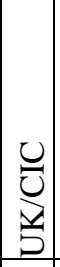 & 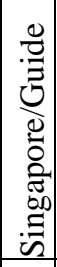 & 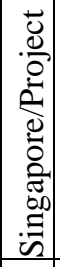 & 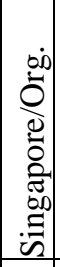 & 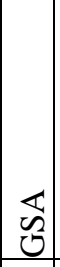 & $\begin{array}{l}0 \\
0 \\
0 \\
0 \\
0 \\
0 \\
\Xi \\
0 \\
0 \\
\end{array}$ & 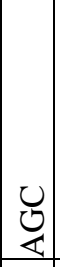 & 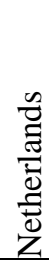 \\
\hline Hardware & $\bullet$ & & $\bullet$ & $\bullet$ & & & & & & $\bullet$ & & & $\bullet$ & $\bullet$ & $\bullet$ & & $\bullet$ & & $\bullet$ & $\bullet$ & $\bullet$ & $\bullet$ & \\
\hline $\begin{array}{l}\text { Support } \\
\text { Services }\end{array}$ & $\bullet$ & & & & & & & & & & & & $\bullet$ & & & & & & & & & & \\
\hline Personnel Plan & $\bullet$ & $\bullet$ & $\bullet$ & $\bullet$ & & & & & & $\bullet$ & & & & & & & & & & & • & & \\
\hline Milestones & $\bullet$ & & & $\bullet$ & $\bullet$ & & & & & & & & $\bullet$ & $\bullet$ & $\bullet$ & & & & $\bullet$ & $\bullet$ & $\bullet$ & & \\
\hline $\begin{array}{l}\text { Project } \\
\text { Schedule }\end{array}$ & & & $\bullet$ & & & $\bullet$ & & & & $\bullet$ & & $\bullet$ & $\bullet$ & $\bullet$ & & & $\bullet$ & & $\bullet$ & $\bullet$ & $\bullet$ & & \\
\hline BEP & $\bullet$ & & $\bullet$ & & $\bullet$ & $\bullet$ & • & & & $\bullet$ & $\bullet$ & $\bullet$ & & $\bullet$ & • & $\bullet$ & - & • & $\bullet$ & • & $\bullet$ & & \\
\hline $\begin{array}{l}\text { Discipline- } \\
\text { Specific BEP }\end{array}$ & & & & & $\bullet$ & $\bullet$ & $\bullet$ & & & & $\bullet$ & & & & & $\bullet$ & $\bullet$ & $\bullet$ & $\bullet$ & & $\bullet$ & & \\
\hline Process Plan & $\bullet$ & & $\bullet$ & $\bullet$ & $\bullet$ & $\bullet$ & $\bullet$ & • & & $\bullet$ & $\bullet$ & $\bullet$ & $\bullet$ & $\bullet$ & & $\bullet$ & • & $\bullet$ & & & $\bullet$ & & \\
\hline $\begin{array}{l}\text { Detailed } \\
\text { Process Plan }\end{array}$ & & & $\bullet$ & & & $\bullet$ & & & & $\bullet$ & & • & & $\bullet$ & & & & & • & & • & & \\
\hline $\begin{array}{l}\text { Workflow } \\
\text { Design }\end{array}$ & & & $\bullet$ & & & & & & & • & & & & & & & & $\bullet$ & & & & & \\
\hline $\begin{array}{l}\text { Responsible } \\
\text { Parties }\end{array}$ & & & $\bullet$ & & & & & & & $\bullet$ & & $\bullet$ & $\bullet$ & & & $\bullet$ & $\bullet$ & • & & & & & \\
\hline $\begin{array}{l}\text { Information } \\
\text { Exchange }\end{array}$ & & & • & $\bullet$ & $\bullet$ & $\bullet$ & $\bullet$ & • & $\bullet$ & $\bullet$ & $\bullet$ & $\bullet$ & $\bullet$ & $\bullet$ & $\bullet$ & $\bullet$ & • & $\bullet$ & $\bullet$ & $\bullet$ & $\bullet$ & $\bullet$ & $\bullet$ \\
\hline $\begin{array}{l}\text { Information } \\
\text { Exchange } \\
\text { Content }\end{array}$ & & & $\bullet$ & $\bullet$ & & $\bullet$ & & & & $\bullet$ & $\bullet$ & & $\bullet$ & $\bullet$ & $\bullet$ & & & $\bullet$ & & $\bullet$ & $\bullet$ & & \\
\hline $\begin{array}{l}\text { Responsible } \\
\text { Parties of } \\
\text { Information } \\
\text { Exchange }\end{array}$ & & & $\bullet$ & & $\bullet$ & & & & $\bullet$ & • & & $\bullet$ & $\bullet$ & & $\bullet$ & $\bullet$ & & $\bullet$ & & & & & \\
\hline Inputs/Outputs & & & $\bullet$ & & $\bullet$ & $\bullet$ & & & & $\bullet$ & & & & & & & & $\bullet$ & & & $\bullet$ & & $\bullet$ \\
\hline $\begin{array}{l}\text { Information } \\
\text { Quality } \\
\text { Definitions }\end{array}$ & & & & & & & & & & • & & & & & & & & & & • & & & \\
\hline $\begin{array}{l}\text { Information } \\
\text { Exchange } \\
\text { Strategies\& } \\
\text { Methods }\end{array}$ & & & & $\bullet$ & $\bullet$ & $\bullet$ & $\bullet$ & & & $\bullet$ & & $\bullet$ & $\bullet$ & • & $\bullet$ & & $\bullet$ & $\bullet$ & $\bullet$ & $\bullet$ & $\bullet$ & $\bullet$ & $\bullet$ \\
\hline
\end{tabular}




\begin{tabular}{|c|c|c|c|c|c|c|c|c|c|c|c|c|c|c|c|c|c|c|c|c|c|c|c|}
\hline & 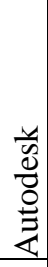 & 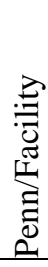 & 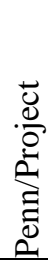 & 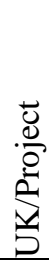 & 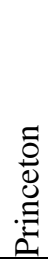 & 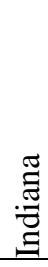 & $\mathbb{Z}$ & 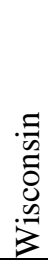 & 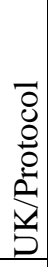 & 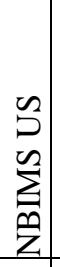 & $\begin{array}{l}\sum_{1} \\
0 \\
0 \\
0\end{array}$ & 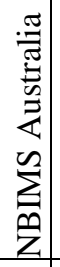 & $\begin{array}{l}0 \\
\\
\end{array}$ & $\stackrel{\ominus}{\xi}$ & $\begin{array}{c}\underset{\widetilde{Z}}{\tilde{Z}} \\
\underset{\widetilde{J}}{U}\end{array}$ & 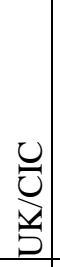 & 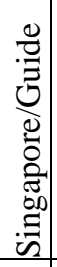 & 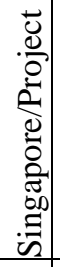 & 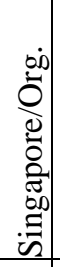 & $\begin{array}{l} \\
\mathbb{S} \\
心 \\
\end{array}$ & $\begin{array}{l}0 \\
0 \\
0 \\
0 \\
00 \\
0 \\
0 \\
0\end{array}$ & \begin{tabular}{|c} 
\\
0 \\
$ن$ \\
\\
\end{tabular} & 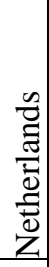 \\
\hline Collaboration & $\bullet$ & $\bullet$ & $\bullet$ & $\bullet$ & $\bullet$ & $\bullet$ & $\bullet$ & $\bullet$ & $\bullet$ & $\bullet$ & $\bullet$ & $\bullet$ & $\bullet$ & $\bullet$ & & & $\bullet$ & $\bullet$ & $\bullet$ & $\bullet$ & $\bullet$ & $\bullet$ & \\
\hline $\begin{array}{l}\text { Data } \\
\text { Management }\end{array}$ & $\bullet$ & & $\bullet$ & $\bullet$ & $\bullet$ & $\bullet$ & $\bullet$ & & $\bullet$ & $\bullet$ & & $\bullet$ & $\bullet$ & $\bullet$ & & & & $\bullet$ & & & $\bullet$ & & \\
\hline Contracts & $\bullet$ & & $\bullet$ & & & $\bullet$ & & & & $\bullet$ & $\bullet$ & $\bullet$ & $\bullet$ & $\bullet$ & $\bullet$ & $\bullet$ & $\bullet$ & & $\bullet$ & $\bullet$ & & $\bullet$ & \\
\hline $\begin{array}{l}\text { Authorization } \\
\text { of Information }\end{array}$ & $\bullet$ & & & & & & & & $\bullet$ & & & & $\bullet$ & & $\bullet$ & $\bullet$ & & & & & $\bullet$ & & \\
\hline Data Ownership & $\bullet$ & & & & & $\bullet$ & $\bullet$ & & & & $\bullet$ & $\bullet$ & $\bullet$ & & • & & & & & $\bullet$ & $\bullet$ & & \\
\hline Data Security & $\bullet$ & & & & & & $\bullet$ & & $\bullet$ & & & $\bullet$ & • & & $\bullet$ & & $\bullet$ & & & $\bullet$ & & & \\
\hline $\begin{array}{l}\text { Modeling } \\
\text { Procedure }\end{array}$ & - & $\bullet$ & $\bullet$ & $\bullet$ & - & $\bullet$ & $\bullet$ & $\bullet$ & $\bullet$ & $\bullet$ & $\bullet$ & $\bullet$ & $\bullet$ & $\bullet$ & • & $\bullet$ & • & $\bullet$ & $\bullet$ & $\bullet$ & $\bullet$ & $\bullet$ & - \\
\hline LOD & $\bullet$ & & & $\bullet$ & $\bullet$ & $\bullet$ & $\bullet$ & $\bullet$ & $\bullet$ & & $\bullet$ & $\bullet$ & $\bullet$ & & $\bullet$ & $\bullet$ & $\bullet$ & $\bullet$ & $\bullet$ & $\bullet$ & $\bullet$ & $\bullet$ & $\bullet$ \\
\hline $\begin{array}{l}\text { Modeling } \\
\text { Standards }\end{array}$ & & & $\bullet$ & $\bullet$ & $\bullet$ & & $\bullet$ & $\bullet$ & $\bullet$ & $\bullet$ & $\bullet$ & $\bullet$ & & $\bullet$ & - & & $\bullet$ & $\bullet$ & $\bullet$ & • & • & $\bullet$ & - \\
\hline $\begin{array}{l}\text { Model } \\
\text { Divisions }\end{array}$ & & & & $\bullet$ & $\bullet$ & & $\bullet$ & & $\bullet$ & & $\bullet$ & $\bullet$ & $\bullet$ & $\bullet$ & - & & - & & - & $\bullet$ & $\bullet$ & & - \\
\hline $\begin{array}{l}\text { Analysis } \\
\text { Purposes }\end{array}$ & $\bullet$ & & & & & $\bullet$ & $\bullet$ & $\bullet$ & & $\bullet$ & $\bullet$ & $\bullet$ & $\bullet$ & $\bullet$ & $\bullet$ & $\bullet$ & $\bullet$ & • & • & $\bullet$ & $\bullet$ & $\bullet$ & $\bullet$ \\
\hline $\begin{array}{l}\text { Model View } \\
\text { Definitions }\end{array}$ & & & & & & & $\bullet$ & & & & • & & & & & & & & & & - & & \\
\hline $\begin{array}{l}\text { Communication } \\
\text { Plan }\end{array}$ & - & & $\bullet$ & $\bullet$ & • & & & & & • & & & & $\bullet$ & & & & & $\bullet$ & - & & & \\
\hline Meetings & $\bullet$ & & $\bullet$ & $\bullet$ & $\bullet$ & • & $\bullet$ & • & $\bullet$ & $\bullet$ & • & & & $\bullet$ & $\bullet$ & $\bullet$ & & & - & & $\bullet$ & & \\
\hline Minimum BIM & & & & & & & & & & $\bullet$ & & & & & & & & & & & & & \\
\hline $\begin{array}{l}\text { Quality } \\
\text { Assurance }\end{array}$ & & & $\bullet$ & - & & & • & $\bullet$ & & $\bullet$ & $\bullet$ & $\bullet$ & $\bullet$ & • & $\bullet$ & $\bullet$ & $\bullet$ & • & • & - & $\bullet$ & • & - \\
\hline $\begin{array}{l}\text { Quality } \\
\text { Criterias }\end{array}$ & & & & $\bullet$ & & & & & & • & & & & & & & • & $\bullet$ & - & $\bullet$ & - & & • \\
\hline Validation & & & • & & & & $\bullet$ & & $\bullet$ & $\bullet$ & $\bullet$ & & & $\bullet$ & & • & & & & & $\bullet$ & & \\
\hline Deliverables & $\bullet$ & & • & & • & - & $\bullet$ & - & & $\bullet$ & • & & & $\bullet$ & $\bullet$ & $\bullet$ & $\bullet$ & $\bullet$ & $\bullet$ & $\bullet$ & $\bullet$ & $\bullet$ & $\bullet$ \\
\hline
\end{tabular}




\begin{tabular}{|c|c|c|c|c|c|c|c|c|c|c|c|c|c|c|c|c|c|c|c|c|c|}
\hline & 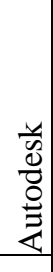 & 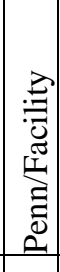 & 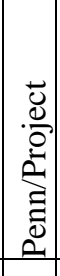 & 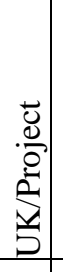 & 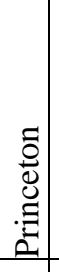 & 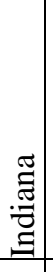 & 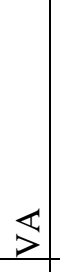 & 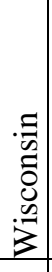 & 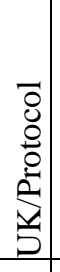 & $\begin{array}{l}n \\
D \\
\infty \\
\sum_{\Delta}^{n} \\
\Sigma\end{array}$ & $\begin{array}{l} \\
\sum \\
0 \\
0 \\
0\end{array}$ & 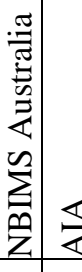 & $\underset{\Sigma}{S}$ & \begin{tabular}{|l}
$\tilde{\pi}$ \\
$\mathbb{\pi}$ \\
$\tilde{U}$ \\
\end{tabular} & $\mid \begin{array}{l}0 \\
v \\
y \\
5 \\
5\end{array}$ & 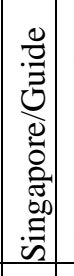 & 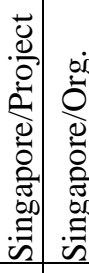 & 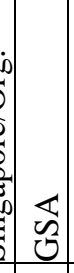 & $\begin{array}{l}0 \\
0 \\
0 \\
0 \\
00 \\
0 \\
0 \\
0 \\
\end{array}$ & $\begin{array}{r} \\
\\
ن \\
\\
\end{array}$ & 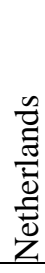 \\
\hline $\begin{array}{l}\text { Model } \\
\text { Submission }\end{array}$ & & & & & $\bullet$ & $\bullet$ & $\bullet$ & $\bullet$ & $\bullet$ & $\bullet$ & $\bullet$ & & $\bullet$ & & & $\bullet$ & & $\bullet$ & $\bullet$ & & - \\
\hline 2D Drawings & - & & & & $\bullet$ & - & $\bullet$ & $\bullet$ & $\bullet$ & $\bullet$ & $\bullet$ & & $\bullet$ & $\bullet$ & & $\bullet$ & & $\bullet$ & $\bullet$ & & $\bullet$ \\
\hline Close-Out & & - & - & & & - & & & & - & $\bullet$ & & & & & & & & & & \\
\hline $\begin{array}{l}\text { Submission of } \\
\text { Deliverables }\end{array}$ & $\bullet$ & & & & & - & & - & & & - & & - & & & & & - & $\bullet$ & & - \\
\hline $\begin{array}{l}\text { Operation and } \\
\text { Maintenance } \\
\text { Documents }\end{array}$ & & & & & & - & & & & & - & & $\bullet$ & & & & & - & & & \\
\hline Archiving & & & 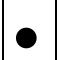 & & & & & & c & & - & & - & - & - & - & & - & & & \\
\hline
\end{tabular}

\section{Legend:}

\begin{tabular}{|l|l|l|}
\hline & Name & Abbreviation \\
\hline 1. & Autodesk Organizational And Project BIM Deployment Plan & Autodesk \\
\hline 2. & $\begin{array}{l}\text { BIM Planning Guide For Facility Owners V1.02 (Penn State } \\
\text { University) }\end{array}$ & $\begin{array}{l}\text { Penn/ } \\
\text { Facility }\end{array}$ \\
\hline 3. & $\begin{array}{l}\text { BIM Project Execution Planning Guide V2.1 (Penn State } \\
\text { University) }\end{array}$ & $\begin{array}{l}\text { Penn/ } \\
\text { Project }\end{array}$ \\
\hline 4. & AEC UK BIM Protocol Project BIM Execution Plan & UK/Project \\
\hline 5. & Princeton University BIM Execution Plan & Princeton \\
\hline 6. & Indiana University BIM Guideline & Indiana \\
\hline 7. & The VA BIM Guide & VA \\
\hline 8. & State of Wisconsin & Wisconsin \\
\hline 9. & AEC UK BIM Protocol & UK/Protocol \\
\hline 10. & NBIMS US V3 & NBIMS US \\
\hline 11. & COBIM & COBIM \\
\hline 12. & NBIMS Australia & NBIMS Aus \\
\hline 13. & AIA Documents & AIA \\
\hline 14. & $\begin{array}{l}\text { MIT BIM Execution Plan (Pilot Use) \& CAD And BIM } \\
\text { Guidelines }\end{array}$ & MIT \\
\hline 15. & AEC Canada BIM Protocol & Canada \\
\hline 16. & CIC BIM Protocol & UK/CIC \\
\hline
\end{tabular}




\begin{tabular}{|l|l|l|}
\hline & Name & Abbreviation \\
\hline 17. & Singapore BIM Guide V2 & $\begin{array}{l}\text { Singapore/ } \\
\text { Guide }\end{array}$ \\
\hline 18. & Singapore BIM Essential Guide for BIM Execution Plan & $\begin{array}{l}\text { Singapore/ } \\
\text { Project }\end{array}$ \\
\hline 19. & $\begin{array}{l}\text { Singapore BIM Essential Guide for BIM Adoption in an } \\
\text { Organization }\end{array}$ & $\begin{array}{l}\text { Singapore/ } \\
\text { Organization }\end{array}$ \\
\hline 20. & GSA BIM Series & GSA \\
\hline 21. & Hong Kong CIC BIM Standards & Hong Kong \\
\hline 22. & AGC Guide to BIM V1 & AGC \\
\hline 23. & RGD BIM Standard & Netherlands \\
\hline
\end{tabular}




\section{APPENDIX B}

\section{INTERVIEW GUIDE FOR QUALITATIVE STUDY}

\section{Topic:}

Documentation and evaluation of BIM implementation processes at LC

\section{Questions:}

1. In which phase of the building project do you involve in BIM implementation? What are your responsibilities? Could you explain the tasks you accomplish?

2. Which software are used in BIM implementation?

3. Have you experienced any challenges/problems related to BIM adoption? How long did it take to overcome these?

4. In what format do you exchange information between project stakeholders?

5. What reports and documentation do you produce from BIMs? What are the contents of these?

6. Have you faced any resistance to BIM implementation and/or processes from other project stakeholders?

7. Did BIM implementation require changes in project execution? If yes, please explain the changes.

8. What kind of benefits do you think BIM can offer to project success?

9. Do you have any recommendations to improve BIM processes? 